AL. $2.2006-66$
C. 2

\title{
Commercial Echinacea Production
}
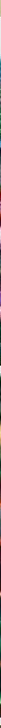
8 


\section{Commercial Echinacea Production}

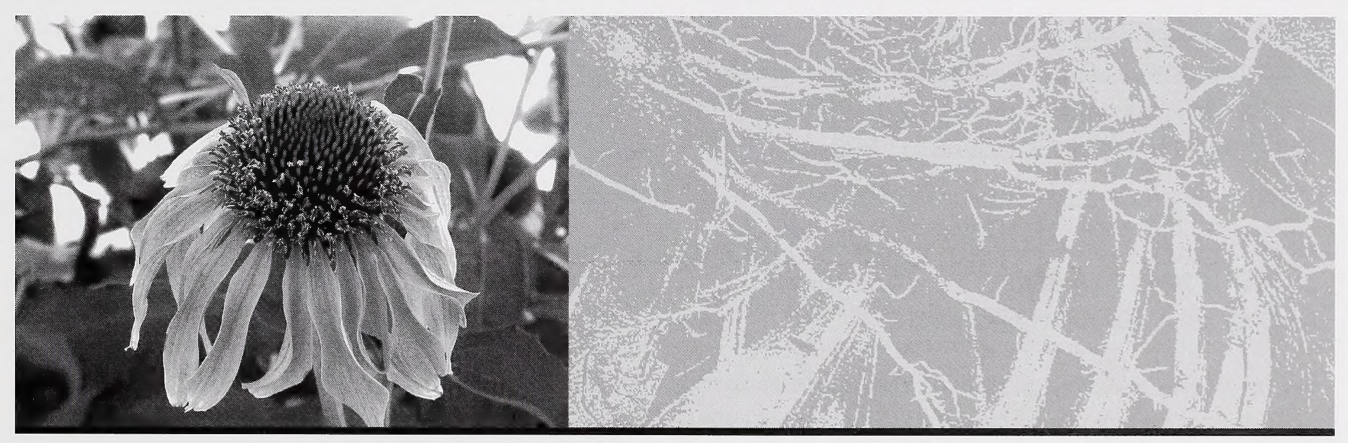

Albertad Aarraturere frod and 


\section{Published by:}

Alberta Agriculture, Food and Rural Development Information Packaging Centre 7000 - 113 Street

Edmonton, Alberta

Canada T6H 5T6

Editor: Carolyn King

Production Editor: Chris Kaulbars

Graphic Designer: John Gillmore

Page Production: Sherrill Strauss

Copyright (C) 2005. Her Majesty the Queen in Right of Alberta (Alberta Agriculture, Food and Rural Development). All rights reserved.

No part of this publication may be reproduced, stored in a retrieval system, or transmitted in any form or by any means, electronic, mechanical, photocopying, recording, or otherwise without written permission from the Information Packaging Centre, Alberta Agriculture, Food and Rural Development.

ISBN 0-7732-6074-9

Copies of this publication may be purchased from:

Publications Office

Alberta Agriculture, Food and Rural Development

Phone: 1-800-292-5697 (toll-free in Canada)

(780) 427-0391

or

see our website <www.agric.gov.ab.ca/publications> for information about other publications, videos and CD-ROMs 


\section{Contents}

Acknowledgements iv

Abbreviations

\section{Introduction} 1

Purpose of this guide 1

\section{Background} 2

Alberta's echinacea industry ......................................... 2

Echinacea in the natural health products market....2

Sources of echinacea ...................................................... 3 Wild harvesting ............................................................. 3

Cultivated echinacea ……………………………..... 3

Botanical history of echinacea ........................................ 4

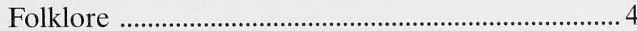

Historical uses of echinacea in North America ....... 4

Native tribes

Settlers and physicians ............................................... 4

Modern health claims ................................................... 6

\section{The Echinacea Plant ……………………....}

Echinacea species ......................................................... 7

Ensuring the botanical identity of echinacea ........... 7 Taxonomy of echinacea …………………………..... 7

Active ingredients ........................................................ 9 Compounds with immunostimulatory activities .....9

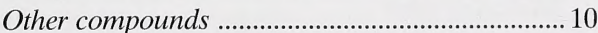

Latitudinal effect 10

\section{Preliminary Considerations .................11}

Business basics ............................................................... 11

Business and production plans .................................... 11

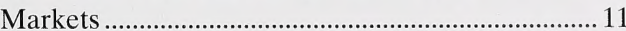

Contracts ................................................................ 12

Breaking the traditional farming mentality ............. 12

Just because it looks good on paper......................... 12

Labour .................................................................. 12

Other considerations ................................................... 13

Organic production ...................................................... 13

Key considerations ...................................................... 13

Organic certification ................................................. 14
Field Production Systems ...................... 16

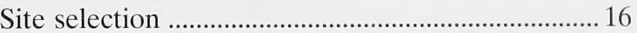

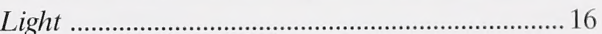

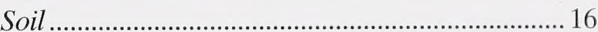

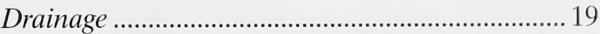

Previous crops and crop rotations ........................... 19

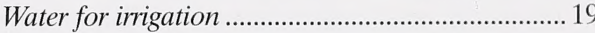

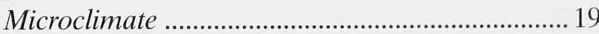

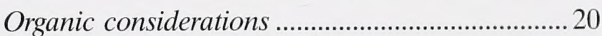

Site and soil preparation ............................................ 20

Pre-planting weed management ..............................2 21

Pre-planting soil fertility management .................... 21

Organic considerations .............................................. 21

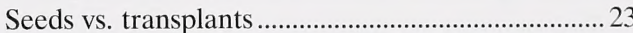

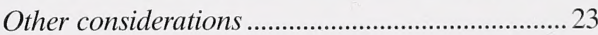

Seed considerations ..................................................... 24

Varietal purity and botanical identification ........... 24

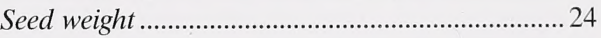

Seed germination ……................................................24

Treatments to improve germination ........................ 24

Organic considerations ........................................... 26

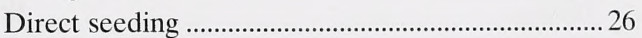

Spring vs. fall planting .............................................. 26

Seeding density .......................................................... 26

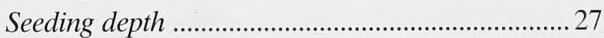

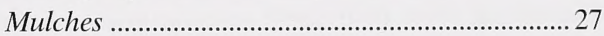

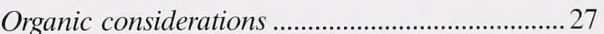

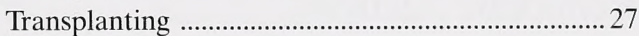

Transplant characteristics ........................................ 27

Transplant type and production timing ..................22

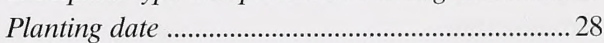

Plant spacing ........................................................... 28

Transplanting depth ..................................................29

Transplant establishment and survival ..................29

Planting bed design ................................................... 30

Organic considerations ............................................. 30

Fertility management .................................................. 30

Organic considerations ............................................. 32 
Irrigation 32

Irrigation system options .34

Irrigation timing and amounts ................................. 34

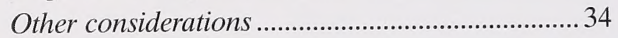

Organic considerations .............................................. 35

Pest management ............................................................. 36

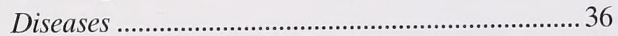

Insect pests ................................................................... 40

Vertebrate pests ........................................................... 40

Weed management ……………………………........... 40

Nutrient deficiencies ................................................. 41

Organic considerations .............................................. 41

Over-wintering ............................................................... 41

Winterkill .................................................................. 41

Improving winter survival ....................................... 42

Organic considerations .............................................. 43

Estimating plant populations .................................. 43

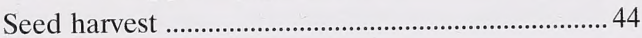

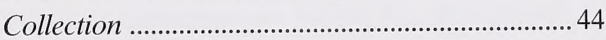

Cleaning ...................................................................... 45

Seed numbers per gram ............................................ 46

Seed production per hectare ......................................46

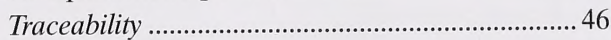

Organic considerations ................................................ 46

\section{Color Section ........... between pages 46 and 47}

Root harvest ..................................................................... 47

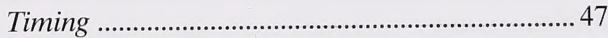

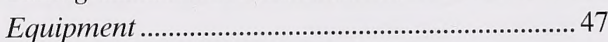

Root cleaning, drying and storage .......................... 48

Sample analysis ........................................................ 51

Harvesting other plant parts ....................................... 51

Economic Analysis ........................................52

Yield potential ............................................................. 52

Capital investment requirements .................................5 53

Gross margin ............................................................... 53

Gross margin sensitivity analysis .............................5 55
Financial risk management .........................................55

Cash flow projections ...............................................56

Risk management strategy: a five-year

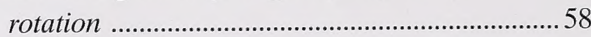

Risk management strategy: reduce the

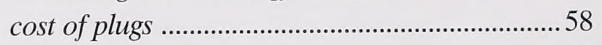

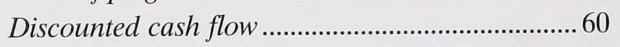

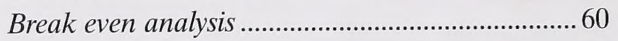

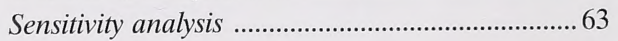

Financial benchmarks ............................................. 64

Business and Marketing ........................... 66

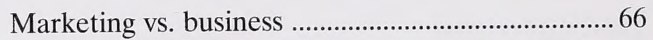

Value of market research ............................................. 66

Conducting market research ........................................ 66

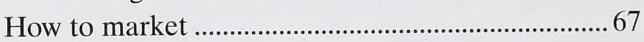

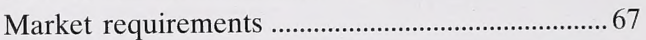

Selling root, seed and/or herb .................................... 67

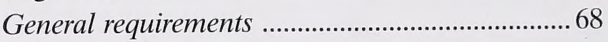

Value-added options .................................................... 68

\section{Greenhouse Production}

Systems ……………………………………..... 70

Transplant production .................................................. 70

Production timing .................................................... 71

Growing medium .................................................... 71

Growing containers ................................................ 75

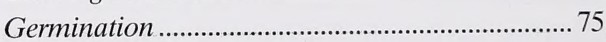

Environmental factors ............................................. 75

Fertility management .............................................. 76

Water quality .......................................................... 77

Managing pests ....................................................... 78

Organic considerations .......................................... 78

Root production - experimental method ................ 78

Root culture systems ............................................... 79

Root production in soil-less hydroponic system .................................................. 79

Aeroponic root production ....................................... 80

Organic considerations ............................................ 81 


\section{Good Agricultural Practices}

On-Farm Food Safety and HACCP-based

GAPs .82

HACCP basics

One up, one down model .83

Auditing/certification .83

Traceability

GAPs for echinacea production .84

CHSNC Growers' GAP Workbook .86

Natural Health Products

Regulations and Echinacea .87

Definition of a natural health product .87

Applying for a Natural Product Number

Site license application .88

Product licensing application .89

Sample monograph 89 91

Resources 94

Equipment and material suppliers ............................ 94

Equipment ………………………….................... 94

Materials ..................................................................94

Governments: information and contacts ................. 94

Alberta Agriculture, Food and Rural

Development (AAFRD) .. .94

Health Canada/NHP Regulation information ..... 94

Pest Management Regulatory Agency (PMRA) 95

Research centres conducting echinacea research 95

Laboratory services .95

Plant health diagnostics .95

Bioactive compound analysis .95

Soil and water testing laboratories ......................... 95

Producer associations ..................................................96

Seed cleaning services .................................................. 96

Other resources (literature, websites).
Appendix A ………….........................................99

Sample soil test report ................................................. 97

Appendix B ...................................................... 98

Plant populations and dry root yields -

trial data 98

Appendix C 100

Hydrogen peroxide 100

Appendix D ......................................................... 101

Bioactive compounds in echinacea species ...........101 Compounds with immunostimulatory activities

Other compounds 102

Glossary .

4

(94)




\section{Acknowledgements}

\section{Project Team Lead/Editor}

Robert Spencer - AAFRD

\section{Project Team}

Dr. Manjula Bandara - AAFRD

Dr. Kwesi Ampong-Nyarko - AAFRD

Kirsty Piquette - AAFRD

Dr. Mohyuddin Mirza - AAFRD

\section{Writing/Internal Review}

Robert Spencer - AAFRD

Dr. Manjula Bandara - AAFRD

Dr. Kwesi Ampong-Nyarko - AAFRD

Kirsty Piquette - AAFRD

Dr. Mohyuddin Mirza - AAFRD

Donna Fleury - AAFRD

Nabi Chaudhary - AAFRD

Dean Dyck - AAFRD

Shirzad Chunara - AAFRD

\section{Section Review}

Kathy Bosse - AAFRD

Roger Hohm - AAFRD

Dr. Ron Howard - AAFRD

Dr. Karen Tanino - U of Saskatchewan, Dept. of Plant Sciences

Dr. Branka Barl

Gregg Dill - AAFRD

\section{Information Contribution}

Dr. Jazeem Wahab - CSIDC

Dr. Kan-Fa Chang - AAFRD

Dr. Hong Qi - AAFRD

Forrest Scharf - AAFRD

Lasantha Ubayasena

Stewart Jangula - AAFRD

\section{External Review}

Wanda Wolf - Lone Wolf Herbs, Phippen, SK

Dave \& Monica Blaeser - Herbs Plus More, Millet, $\mathrm{AB}$

Doris Sabean - Edmonton, AB

Judy \& Julian Strumecki - Camrose, AB

Christa \& Wayne Cornelssen - Stettler, AB

Arjan Koekkoek - Barrhead, AB

Alberta Natural Health Agricultural Network (ANHAN)

Connie Kehler - CHSNC

Gillian Spencer - Stettler, AB 


\section{Abbreviations}

AAFRD Alberta Agriculture, Food and Rural Development

AHPA American Herbal Products Association

ANHAN Alberta Natural Health Agricultural Network

ASTA American Spice Trade Association

CDCN Crop Diversification Centre North (Alberta Agriculture, Food and Rural Development)

CDCS Crop Diversification Centre South (Alberta Agriculture, Food and Rural Development)

CHSNC Canadian Herb, Spice and Natural Health Products Coalition

COFFS Canadian On-Farm Food Safety (program)

CSIDC Canada-Saskatchewan Irrigation Diversification Centre (Prairie Farm Rehabilitation

Administration, Agriculture and Agri-Food Canada)

EC Electrical conductivity

GAP Good Agricultural Practices

GMP Good Manufacturing Practices

HACCP Hazard Analysis and Critical Control Points

HPFBI Health Products and Food Branch Inspectorate (Natural Health Products Directorate, Health Canada)

Lpm, gpm Litres per minute, gallons (imperial) per minute

$\mathrm{meq} / \mathrm{L} \quad$ Milliequivalents per litre (used to describe the amount of a substance in a water sample and the relative ability of a substance to combine with other substances)

$\mathrm{mS} / \mathrm{cm} \quad$ Millisiemens per centimetre (measure of electrical conductivity)

NHP Natural health products

NHPD Natural Health Product Directorate (Health Canada)

NPN Natural Product Number

ppm Parts per million

psi Pounds per square inch (unit of pressure)

QA Quality assurance

SAR Sodium absorption ratio

SOP Standard operating procedure 


\section{Introduction}

Echinacea is a perennial plant native to North America. It has a long history as a herbal remedy, and today, it is used for stimulating the immune system and protecting against coughs and colds.

Commercial production of Echinacea angustifolia is relatively new to Alberta. To be successful, producers need to acquire knowledge and practical experience. They must also make a significant investment to cover the costs of input materials, labour, equipment and land base for three to four years before harvest. As well, producers are responsible for defining the market for and the marketing of their product.

\section{Purpose of this guide}

This guide provides information needed to help potential new producers of echinacea to make decisions about investment or entry into the industry, while assisting current producers to grow a quality crop.

It describes production practices and economics for field-grown echinacea. It also looks at other options beyond field production including greenhouse production and value-added processing. It discusses business and marketing considerations for echinacea producers, as well as the good agricultural practices and the regulations that help to ensure consumer confidence and to develop strong business relationships. Finally, it provides a list of sources of information, supplies and services for echinacea producers. Terms shown in this type are defined in the Glossary.
Producers will need to adapt the information in this guide to the needs of their own farms. As in any developing industry, there is always opportunity for innovation and adaptation to deal with specific problems and situations. To be fully informed on local conditions and new developments in this emerging industry, producers should attend field days and seminars to network and learn about new research results. Membership in herbal associations is also an excellent way to connect with other growers and obtain the most current information on marketing and production. 


\section{Background}

\section{Alberta's echinacea industry}

The echinacea industry in Alberta started in 1990 with contract growing and marketing of Echinacea angustifolia. At that time, there were three major players. One contractor started the concept of growing 10,000 plants on small acreages, suggesting that a fairly large return on investment was possible. There were serious risk factors for producers, such as winterkill, unsuitable growing conditions and other factors that led to low yields.

With time, the level of knowledge and expertise in the industry has grown. The industry is beginning to mature, and better information is available for producers. Table 1 shows the maturity breakdown of the approximately 53 hectares (130 acres) in production in the 2003-2004 growing season.

As the industry has matured, producers have developed new marketing strategies. These include the creation of value chains and the development of an actual product for commercial testing based on Alberta-grown Echinacea angustifolia. The industry is expected to develop further, as research addresses production issues and as market development continues.

\section{Echinacea in the natural health products market}

The three main consumer market drivers for herbs in natural health products:

- a growing interest in overall health and wellness

- a desire to take a more active role in preventative health care

- a movement towards self-treatment

According to a report by Global Industry Analysts, Inc., the worldwide herbal supplements and remedies market amounted to an estimated \$US 12.72 billion in 2002 .

Echinacea as a single herb, not including its use in multi-herbs, accounts for 5 per cent of all herbal supplements and remedies sold worldwide. As a single herb, global echinacea sales in 2001 were \$US 616 million and are estimated to reach \$US 795 million by 2010 .

In the United States, sales of single herb echinacea in 2001 were \$US 154 million accounting for 25 per cent of the echinacea world market (Figure 1). The Asia-Pacific market, which includes China, Australia and India, had 2001 sales of \$US 108.66 million. Other top users of echinacea in 2001 were Germany at \$US 83.9 million, Japan at \$US 83.19 million, United Kingdom at \$US 37.63 million, and Italy at \$US 23.58 million. Canadian sales in 2001 were \$US 17.64 million.

\section{Table 1. Estimated area planted to echinacea of various maturities in Alberta in 2003-2004}

\begin{tabular}{|l|c|c|c|c|}
\hline Year & 4th year crop & 3rd year crop & 2nd year crop & 1st year crop \\
\hline $2003-2004$ & $\begin{array}{c}20 \text { ha } \\
(50 \text { acres })\end{array}$ & $\begin{array}{c}12 \text { ha } \\
(30 \text { acres })\end{array}$ & $\begin{array}{c}12 \text { ha } \\
(30 \text { acres })\end{array}$ & $\begin{array}{c}8 \text { ha } \\
\text { (20 acres })\end{array}$ \\
\hline
\end{tabular}




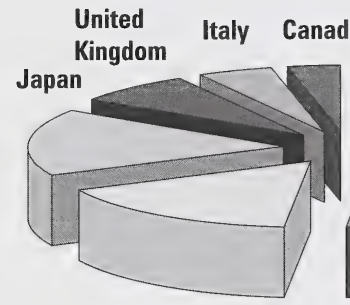

Germany

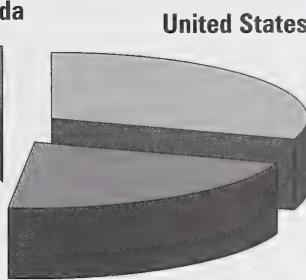

Asia-Pacific (China, Australia, India)

\section{Figure 1. Global single herb echinacea sales in 2001}

Echinacea is the most well-known and important herbal remedy for the immune system and protection against coughs and colds. According to the Nutrition Business Journal Supplement Report 2003 , sales in the U.S. of all products containing echinacea for the cold/flu-immune market in 2002 were \$US 801 million.

\section{Sources of echinacea}

Echinacea, like other medicinal plants, was initially harvested from the wild. The current trend is to replace wild-sourced echinacea with cultivated supplies.

\section{Wild harvesting}

Wild harvesting, also called wild crafting, is the practice of collecting plant materials in their natural habitat for food, medicine and craft. Wild harvesting has been the traditional source of medicinal plant materials. Wild harvested material is thought by some to be pure and of very high quality. It is assumed to be free from exposure to contaminants or human influence.

Wild harvesting needs a high level of skill and knowledge of botany and plant identification to ensure the collected material is what it is reported to be. It also requires a larger land base than cultivated production to supply a similar quantity of material.

In addition, wild harvesting requires some restraint as excessive harvesting can irreparably deplete the natural sources of the material. The gradual depletion of wild populations is one of the factors that have led to cultivated cropping of medicinal crops, such as echinacea.

\section{Cultivated echinacea}

The trend toward using cultivated supplies of echinacea has arisen in response to various issues. These include concerns over the ecological effects of wild harvesting, concerns over standardization and purity of product and the need for larger supplies as the demand for echinacea increases. Table 2 shows the shift in echinacea sources in the United States.

Table 2. United States tonnage of Echinacea angustifolia dried root - wild versus cultivated sources

\begin{tabular}{|l|c|c|c|c|}
\hline Year & \multicolumn{2}{|c|}{ Wild } & \multicolumn{2}{c|}{ Cultivated } \\
\hline & $\mathbf{k g}$ & $\mathbf{l b}$ & $\mathbf{k g}$ & $\mathbf{l b}$ \\
\hline 1998 & 102,681 & 226,372 & 47,563 & 104,858 \\
\hline 1999 & 22,672 & 49,984 & 99,433 & 219,211 \\
\hline
\end{tabular}

Adapted from 1999 Tonnage Survey Results by A. Andersen, 2000. 


\section{Botanical history of echinacea}

Plants of the genus Echinacea (pronounced ek-i-NAY-see-a), or the Purple Coneflowers, have been known as medicinal plants for many centuries. The name is derived from the Greek word root echinos, meaning sea urchin or hedgehog, which refers to the sharp, spiny projections on the seed cone head. Echinacea is a member of the Aster Family (Asteraceae), and the nine species of this genus are found in various regions of North America. Echinacea angustifolia is the main commercially grown species in Alberta.

In his book Echinacea: Nature's Immune Enhancer, S. Foster documents the history of the naming and differentiation of the various echinacea species. Augustine Pyramus DeCandolle first described Echinacea angustifolia DC in 1836. Despite disputes over similarities between some of the species, Echinacea angustifolia was eventually recognized as a separate and distinct species. More recently, Echinacea angustifolia was found to be a variety in the subgenus $E$. pallida (see the section on the Taxonomy of Echinacea).

\section{Folklore}

Many myths and legends relate to echinacea, both in where it originated and what it was used for. The Meskwaki tribe of southern Wisconsin referred to echinacea as "the hairs of Grandmother Earth's head."

Many native tribes and some physicians claimed that echinacea could cure snakebite. One individual, Dr. H.C.F. Meyer, offered to allow himself to be bitten by a rattlesnake to prove the efficacy of his echinacea medicine, becoming the first "snake-oil salesman."

A Winnebago Indian claimed to use echinacea to make his mouth insensitive to heat so that he could put a live coal in his mouth for show.
Plains Indians used water containing echinacea roots to pour over burning embers during sweat lodge ceremonies. The steam by-product was thought to provide additional cleansing in the sweat process.

\section{Historical uses of echinacea in North America}

\section{Native tribes}

Echinacea has long been recognized as a plant species with significant medicinal value. In their book Canadian Medicinal Crops, Small and Catling note that archaeological records show echinacea's use since at least the 1600 s. It was an important and well-known medicinal plant used by the Native people of North America to treat various illnesses (Table 3). Treatment was administered in a number of ways, including chewing the whole root, drinking an infusion or tea of the powdered leaves, or applying the juice or a poultice of the plant.

\section{Settlers and physicians}

North American settlers learned to use the medicinal plants of the various regions from their local Native tribes. Settlers used echinacea in the 1700s, and its use was described in a European botanical publication in 1739. In North America in the late 19 th and early 20 th centuries, medical practitioners who focused on Native tribe-derived medicines or remedies were referred to as Eclectics. Despite attacks from conventional doctors as to its efficacy, Eclectics used echinacea for the treatment of a wide range of diseases and illnesses (Table 4).

Small and Catling state that the first medical patent for an echinacea product was listed in 1870 . The use of echinacea continued until the development of antibiotics, such as penicillin, and other medicines in the early to mid 1900 s when echinacea use dropped off. In recent years, there has been a revival of the use of traditional medicinal herb products, of which echinacea is a leader. 
Table 3. Uses of echinacea by North American Native tribes

\begin{tabular}{|c|c|c|}
\hline Tribo & Ares & Uneas \\
\hline Blackfoot & Southern Alberta & - Treating toothaches \\
\hline Cheyenne & Colorado, Kansas & $\begin{array}{l}\text { - Treating sore throats, mouth and gum problems, } \\
\text { aches and pains, arthritis, measles, mumps, rheumatism, } \\
\text { smallpox } \\
\text { - Stimulating saliva }\end{array}$ \\
\hline Choctaws & Mississippi, Alabama & - Treating coughs, dyspepsia \\
\hline Comanche & Northern Texas & - Treating toothaches, sore throat \\
\hline Crow & Montana, Wyoming & - Treating colds, toothaches, colic \\
\hline Dakota (Oglala) & South Dakota & $\begin{array}{l}\text { - Treating inflammation, burns, headaches, poisonings, } \\
\text { bites and stings, enlarged glands (mumps), toothaches } \\
\text { - Providing heat tolerance } \\
\text { - Treating horses with distemper }\end{array}$ \\
\hline Delaware & Southern New York & - Treating gonorrhoea \\
\hline Hidatsa & - & - Stimulating energy \\
\hline Kiowa & South-western Kansas & $\begin{array}{l}\text { - Treating coughs, sore throat } \\
\text { - Hair combs (dried flower heads) }\end{array}$ \\
\hline Lakota & North Dakota & $\begin{array}{l}\text { - Treating swellings, wounds and sores, stomach aches, } \\
\text { thirst, over-perspiration, tonsillitis, toothaches }\end{array}$ \\
\hline Meskwaki (Fox) & Southern Wisconsin & $\begin{array}{l}\text { - Treating cramps, fits, eczema } \\
\text { - Hair combs (dried flower heads) }\end{array}$ \\
\hline Montana & Montana & $\begin{array}{l}\text { - Treating rattlesnake bites } \\
\text { - Increasing saliva }\end{array}$ \\
\hline Omaha & Eastern Nebraska & $\begin{array}{l}\text { - Treating septic diseases, sore eyes, burns, headaches, } \\
\text { poisonous conditions, stings, enlarged glands (mumps), } \\
\text { snakebites } \\
\text { - Providing anaesthetic } \\
\text { - Treating horses with distemper }\end{array}$ \\
\hline Omaha-Ponca & Northern Nebraska & $\begin{array}{l}\text { - Treating toothaches, mumps, burns, headaches, snakebites, } \\
\text { poisonous conditions } \\
\text { - Providing heat tolerance } \\
\text { - Eye wash } \\
\text { - Treating horses with distemper }\end{array}$ \\
\hline Pawnee & Central Nebraska & $\begin{array}{l}\text { - Children's game } \\
\text { - Treating burns, headaches, poisonous conditions, } \\
\text { enlarged glands (mumps), toothaches, snakebites } \\
\text { - Providing heat tolerance } \\
\text { - Treating horses with distemper }\end{array}$ \\
\hline Sioux (Dakota) & $\begin{array}{l}\text { Northern Nebraska } \\
\text { South Dakota }\end{array}$ & $\begin{array}{l}\text { Treating bowel problems, tonsillitis, hydrophobia, sepsis, } \\
\text { toothaches }\end{array}$ \\
\hline Winnebago & Eastern Wisconsin & $\begin{array}{l}\text { - Anaesthetic against heat } \\
\text { - Treating burns, headaches, enlarged glands (mumps), } \\
\text { poisonous conditions, snakebites, toothaches } \\
\text { - Treating horses with distemper }\end{array}$ \\
\hline
\end{tabular}

Adapted from Echinacea: The Immune Herb by Christopher Hobbs, 1990, with additional information added. 
Table 4. Eclectic uses of echinacea

\begin{tabular}{|c|c|c|c|c|}
\hline Bites, stings & $\begin{array}{l}\text { Sores, wounds, } \\
\text { skin conditions }\end{array}$ & Chronic diseases & Fevers & $\begin{array}{l}\text { Respiratory } \\
\text { illnesses }\end{array}$ \\
\hline $\begin{array}{l}\text { Bee sting } \\
\text { Scorpion sting } \\
\text { Snake bite } \\
\text { Spider bite } \\
\text { Wasp sting }\end{array}$ & $\begin{array}{l}\text { Abscesses } \\
\text { Bed sores } \\
\text { Boils } \\
\text { Carbuncles } \\
\text { Eczema } \\
\text { Impetigo } \\
\text { Leg ulcers } \\
\text { Wounds }\end{array}$ & $\begin{array}{l}\text { Cancer } \\
\text { Chronic bronchitis } \\
\text { Chronic glandular } \\
\quad \text { indurations } \\
\text { Chronic malaria } \\
\text { Chronic ulcerations } \\
\text { Diabetes mellitus }\end{array}$ & $\begin{array}{l}\text { Fevers } \\
\text { Scarlet fever } \\
\text { Typhoid fever }\end{array}$ & $\begin{array}{l}\text { Emphysema } \\
\text { Nasal catarrh } \\
\text { Respiratory catarrh } \\
\text { Tubercular phthisis } \\
\text { Typhoid pneumonia }\end{array}$ \\
\hline \multicolumn{3}{|l|}{ Infections, illnesses } & Internal maladies & Other \\
\hline $\begin{array}{l}\text { Anthrax } \\
\text { Chicken-pox } \\
\text { Cholera } \\
\text { Diphtheria } \\
\text { Epidemic influenza } \\
\text { Erysipelas } \\
\text { Exophthalmic goiter } \\
\text { Dysentery }\end{array}$ & $\begin{array}{l}\text { Gangrene } \\
\text { Malaria } \\
\text { Mastitis } \\
\quad \text { acute and chronic } \\
\text { Measles } \\
\text { Meningitis } \\
\text { Psoriasis } \\
\text { Pulmonary gangrene }\end{array}$ & $\begin{array}{l}\text { Puerperal infection } \\
\text { Tubercular abscesses } \\
\text { Quinsy } \\
\text { Septic injuries } \\
\text { Septicemia } \\
\text { Small pox } \\
\text { Tetanus } \\
\text { Tonsillitis }\end{array}$ & $\begin{array}{l}\text { Appendicitis } \\
\text { Intestinal indigestion } \\
\text { Renal haemorrhage } \\
\text { Ulcerative stomatitis }\end{array}$ & $\begin{array}{l}\text { Alopecia } \\
\text { Impotence } \\
\text { Rabies }\end{array}$ \\
\hline
\end{tabular}

Adapted from Table 14-1, Echinacea: The genus Echinacea, by S.C. Miller and H. Yu (editors), 2004.

\section{Modern health claims}

Despite its wide scope of use in early prescriptions, the modern uses of echinacea are typically for the enhancement of immune activity and the reduction of the duration and severity of illness. Bioactive compounds associated with echinacea are known to contribute to immunostimulatory activity.

According to the literature, echinacea is thought to have the following medical effects:

- stimulation of phagocytosis (the consumption of invading organisms by white blood cells and lymphocytes)

- proliferation of cells, which enhances the overall activity of the immune system.

- stimulation of the production of interferon, which helps regulate the body's immune response
- inhibition of hyaluronidase (an enzyme secreted by bacteria)

- stimulation of growth of new tissue

- fungicidal and bacteriostatic properties (controls fungus and slows the proliferation of bacteria)

It is now generally believed that the broad immunostimulatory activity of echinacea results from the combination of the whole spectrum of the chemical composition of the plant, rather than from a single specific compound. 


\section{The Echinacea Plant}

\section{Echinacea species}

A number of echinacea species are cultivated in Canada. The three species of economic importance are Echinacea angustifolia, Echinacea pallida and Echinacea purpurea (Figure 2 - color section). Table 5 summarizes the characteristics of these three species. Only E. angustifolia is native to Canada, and it is the predominant species grown commercially in Alberta.

\section{Ensuring the botanical identity of echinacea}

It is important to be sure of the botanical identity (species purity) of the echinacea being grown because the identity affects market quality and revenue. One of the greatest issues of concern in the natural health product industry is incorrect identity of plant material within the product. As regulations become tighter, botanical identification must be done at the farm level to ensure market access.

Producers should ask for species documentation or any other identification when purchasing seed or plants. Some crosses may occur between the various species resulting in altered quality. Off-type species or non-pure E. angustifolia should be removed from a planting.

One option for producers who have concerns about the identity of their seeds or plants is to have a laboratory conduct a chemical analysis (see the Resources chapter). At present, chemical marker processes are available that can be used to detect species impurity. Some research is underway that will allow the species of echinacea to be identified using genetic marker technology. In the future, some genetic fingerprints should be available.
Another option is to use a recognized botanist, taxonomist or herbarium to provide certification of species authenticity. Producers should contact botanic gardens or herbaria (often connected with universities) to determine if they have staff who are qualified and/or willing to do this work.

Producers may follow the Plant Identification Practice from the Canadian Herb, Spice and Natural Health Products Coalition, which outlines the appropriate steps to follow to ensure botanical identity.

\section{Taxonomy of echinacea}

Researchers recently clarified the taxonomic classification of Echinacea species and varieties by using advanced scientific techniques and looking at over 80 different traits. Their analysis revealed a hierarchy of two subgenera, four species and eight varieties in the genus Echinacea (see Figure 3).

The two subgenera (E. purpurea and E. pallida) are new, and some taxa that were previously considered to be species are now understood to be varieties. For scientific purposes, E. angustifolia is now E. pallida var. angustifolia; E. pallida is now E. pallida var. pallida; and E. purpurea is still called E. purpurea.

This guide retains the older naming conventions E. angustifolia, E. pallida and E. purpurea - for the three commercial taxa.

It is very important for producers to recognize that taxonomical errors may have occurred in certified seed lots. If producers have any concerns about the taxonomic identity of their seeds or plants, they should have them analyzed. 
Table 5. Key characteristics of the three main echinacea species

\begin{tabular}{|c|c|c|c|}
\hline Characteristies & Echipacea angustifolia & Echinacea pallida & Echinacea purpurea \\
\hline Common name & $\begin{array}{l}\text { Narrow-leaved purple } \\
\text { coneflower }\end{array}$ & Pale purple coneflower & Purple coneflower \\
\hline Origin & Native to Canada & Not native to Canada & Not native to Canada \\
\hline Plant size & $15-50 \mathrm{~cm}(6-20 \mathrm{in})$. & $60-120 \mathrm{~cm}(24-48$ in.) & $60-150 \mathrm{~cm}(24-60 \mathrm{in})$. \\
\hline Root system & Mainly tap rooted & Mainly tap rooted & Fibrous root system \\
\hline Leaves & $\begin{array}{l}\text { Oblong and lance-shaped with } \\
\text { stiff hairs }\end{array}$ & Oblong and lance-shaped & $\begin{array}{l}\text { Oval to broadly lance-shaped } \\
\text { and coarsely serrated }\end{array}$ \\
\hline Flower colour & Pale purple to deep purple & Pale purple to white & Pale purple to white \\
\hline Disk fiorets & Cone-shaped & Cone-shaped & Flat \\
\hline Ray florets & Spreading & Drooping & Spreading \\
\hline Pollen colour & Yellow & White & Yellow \\
\hline Level of bioactivity & $\begin{array}{l}\text { Greatest bioactivity of three } \\
\text { species }\end{array}$ & Least of three species & $\begin{array}{l}\text { Less bioactivity than } \\
E \text {. angustifolia }\end{array}$ \\
\hline Market demand & $\begin{array}{l}\text { Highest demand of three } \\
\text { species }\end{array}$ & $\begin{array}{l}\text { North American demand } \\
\text { unknown, mainly used in Europe }\end{array}$ & Good demand \\
\hline $\begin{array}{l}\text { Preferred } \\
\text { environmental } \\
\text { conditions }\end{array}$ & $\begin{array}{l}\text { Open plains plant that likes hot } \\
\text { sun;most environmentally } \\
\text { sensitive of three species } \\
\text { (especially to soil pH) }\end{array}$ & $\begin{array}{l}\text { Likes rocky, open sites, sunny } \\
\text { locations }\end{array}$ & $\begin{array}{l}\text { Woodland plant that does not } \\
\text { like the sun as much as } \\
\text { E. angustifolia }\end{array}$ \\
\hline $\begin{array}{l}\text { Moisture } \\
\text { requirements }\end{array}$ & $\begin{array}{l}\text { More drought-tolerant than } \\
\text { E. purpurea, and equal to } \\
\text { E. pallida; won't tolerate } \\
\text { standing water }\end{array}$ & $\begin{array}{l}\text { Equal in drought-tolerance to } \\
\text { E. angustifolia }\end{array}$ & $\begin{array}{l}\text { Not as drought tolerant as } \\
E \text {. angustifolia and } E \text {. pallida }\end{array}$ \\
\hline \multirow{3}{*}{$\begin{array}{l}\text { Expected harvest } \\
\text { time/duration }\end{array}$} & Root harvested year 3 or 4 & Highest root yield year 3 or 4 & $\begin{array}{l}\text { Root crown harvested year } \\
2 \text { or } 3\end{array}$ \\
\hline & $\begin{array}{l}\text { Herb may be harvested years } \\
2 \text { and/or } 3\end{array}$ & Herb not usually harvested & $\begin{array}{l}\text { Herb harvested years } \\
2 \text { and/or } 3\end{array}$ \\
\hline & Seed harvested years 2 and 3 & Seed harvested years 2 and 3 & Seed harvested years 2 and 3 \\
\hline Ease of cleaning & Easier than E. purpurea & Similar to $E$. angustifolia & Difficult \\
\hline $\begin{array}{l}\text { Seed treatment to } \\
\text { overcome } \\
\text { dormancy }\end{array}$ & $\begin{array}{l}\text { Stratification of seed } \mathrm{OR} \\
\text { Treatment with ethylene product } \\
\text { necessary }\end{array}$ & $\begin{array}{l}\text { Stratification of seed } \mathrm{OR} \\
\text { Treatment with ethylene product } \\
\text { necessary }\end{array}$ & No stratification necessary \\
\hline Ease of cultivation & Hard to cultivate & Hard to cultivate & Easiest to cultivate \\
\hline
\end{tabular}

Adapted from Field Scale Production of Echinacea by Clayton Jackson, 1997, with other information added 


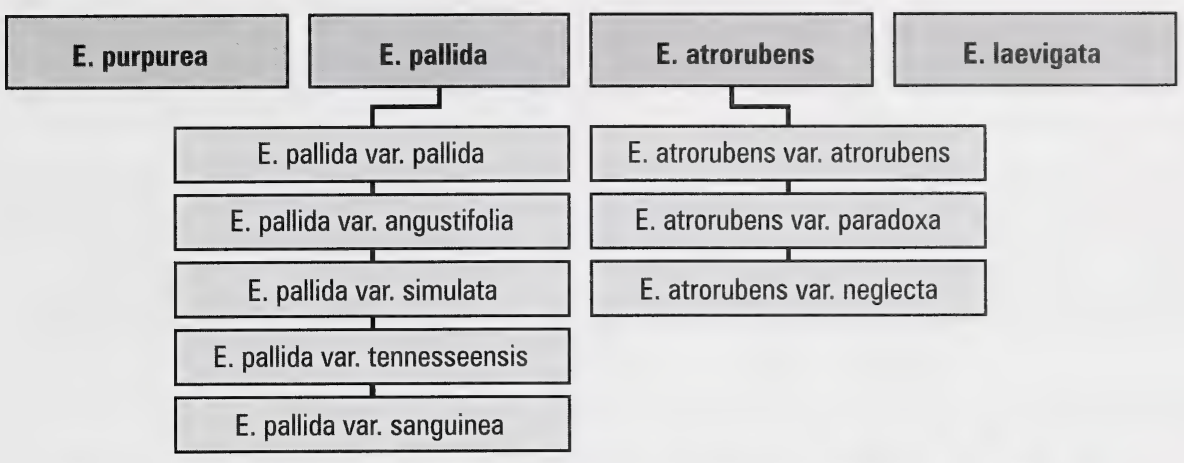

Figure 3. Taxonomic breakdown of the four species of echinacea and their varieties

\section{Active ingredients}

The species of echinacea can be differentiated by chemical analysis to determine the presence or absence of a number of compounds. The quality of harvested echinacea is determined by the relative quantity of the various compounds. Remember that different buyers or markets will demand certain levels of different compounds.

It is also important to understand the relative distribution of a particular marker compound within the various plant parts so as to ensure correct handling to minimize losses. For example, studies have shown that the main marker compounds in $E$. angustifolia are highest in the taproot, bark and secondary roots necessitating careful harvest and post-harvest handling of the root.

For the three commercial species of echinacea, four classes of compounds are known to contribute to the immunostimulatory activity of the plant extracts, namely alkamides, glycoproteins, polysaccharides and cinnamic acids. Other compounds found in the plant extracts include alkaloids, hydrocarbons, essential oils and flavonoids.

\section{Compounds with immunostimulatory activities}

The following summarizes the major chemical compound classes found in the three commercial echinacea species. Detailed chemical descriptions of the various compounds and a breakdown of the distribution of these compounds within the different species are found in Appendix D.

\begin{abstract}
Alkamides
Alkamides are found in the rhizomes (or roots) of $E$. angustifolia and in the rhizomes and aerial (aboveground) parts of E. purpurea in relative abundance. Small amounts of alkamides can be detected in the rhizomes of E. pallida, but at nowhere near the amounts found in the root systems of the other two species. As many as 15 different alkamides have been found in E. angustifolia and E. purpurea.
\end{abstract}

\section{Glycoproteins}

Echinacea glycoproteins may induce cytokine production (cytokines are molecules that provide communication between immune system cells, as well as between immune system cells and cells belonging to other tissue types) and stimulate the beginning of cell division. E. angustifolia and E. purpurea roots contain similar amounts of glycoproteins, but E. pallida contains fewer glycoproteins. 


\section{Polysaccharides}

Two polysaccharides with immunostimulatory properties have been isolated from the aerial parts of $E$. purpurea. One of the polysaccharides from E. purpurea stimulates phagocytosis (activity conducted by specialized cells that remove bacteria, dead cells, small mineral particles, etc. and fight infection). A different polysaccharide stimulates large cells that are a part of the innate immune system to release tumour necrosis factor (a substance that seems to play a role in the breakdown of cancer cells).

\section{Cinnamic acids}

Cinnamic acid and its derivatives are used as important components in flavours, perfumes, synthetic indigo and pharmaceuticals. In echinacea, the particular chemical structures present can be used to distinguish between the three species. The roots of $E$. angustifolia have cynarin and lack chicoric acid (which the other two species have), whereas the roots of $E$. purpurea lack echinacoside, which E. pallida and E. angustifolia have. E. pallida is particularly rich in chicoric acid. It is the major component in all plant parts, whereas echinacoside is a major constituent of the roots, but is present in moderate amounts in the flowers and only in trace amounts in the leaves. The flowers of E. pallida also have several other compounds. In contrast, all of the plant parts of $E$. purpurea had similar profiles of chicoric acid, caftaric acid and chlorogenic acid.

Chicoric acid from echinacea has been shown to have phagostimulatory (infection fighting) effects in culture and to inhibit hyaluronidase activity.

\section{Other compounds}

\section{Alkaloids}

Two different alkaloids have been isolated from $E$. angustifolia and E. purpurea extracts, comprising about 15 per cent of the crude extract and 0.006 per cent of $E$. purpurea dried root.

\section{Hydrocarbons}

Eleven hydrocarbons have been found in E. pallida roots, serving to identify E. pallida. Two simple hydrocarbons have been detected as major root constituents of both E. pallida and E. angustifolia, whereas only one hydrocarbon has been detected in E. purpurea, but this is also found in roots of $E$. angustifolia. The profile of hydrocarbons is a useful way to distinguish species, especially among the various root preparations sold commercially.

\section{Essential oils}

The roots of E. purpurea have up to 0.2 per cent essential oil. The flowering parts of all three species have less than 0.1 per cent essential oil.

Over 70 compounds were identified in the headspace analysis (analysis of plant volatile gas) from all plant parts from the three species. The three species differ in terms of the chemical constituents of the headspace.

\section{Flavonoids}

Flavonoids are divided into many subclasses. They include compounds like anthocyanins, etc.

Flavonoids are not considered to be essential nutrients, but some flavonoids support health by strengthening capillaries and connective tissue and function as anti-inflammatory agents, antihistaminics and antiviral agents.

\section{Latitudinal effect}

Some medicinal plants grown in northern climates show what is referred to as a "latitudinal effect." For example, sometimes material that originates from an area with a harsh climate will have elevated levels of bioactive compounds, improved yields or, in some cases, improved propagative strength when grown in an area with a more moderate climate.

It has not yet been determined whether echinacea is subject to a latitudinal effect. No difference has been found between samples produced in either northern or southern Alberta. 


\section{Preliminary Considerations}

Echinacea is not a guaranteed path to riches. There are many risks, and a lot of hard work is required before reaping any economic benefits. To improve the chances of success, producers must thoroughly research and develop their business, production and marketing plans.

Failure to plan is a plan for failure.

\section{Business basics}

When starting a new business or expanding an existing operation, some key questions must be addressed:

- What is the purpose of the business?

- Why is the business being started?

-What is the plan for the business?

-What will be the main activities of the business?

- What resources or skills are present?

-What are the costs of production?

- Is the operation potentially economically feasible, based on a number of economic scenarios?

- Who will be involved in the business?

- Who will be responsible for running the business? Is there a management team?

- Why would someone want to buy this product?

- Who are the potential customers? What is the market? Where is the market?

-What needs to be done before starting?
New producers need to gather all relevant information, carefully consider the pros and cons and then plan out the details of the proposed operation. These initial steps will allow sound decisions to be made, not the least of which is whether or not to proceed.

\section{Business and production plans}

Those interested in growing and marketing echinacea need to carefully prepare a detailed business plan and outline their production plan to ensure they have covered all relevant aspects of the operation and have prepared strategies for the wide range of situations that may arise. Planning will help minimize risks as well as providing other benefits.

Producers should consider land and equipment requirements, availability of labour and sources of starter plant material (seed or seedlings), market proximity and access, and potential value-adding or processing opportunities. Producers should also decide whether they want to pursue an organic production system, which may provide increased market access, or a conventional system. The economics and cost of production should be reviewed or estimated as a part of this decision (see the Economic Analysis section).

\section{Markets}

Breaking or preparing land and planting a crop without giving thought to markets can lead to failure. Producers MUST consider where they will sell their product at the end of the production cycle. 
There is no single desk commodity marketing board for echinacea. Producers of echinacea must also be marketers of echinacea (see the Business and Marketing chapter).

\section{Contracts}

Producers need to be careful if and when establishing a contract. They must ensure they have a clear and complete understanding of all the terms of the contract. These terms would include the price to be paid for the supplied product at the end of the production cycle and any clauses, conditions or points that may affect returns. It is also important to be realistic about expectations for plant survival and yield.

\section{Breaking the traditional farming mentality}

Traditional farming typically deals with field crops grown on a large acreage scale. Returns per hectare are typically low, necessitating production from many hectares to spread out costs. While some aspects of a traditional farming system will be valuable assets, echinacea is not a traditional crop, so traditional assumptions do not always apply. Producers must carefully break some of the mental habits developed in the traditional farming system.

One of the first mental barriers to remove is the thought, "If I grow it, someone will buy it."

Producers must research their markets, target their product to meet specific buyer requirements and become marketers of their product.

Another barrier is the belief that "More is better." Producers must consider what their market can support and what they are able to produce. While 12 hectares (30 acres) may seem small in the context of a traditional farming system, the management and cost of planting 12 ha or even 2 ha ( 5 acres) would be excessive for a new grower of echinacea (see the Economic Analysis section). It is recommended that producers start with a very small planting, develop the skills and experience needed to be successful and then expand slowly, as they are able and as the market demands.
Just because it looks good on paper...

People who are interested in growing echinacea but have little or no farming background will have an even greater learning curve. All aspects of the proposed operation should be considered, including the costs and the potential risks and effects of mistakes. Although the potential returns per hectare or per kilogram for echinacea may look attractive, new growers need to be very conservative when calculating their potential income in their business plan. There may be hidden or unforeseen costs (such as extra labour) or other factors (such as winterkill) that will affect final income and, ultimately, the operation's success.

Remember that not all aspects of the operation will provide returns on the same level on a yearly basis (e.g. seed collection and sales), or in some cases, may not provide any return despite the potential. As well, market fluctuations may result in reduced returns. Yield estimates should be based on the plant population remaining at harvest rather than on the initial plant population.

The reality is that producers MUST be prepared to make difficult decisions based on the realistic economics that they generate during their preparations.

\section{Labour}

Labour is one of the most expensive aspects of an echinacea operation. A good source of skilled seasonal labour is a must for any operation. Labour requirements may peak at different times throughout the production cycle, such as during root harvest or seed harvest. There is also an ongoing need for labourers throughout the summer for weeding.

New growers should consider what sources of labour are available to them and what potential competition there may be for labourers. Shortfalls in labour or a high level of turnover can seriously affect the viability of an operation, which should be considered in advance as well as contingency plans made. 


\section{Other considerations}

Growing echinacea is a long-term investment with significant costs incurred before any sales. To be successful, producers must not only invest in equipment and land base, but must also acquire knowledge and skills.

Producers must recognize the differences in scale between traditional agricultural commodities and echinacea. The level of production achieved by a single, viable farm may not be sufficient to supply the needs of a particular buyer. As a result, producers may need to cooperatively market their product or seek a broker that can consolidate the product of multiple suppliers to fill large orders. Producers should explore all available options to minimize risk.

Producers should consider where they will derive income in the period between planting and harvest. They may want to consider the production of other annual medicinal crops to offset the investment costs of echinacea. These crops should be compatible with or complement echinacea and should not require extra or different equipment or compete in terms of harvest operations, etc.

Producers could also experiment with intercropping or multiple cropping to generate revenue from the echinacea land base. Care should be taken in choosing a crop for this purpose, as it should not increase the risk of disease or insect pest infestation.

\section{Organic production}

Many growers consider organic production when starting an echinacea operation. Certified organic production may increase market access, as some buyers demand organically produced echinacea, whereas others simply have a preference for organic echinacea over conventional echinacea, if samples are of equal quality.

Certified organic production does not allow the use of manufactured crop inputs (herbicides, fungicides, insecticides, fertilizers, etc.), both in the years of production and the years surrounding production.
Growers must comply with the use of accepted inputs as recognized by their certifying body and ensure that they use only organic or biological pest control products registered by the Pest Management Regulatory Agency (PMRA). True organic production does not allow the application of manures from animals that were not fed organic feed. Certified organic production also requires the use of certified organic seed, unless an exemption has been obtained (if no organic seed is available). An audited and certified trail of records is also required.

Certified organic production systems have unique challenges that producers must consider. Organic production is not as simple as avoiding the application of conventional fertilizers and pesticides. Producers must be aware of the complexities of organic production before starting this type of operation and then make adjustments or preparations to meet the requirements.

\section{Key considerations}

- Do extensive market research.

It is critical, as with any product, to determine what the demand for the product is and who the potential buyers are. This information allows producers to make production and management decisions and gear their practices towards their buyer's requirements.

\section{- Certified organic production is both a business and a philosophy.}

Some producers may choose to produce organically because they perceive a potential economic advantage in an organic product. Others may decide to produce organically because of a philosophical motivation such as a desire to conserve the environment, reduce pesticide use or produce a product in a more "natural" way. This motivation may influence or override decisions that might otherwise be made from a purely economic perspective. Producers should have a clear understanding of their own goals and values, and make their decisions accordingly. 


\section{- Learn from other people's mistakes and successes.}

In some cases, producers may be breaking new ground (metaphorically) and will have to deal with all the unknowns and challenges that may arise when experiencing something for the first time. New producers can save time, energy and cost by learning from others' experiences.

Communication and interaction with other producers will increase the overall strength of the industry and may lead to more rapid developments than might be achieved by a single individual.

\section{- Become very familiar with the standards of the organic certifying body.}

Each organic certifying body may have different requirements and standards, although there will be some commonalities. Differences are based on where the product is going to be sold (e.g. Europe, U.S.) and in the use of accepted inputs. Failure to meet these requirements will result in a failure to access a market. No assumptions should be made about the preferences of a certifying body. If a producer is going to spend the time and money to certify, all decisions should be made to maintain that certification.

\section{- Start small.}

Organic production is not simply abstaining from the application of synthetic fertilizers or pesticides. To be successful, producers will have to be much better organized and cannot simply react to situations, as might sometimes be possible in a conventional system. The rules and standards are more detailed and complex in an organic system. Expansion should only be considered after some experience has been gained.

\section{- Be prepared to learn as you go.}

It is not possible to understand all aspects of organic production at the beginning. Experience will help to correct early mistakes, provided experiences are reviewed and learned from.
Contact with other producers and participation in learning activities are very valuable. Producers should also seek out magazines, newsletters, Internet resources and other sources of information related to echinacea research, production and marketing that could improve their operations.

\section{Organic certification}

Organic producers must be certified by a specific certifying body. At present, there are no national regulations; however, the adoption of an enforced national standard appears likely in 2006. Some provinces have an organic regulation in place (e.g. Quebec and British Columbia).

Certification with different certifying bodies will allow access to different markets. The final target market will determine which certifying body to choose. Each organic certifying body has specific guidelines and standards that must be adhered to. There is a difference in certification costs associated with following the different protocols and certifying criteria.

Organic certification is a process based on standards. Producers must have their operation validated annually through third-party inspection to ensure compliance. Producers who meet the required standards may call their product "certified organic."

\section{Key steps for organic certification}

To start the organic certification process, a prospective organic producer has a number of initial tasks:

- Contact a certifying body to learn about its standards, regulations, forms and costs.

- Determine whether the various aspects of the certifying body are consistent with the producer's personal standards and practices.

- Determine whether certification with a particular certifying body will allow access to the desired market.

- Assess the current operation to develop an action plan to phase in certification and determine the costs of implementation. 
- Determine whether the required changes will result in the anticipated economic benefits.

- Fill out and submit all the necessary applications to the certifying body.

- Develop a record keeping system and plan for continued compliance to the certifying body's standards.

- Participate in training sessions by the certifying body to improve organic practices.

- Arrange a site inspection and evaluation with the certifying body.

Certification is a process that will involve reviews, inspections and assessment. Becoming certified may take some time to accomplish, particularly if a producer is attempting to convert land that was farmed conventionally in the past. A phase-in period of up to three years may be required. Producers may be able to shorten the process if they can provide documentation demonstrating compliance to certain standards.

Organic certification must be maintained once it has been put in place. Producers need to be aware of the agricultural practices on the lands around them, as non-organic practices could have an effect on their operation at some point. 


\section{Field Production Systems}

The vast majority of echinacea grown in Alberta is produced in the field (see Figure 4 - color section), with some variation as to how plants are started. Many producers transplant greenhouse seedlings into their fields, but some sow the seed directly into the field (referred to as direct seeding).

This chapter describes all aspects of field production of echinacea, from site selection and preparation through to post-harvest practices, for both transplanting and direct seeding. It also outlines considerations for organic operations for each aspect of production. And it presents an economic analysis as a guide to help producers assess the economics of their own operation or of a potential operation.

\section{Site selection}

Although echinacea is native to North America, it cannot be grown in just any area or soil type. Site selection has a significant influence on the success of an echinacea operation.

When selecting a location for a new planting, producers need to consider such site factors as light, soil, previous crops, water, microclimate and shelterbelts. The proposed site should meet at least the minimum requirements of the plants. A site with limitations will increase the level of management needed and may affect the operation's success.

\section{Light}

Echinacea angustifolia prefers locations with bright sunlight. Excessive shading from adjacent plantings of trees should be avoided.

\section{Soil}

Generally, echinacea prefers good, loose topsoil, with good aeration, drainage and fertility. Some soil types are not recommended for echinacea, such as the grey forest soils (Luvisolic). Soils containing impermeable layers (e.g. solonetzic soils), compacted layers or layers of heavy clay should be avoided. Stony soils should also be avoided.

\section{Soil testing}

Producers should use soil tests to determine the suitability of a field for echinacea production and to guide the ongoing fertility management program.

A soil test provides a great deal of useful information about the soil in the chosen location, including basic information such as $\mathrm{pH}$, texture and organic matter, as well as soil nutrient levels at the time of sampling. Regular soil testing helps producers track changes in soil fertility in their fields and can be the basis for fertilizer management and application decision making.

The quality of the laboratory results is related to the procedure the producer used to collect the sample.

Key points to remember in soil sampling:

- Use proper augers and clean containers for sampling.

- Most soil sampling is done in the fall, due to nutrient stability, but samples can be taken in the spring.

- Deeper rooted or perennial crops might require information from deeper in the soil profile; therefore, a soil test should be done for samples from 0 to $30 \mathrm{~cm}(0-12 \mathrm{in}$.) and 30 to $60 \mathrm{~cm}$ (12 - 24 in.) depths.

- A soil sample should be representative of the entire field, so it should be collected from a wide range of locations across the field. 
- When sampling, avoid obviously unusual or abnormal locations, such as low spots, eroded knolls, field margins or areas where high levels of manure have been applied.

- Keep samples free from contaminants.

- Once a sample has been collected, air-dry it immediately, keep it cool, and ship it immediately.

\section{Soil test reports}

Field description and cropping history information enables the laboratory to maintain records for research purposes. More importantly, it helps the lab make sound fertilizer and management recommendations for the producer. Over time, individual producers can monitor the fertilizing history and nutrient levels in their fields.

Appendix A shows a sample soil test report. The appearance of these reports varies depending on the soil testing company. The general information provided should be similar, although different companies may include different tests in their soil test packages.

The following information will help the producer understand and use the results of a soil test report.

Carbonate content indicates the calcium carbonate content of the sample. High to very high calcium levels in the soil can restrict nutrient availability to the plants. Absence of calcium carbonate does not mean the fields require lime. Only very acid soils require additions of lime.

The $\boldsymbol{p} \boldsymbol{H}$ value indicates the soil's acidity level. Soils with a $\mathrm{pH}$ in the range of 5.9 to 8.0 are acceptable for echinacea production. Echinacea angustifolia appears to be adapted to soils with a pH close to 8 . Soil $\mathrm{pH}$ is important because it influences the solubility or availability of mineral elements required for plant growth (see Figure 5). For example, phosphorus becomes less available to plants at levels below $\mathrm{pH}$ 5.3; many micronutrients become much more available at lower $\mathrm{pH}$ levels, and nitrogen is available in the $\mathrm{pH} 5$ to 8 range.
The use of acidifying fertilizers and green manures (crops grown to be incorporated into the soil) can alter the soil $\mathrm{pH}$ to some degree; however, adjusting soil $\mathrm{pH}$ is difficult to achieve and can be fairly expensive.

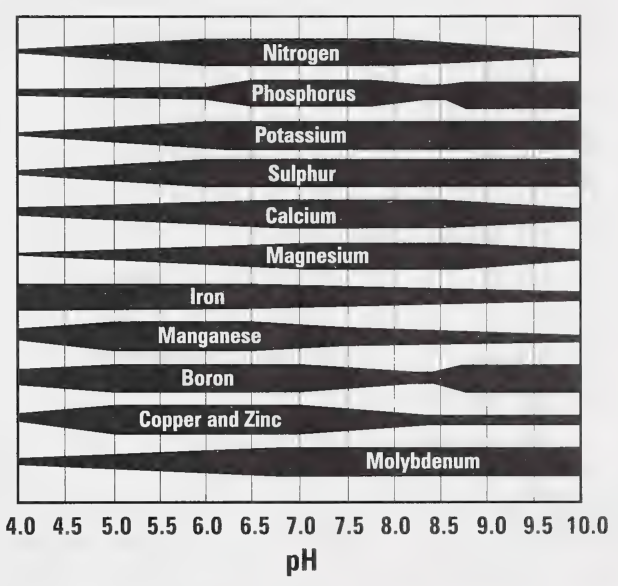

Figure 5. Influence of $\mathrm{pH}$ on nutrient availability in soil

Electrical conductivity (EC) is a measure of the level of salinity (salt). The salt content of some prairie soils is too high for successful echinacea production. A conductivity reading of less than $1 \mathrm{mS} / \mathrm{cm}$ is best. Levels greater that 1 could result in growth problems. Adding lime or gypsum will not correct a soil salinity problem.

Irrigation water with significant salt content, combined with poor soil structure, may also cause soil to develop unacceptable salinity levels. Saline soils can occur in bands or patches throughout a field. 
Texture indicates the relative amounts of sand, silt and clay. Figure 6 shows the soil texture triangle, which describes the variations in soil texture.

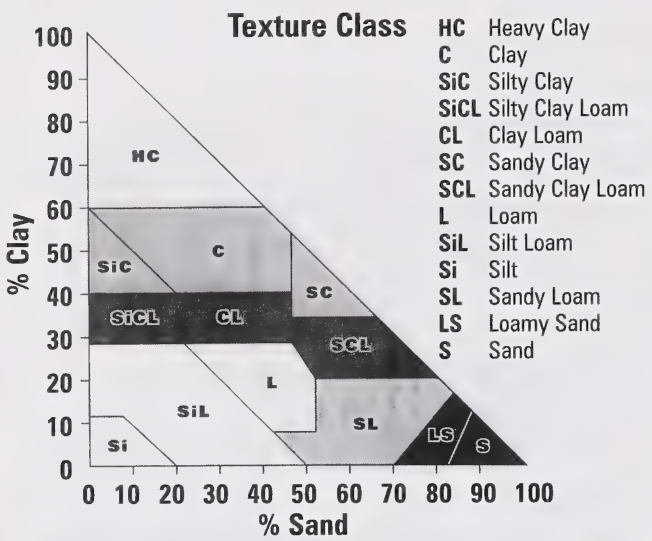

Figure 6. Soil texture triangle

Loam soil is a good mixture of sand, silt and clay and is neither droughty nor difficult to till. Heavy clay soils are usually poorly drained and poorly aerated, encourage disease development and can impede precisely timed field operations. Coarse textured sandy soils are often infertile and droughty, and they require more frequent irrigation and greater attention to fertilization practices.

The best soil for echinacea production is a welldrained soil with good moisture and nutrientholding capacity. It should be easy to wash off the roots. Soils with a clay layer can cause problems for echinacea production resulting in poor, misshapen roots and heavier top growth.

Soil organic matter content refers to the proportion (per cent) of organic matter in the soil. Organic matter represents a store of nutrients and has a significant effect on soil moisture and nutrientholding capacity. Soils with an organic matter content between 3 and 5 per cent are recommended. High organic matter soils may have poor drainage, and soils with excessively low levels of organic matter may be unsuitable for echinacea production, due to their low nutrient-holding capacity.
Nutrient content or soil fertility levels indicate the amount of nutrients in the soil. This information allows producers to make fertility management decisions. A soil test report should state the levels of macronutrients (e.g. nitrogen, phosphorus, potassium, sulphur) and may also include levels of various micronutrients (e.g. magnesium, iron, calcium). The nutrient content section of the report should contain the greatest amount of detail. The measurement units vary by company and nutrient, but typically are either parts per million (ppm) or kilograms per hectare $(\mathrm{kg} / \mathrm{ha})$ or pounds per acre (lb./acre).

Depending on the lab, there may be recommendations for fertilizer application to enhance crop growth and yield. The information will likely be for traditional crops like wheat and canola, but information on the report will allow interpretation and adjustment of these values.

For detailed recommendations on the desired levels of fertility at different stages of the production cycle, see later sections on fertility management.

Other information: A soil test report will likely contain other information:

- customer contact information

- legal land location

- previous cropping information

- soil sample tracking information

\section{Soil tilth}

Soil tilth is a measure of the combined effects of various characteristics of the soil, such as bulk density, texture, porosity, organic matter, compaction and aggregation, which affect the movement of water and nutrients through the soil and the penetration of roots. Tilth reflects the overall health and condition of the soil as well as the suitability for crop production.

Soil tilth and nutrient availability can be improved by using green manure crops such as nitrogen-fixing legumes, buckwheat or rye, which contribute to soil organic matter and improve soil structure and can supply some nutrients. Producers should consider the potential for disease or pest development when selecting a green manure crop. 


\section{Drainage}

Poorly drained sites should be avoided. The surface drainage system must permit water to move from the field quickly and completely. Water standing on the field for a day or two will injure plants, especially when they are actively growing, and can significantly reduce yields. Standing water may occur on sites with dips, depressions or low areas.

The use of clay or plastic drainage tile could be considered on sites where drainage is a problem; however, the cost and complexity of this approach would likely be prohibitive.

\section{Previous crops and crop rotations}

Echinacea should not be grown on land that was planted to canola, sunflower, beans or other crops susceptible to the disease Sclerotinia. Producers should also attempt to minimize the populations of insect vectors (those insects that may transmit viruses) either through the removal of weed hosts or by avoiding crops that may allow an insect species population to develop. (See the Pest Management section for information.)

Producers should also consider the effect of previous crops on soil fertility and soil quality as the level of removal or contribution of nutrients will vary.

\section{Water for irrigation}

Irrigation is essential for the consistent establishment of high yielding echinacea. Since Alberta has fairly low rainfall, compared to other regions, and echinacea plants are initially shallowrooted, supplementary moisture is necessary to ensure strong and uniform establishment.

River or pond water is often used for irrigation. Well water may be suitable but should be tested to determine if the quality is satisfactory. Well water often has high sodium and/or iron levels.

In Alberta, water analysis is done by a number of private laboratories (see Resources chapter for labs). Water quality is satisfactory for echinacea if salinity (as measured by the water's electrical conductivity) is less than $1 \mathrm{mS} / \mathrm{cm}$, adjusted sodium absorption ratio (SAR) is less than 30 and chlorides are less than $3 \mathrm{meq} / \mathrm{L}$.

In Alberta, a water rights license is required before water can be taken from any source other than a pond filled completely by rain or snow that has fallen on the producer's property. Construction of ponds or dams may also require approval. In Alberta, water rights licenses are issued by Alberta Environment, provided the required evaluations have been conducted. (For information on getting a water license, see the Irrigation section.)

Assistance programs may be available for developing farm water or irrigation systems. For details, contact Alberta Agriculture, Food and Rural Development (see the Resources chapter).

\section{Microclimate}

A microclimate is defined as the local climate near the ground that is peculiar to a small area (usually, the radius is less than a kilometre and can be as small as a centimetre). It is an area with uniform temperature, rainfall and drainage, and good protection from the wind. If the site lacks a microclimate suitable for echinacea, the producer must create one.

Land that is slightly sloped provides good air and ideal water drainage. Locations with good air drainage allow cold air to move away from plantings with no restriction in airflow. For this reason, dense wooded areas and shelterbelt plantings that are perpendicular to the prevailing wind should be avoided. Fields should be oriented to allow for natural air drainage. If some shelter is required, openings should be left in the shelterbelt to let cold air move away.

An accumulation or excess of soil water can increase the chance of root and crown rots, and it can decrease plant vigour and nutrient availability. Good drainage can be a result of slope or soil texture, or drainage may be improved artificially. 
Echinacea plants are frost resistant and fairly winter hardy. They can survive temperatures of $-25^{\circ} \mathrm{C}$ $\left(-13^{\circ} \mathrm{F}\right)$ down to $-40^{\circ} \mathrm{C}\left(-40^{\circ} \mathrm{F}\right)$ if there is adequate snow cover for winter insulation and the plants are well established. Locations with limited snowfall are less than ideal for echinacea production. Areas that commonly experience irregular freeze/thaw events may have a higher incidence of winterkill, due to the formation of ice layers over the plant crowns. Seedlings that have not been properly established are likely to experience high levels of winterkill. (For more information, see the Over-wintering section.)

\section{Organic considerations}

Organic producers must be certified, as noted earlier. Therefore, they need to be aware of the requirements of their certifying body to ensure they have adequate time to conform to those requirements. It may be useful to purchase land that is, or can be, certified organic within a shorter time.

Organic producers should also consider the limitations and anticipate the difficulties they will face during organic production. Plans and preparations to deal with these issues need to be made in advance. Innovations may be required. For example, producers may need to do extensive land preparation or purchase special equipment. They must also locate sources of organic manure or other organic fertilizers.

Labour is a major component of any echinacea operation. The labour requirement in an organic operation may be higher than in a conventional operation, as some tasks involving chemicals must be replaced with mechanical or cultural methods. This aspect should be considered when locating an operation.

Proximity to other, non-organic operations must also be considered. Buffer zones should be included in the operational planning and site selection to protect the crop from potential cross contamination from agri-chemicals used in non-organic operations.

\section{Site and soil preparation}

A period of one or two seasons for site and soil preparation is recommended before establishing an echinacea crop. Echinacea is a perennial plant that is usually grown for at least three years in the field before harvesting. Failure to prepare the site properly will minimize the chances of a successful operation. Preparation includes controlling weeds, improving soil quality and preparing the seedbed.

Many echinacea operations do not use herbicides for weed control, and there are few, if any, herbicides registered for this crop. Perennial weeds are difficult to control in an established crop; therefore, every effort should be made to control them before establishment.

At the same time, producers should make plans with consideration for the need for weed management. Since there are different types of mechanical tillage, crop row spacings need to be designed to accommodate these various types of tillage equipment.

Plastic mulch may be an option to reduce in-row weed control requirements. The mulch is relatively inexpensive and can be applied before or during the planting operation. Some equipment is available that will lay the mulch and plant the transplants through the mulch. Drip irrigation is usually necessary to supply plant moisture needs when using plastic mulch; however, some producers have used other methods to apply water. Producers should be careful when using plastic mulch as the plastic may become trapped in the roots (during growth or harvest) and become a contaminant.

Soil quality can be improved by adding nutrients and by increasing organic matter. Planting into soil that is low in nutrients, has poor structure or is generally unsuitable for growing echinacea could result in total loss of investment.

Seedbed preparation is also critical for successful establishment of an echinacea crop. The main purpose is to improve seed/plant-to-soil contact and to create an environment that is conducive to rapid plant establishment. Seedbed preparation may include rototilling to remove lumps, bed shaping and/or applying plastic mulch. 


\section{Pre-planting weed management}

Weed management is one of the most labourintensive activities in an echinacea operation. Weed control before planting will help reduce the weed management requirements throughout the production cycle.

Producers should spend one to two seasons on weed control before planting. This approach will reduce the number of perennial weeds and deplete the number of annual weed seeds in the soil.

Weed management can be accomplished through mechanical tillage or chemical applications. If using pre-planting herbicides, be sure to consider the soil residual characteristics of the chemicals as some chemicals may reside in the soil for several years. Although no studies have been done on the sensitivity of echinacea to herbicide residues, producers should use caution. Non-specific herbicides, such as glyphosate products, can be used with no fear of carryover.

\section{Pre-planting soil fertility management}

Adequate soil fertility is essential to achieving good yields of quality root. Research has clearly demonstrated the benefits of applying fertilizers, both in terms of root yield and levels of bioactive compounds. Failure to provide adequate nutrients for plant growth can lead to reduced yields and quality as well as reduced plant survival due to weakened, deficient plants.

Research at the Canada-Saskatchewan Irrigation Diversification Centre (CSIDC) showed that the application of nitrogen at $100 \mathrm{~kg} / \mathrm{ha}$ (89 lb./acre) and phosphorus at $50 \mathrm{~kg} / \mathrm{ha}$ (45 lb./acre) produced 17 and 48 per cent higher root yields, respectively, in direct seeded echinacea.

In some areas of the world, like Germany, producers apply 112 to $224 \mathrm{~kg} / \mathrm{ha}$ (100 - $200 \mathrm{lb}$./acre) of nitrogen in a split application, as well as $100 \mathrm{~kg} / \mathrm{ha}$ (89 lb./acre) of phosphorus and $250 \mathrm{~kg} / \mathrm{ha}$ (223 lb./acre) of potassium at planting.
The general recommendation for echinacea is that there be approximately $112 \mathrm{~kg} / \mathrm{ha}$ (100 lb./acre) of nitrogen, $56 \mathrm{~kg} / \mathrm{ha}$ (50 lb./acre) of phosphorus, 168 to $224 \mathrm{~kg} / \mathrm{ha}$ ( 150 - $200 \mathrm{lb}$./acre) of potassium, 22 to $34 \mathrm{~kg} / \mathrm{ha}$ ( $20-30 \mathrm{lb}$./acre) of sulphur and 8 to $10 \mathrm{ppm}$ of iron in the soil, available for plants.

These levels should be maintained through regular soil testing and application of fertilizers on a yearly basis.

Producers may also need to increase the level of soil organic matter to improve the soil's structure and nutrient-holding capacity. Adding well-composted animal manure or incorporating a green manure crop will increase organic matter and improve soil tilth. The addition of peat moss will increase organic matter and can decrease soil $\mathrm{pH}$. Producers applying raw or composted manure should consult Alberta's regulations for manure application to ensure they are compliant.

\section{Organic considerations}

Organic producers may face additional challenges in managing weeds and supplying adequate nutrients for plant growth. Both of these issues can be reduced, to some extent, by good management practices before establishment of the echinacea crop.

\section{Pre-planting weed management}

Organic producers are not allowed to apply herbicides. Therefore, they must plan far ahead to anticipate and reduce the difficulties and labour involved in controlling weeds. Weeds will have to be controlled mechanically, so at least two years of tillage should be done before planting to try to control perennial weeds and reduce the annual weed population.

Organic producers should design fields to allow for more mechanical weed control. This approach may include altering row spacing to compensate for different types of tillage equipment. Organic producers should also consider other weed control measures, including the use of plastic mulch. Anything that can be done to control weeds before planting should be done. 


\section{Fertility management}

The nutrient requirements of echinacea plants can be supplied organically through well-planned fertility management practices. Organic producers face some important limitations in the ways they can supply the nutritional needs of their echinacea crop both initially and for the entire production cycle.

Organic fertilizers slowly release plant-available nutrients over a long time by mineralization and degradation of organic matter. Producers need to factor in this time delay when developing organic fertility management strategies. The supply of nutrients must be built up in the soil before planting as organic fertilizers, such as raw manure or compost, cannot meet immediate plant requirements.

The nutrient analysis of many organic fertilizer sources is often lower than conventional fertilizers, necessitating the application of higher amounts of the organic products.

Certified organic producers must ensure that their fertilizer sources are organic. For example, manure must be from organically-fed animals.

Organic producers can build up soil fertility in a number of ways. The application of animal manures or compost will supply some nitrogen, phosphorus, potassium and sulphur as well as a variable amount of other nutrients.

Manure and compost samples should be analyzed to determine the levels of plant-available nutrients in each sample so that an appropriate application rate can be set.

Producers should not over-apply manure or compost and should use appropriate handling and storage methods, to guard against contamination of the environment (e.g. water bodies, etc.) or contamination of the manure or compost itself by some other product. Producers should consult Alberta's regulations on manure application to ensure they are compliant.
Properly composting manure will improve the stability of nitrogen release from the manure and can reduce the possibility of contamination by weed seeds and microbial organisms (such as harmful bacteria). Due to less microbial activity, properly composted manure tends to be less "hot" than fresh manure and will not harm roots and young plants.

While most prairie soils have adequate levels of phosphorus, much of this nutrient is not immediately available to plants, being only gradually released from the soil. All soil samples should be tested for available phosphate rather than total phosphate.

The addition of rock phosphate is an acceptable practice in organic fertility management, and some simple practices can improve the benefit from the application. The more finely ground the rock phosphate is, the more quickly the phosphorus becomes available to the plants. Soils with a $\mathrm{pH}$ less than 7 will have a greater availability of phosphorus. The addition of elemental sulphur can increase the solubilization of rock phosphate making it more available. The source of the rock phosphate will also affect the proportion of available phosphate.

The crop's sulphur requirements may be supplied through application of elemental sulphur. Elemental sulphur (S) must be oxidized to release the sulphate sulphur $\left(\mathrm{SO}_{4}-\mathrm{S}\right)$ that is available to plants. This process takes at least one year. As with rock phosphate, the smaller the particle size, the more rapid the oxidation and release of sulphates.

Growing nitrogen-fixing legumes before planting echinacea can add some nitrogen to the soil.

Similarly, green manuring can add some nutrients to the overall fertility supply.

Studies in Europe showed that the application of 2.26 tonnes/ha (1 ton/acre) of composted and granulated chicken manure (with a nitrogen $(\mathrm{N})$ to phosphorus (P) to potassium ( $\mathrm{K}$ ) ratio of $4: 1: 2$ ) is sufficient to supply two years of nutrients for an echinacea crop. 


\section{Seeds vs. transplants}

Echinacea is usually started from seed, rather than using vegetative propagation techniques such as plant cuttings. Although some producers seed echinacea directly into their field, many producers use either bare root seedlings or plugs for field production. The seedlings or plugs are grown in a greenhouse by the producer or a custom supplier and then transplanted into the field. There are advantages and disadvantages, as well as specific considerations, for each system.

\section{Advantages of direct seeding}

- Less labour intensive than transplanting.

- Easier to thin plants than replace dead transplants.

- More flexibility in plant spacing.

- Precision seeding possible.

\section{Disadvantages of direct seeding}

- Uniform plant density and plant spacing are more difficult to achieve (due to variability of germination).

- Resulting seedlings may vary in health, maturity and vigour.

- Seed germination may be reduced if conditions are not ideal.

- Plant establishment may be slow or delayed.

\section{Advantages of transplanting bare root seedlings or plugs}

- More efficient use of costly seed.

- Weeding is easier than in direct-seeded beds, reducing competition effects from weeds.

- Planting into plastic mulch is easier.

- Provides an opportunity to select healthy seedlings for transplanting.

\section{Disadvantages of transplanting bare root seedlings or plugs}

- Planting costs may be higher, due to the cost of plant material and the need for more labour.
- Source of transplants must be located or the producer must generate the transplants (potential increased capital costs).

- Missing or dead plants in the field must be replaced.

\section{Other considerations}

Establishing a field of echinacea represents a significant capital cost, regardless of whether plants are started from seed or transplants.

Good quality echinacea seed can cost as much as several hundred dollars per kilogram. Growing directly from seed may be somewhat less expensive than from transplants, as it does not require extra planting materials, such as media and trays, or other greenhouse-related costs and requires less labour for field planting. Producers who grow their own transplants in a greenhouse may increase their control over transplant quality.

Transplants are also available for purchase from different suppliers in Alberta. The cost and quality will vary, and producers should use caution when making a purchase. As with any agricultural purchase, producers should choose a reputable supplier and have a clear understanding of the conditions and guarantees provided.

The total cost of transplant material or seeds will depend on the planting density, with a higher planting density obviously costing more money. Producers must carefully weigh the projected returns against the costs and potential risks or benefits of a higher planting density (see sections on Direct Seeding and Transplanting for seeding rates).

It is important for producers to ensure that the seed or seedlings they are using have been verified or botanically identified. Failure to do so may result in reduced returns at market. 


\section{Seed considerations}

\section{Varietal purity and botanical identification}

The end quality of a crop depends on the purity of the seed. If a planting is a mix of Echinacea species, the overall final quality will be reduced, especially if some is E. purpurea, which contains no echinacoside. It is critical to ensure that purchased seed is certified as the species claimed by the seller. It is the responsibility of buyers to ensure they are getting good quality, certified seeds.

Seed sellers should also ensure they are only selling quality seed as this practice will help them maintain their customer base. Having a record of the seed source and purity is essential when the time comes to market the product. It is also wise to keep and properly store a sample of the seed source if confirmation is needed in the future.

\section{Seed weight}

Seed weight varies with the year of collection and such other factors as location, climatic conditions and management. One study found that the number of seeds per gram ranged from 201 seeds per gram to 319 seeds per gram. This represents a possible difference of over 100,000 seeds in one kilogram. A lower seed number per gram does not mean that the seed quality is better than a sample with more seeds per gram. All seed samples should be tested for seed germination. Figure 7 shows echinacea seed.

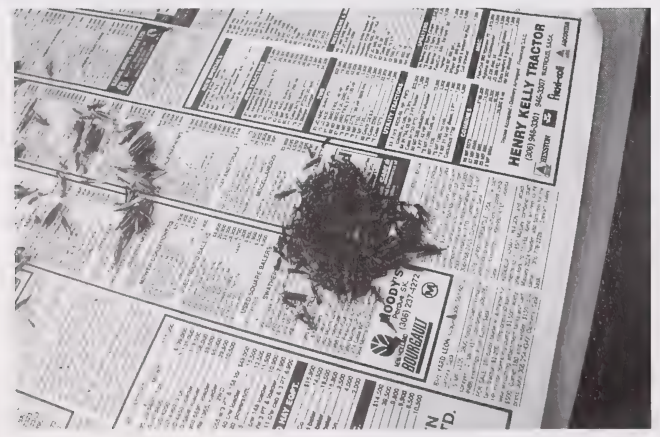

\section{Seed germination}

Seed germination is a critical factor in echinacea production. The quality of seed is determined, in part, by the level of germination. The percentage germination is an important factor in calculating seed cost.

In general, the germination percentage of Echinacea angustifolia seed is naturally poor. Seed germination tests may range from as low as 2 per cent to as high as 50 per cent without any additional treatment. Additional treatments are recommended for improved results.

\section{Treatments to improve germination}

Echinacea seed must be treated to improve germination. Seed treatments may include disinfection, stratification and/or treatment with the plant growth hormone ethylene.

\section{Seed disinfection}

The presence of seed-borne fungal pathogens (disease-causing agents) can reduce or severely limit the germination of otherwise viable echinacea seed. In studies at the Crop Diversification Centre North $(\mathrm{CDCN})$ in Edmonton, treatment of seed with either bleach (1:9 dilution of 5 per cent bleach) or hydrogen peroxide ( 1.5 per cent) significantly reduced fungal infection and improved germination.

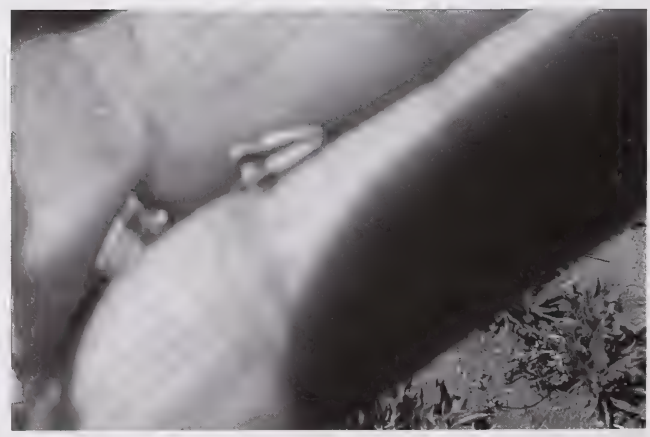

Photos Courtesy AAFRD - K. Piquette and M. Mirza 


\section{Stratification}

Stratification is the process of exposing seeds to low temperatures and moisture for a period of time (normally 4 - 6 weeks) to help remove seed dormancy. For echinacea, seeds should be placed in moist sand and refrigerated at $4^{\circ} \mathrm{C}$ for four weeks and then separated from the sand using a mesh seed separator. Studies at CDCN found that the per cent germination increased as the duration of cold stratification increased, to a maximum after 30 days (Table 6).

Table 6. Effect of duration of cold stratification on per cent germination of $\mathrm{E}$. angustifolia seed

\begin{tabular}{|c|c|}
\hline $\begin{array}{c}\text { Days of cold stratification } \\
\left.\text { (at } 4^{\circ} \mathrm{C}\right)\end{array}$ & \begin{tabular}{c} 
Germination $(\%)$ \\
\hline 0
\end{tabular} \\
\hline 21 & 41 \\
\hline 27 & 60 \\
\hline 30 & 67 \\
\hline 42 & 86 \\
\hline 49 & 78 \\
\hline 56 & 79 \\
\hline 58 & 81 \\
\hline
\end{tabular}

\section{Ethylene}

The use of the plant growth hormone ethylene can help remove seed dormancy and improve germination without the need for stratification. The treatment is used for seed that will be grown into transplants in a greenhouse; it cannot be used for seed that will be used for direct seeding.

Ethylene $\left(\mathrm{C}_{2} \mathrm{H}_{4}\right)$ is a naturally occurring plant growth regulator that plays a role in the ripening and maturation of many crops. Some plant parts contain this compound in higher amounts, and the sensitivity of different plant parts (e.g. fruit) varies. Wounding or exposure to external sources of ethylene often accelerates the internal production of ethylene and accelerates ripening. Ethylene plays a vital role in the control of dormancy.
Ethylene is available commercially as Ethrel. Studies at CDCN found that seed germination increased as the concentration of Ethrel was increased (Table 7).

Table 7. Effect of Ethrel concentration on per cent germination of E. angustifolia seed

\begin{tabular}{|c|c|}
\hline Ethrel $(\mathrm{ppm})$ & Germination $(\%)$ \\
\hline 0 & 50 \\
\hline 100 & 80 \\
\hline 200 & 81 \\
\hline 300 & 89 \\
\hline 400 & 86 \\
\hline 500 & 86 \\
\hline
\end{tabular}

\section{Ethylene treatment}

The following procedure has been found to increase the rate and percentage of seed germination:

1. Soak the seed in a solution of commercial bleach at 1 part bleach to 10 parts good quality water (sodium is less than $100 \mathrm{ppm}$ ). Use distilled water if unsure of water quality. Soak for 5 minutes, and then rinse 4 to 5 times with fresh water.

2. Soak the seeds in water for 24 hours at room temperature with lights. A 40-Watt incandescent bulb is adequate. Change the water 2 to 3 times to remove any chemicals that leach from the seed.

3. After the period of soaking, the seeds will settle to the bottom. Remove the seeds from the water, and place them to soak for 2 hours in a solution containing $1 \mathrm{~mL}$ (0.03 US fluid oz.) Ethrel in $1 \mathrm{~L}$ (0.22 gal.) water.

4. Remove the seeds from the solution and let them air dry for 30 minutes.

5. The air-dried seeds can be sown through an automatic seeder or manually spread over the growing medium. 
6. Do not sow the seeds in thick layers, as the seeds need light for germination. If sowing in plug trays, place the seeds on the top of the growing medium and then gently press them in, with the seeds still exposed to light.

7. Seeds are fully active and must not be allowed to dry out. Use gentle misting to maintain high air humidity until the seed germinates.

8. Air temperature should be close to $22^{\circ} \mathrm{C}\left(72^{\circ} \mathrm{F}\right)$, and light should be present until emergence occurs, and then light should be maintained with natural cycles.

9. The seed will go down in the growing medium.

\section{Simplified ethylene treatment}

Naturally occurring ethylene can be used in a simplified version of the ethylene germination method described above.

Echinacea seed can be placed on a wet paper towel in the presence of one half of a cut apple. The wounded apple will release sufficient ethylene to improve germination. This method could be used for small-scale seed treatment and is compatible with organic production. The percentage germination will vary.

\section{Organic considerations}

Organic producers must determine whether or not seed treatments (e.g. plant growth regulators or disinfectants) are compatible with the established standards of their certifying body.

Organic producers should also determine whether their certifying body requires an organic seed source.

\section{Direct seeding}

Echinacea can be seeded directly into a field. As noted, direct seeding offers some advantages like a lower labour requirement, as well as disadvantages like poor and uneven stands. Studies at various research institutions across the prairies and the practical experiences of some producers have shown that direct seeding is possible.

\section{Spring vs. fall planting}

Direct-seeded echinacea can be sown in either spring or fall. Researchers at CSIDC in Outlook, Saskatchewan, did not find a difference in stand establishment between fall- and spring-seeded echinacea (spring seed was stratified before planting). Plant stand establishment was only 5 to 23 per cent of the actual seeded rate.

For fall seeding, unstratified seed should be seeded at $5 \mathrm{~mm}(1 / 4 \mathrm{in}$.) deep, before winter freeze-up. The seed is naturally stratified over the winter and germinates early in the spring using available soil moisture.

For spring seeding, stratified seed is sown on the soil surface and lightly pressed into the soil. Soil must be kept moist with daily, light irrigation to prevent seeds from drying out.

\section{Seeding density}

Seed should be tested for the per cent germination, the projected plant density should be determined and the seeding rate increased proportionately to compensate for non-viable or non-germinating seeds.

Table 8. Echinacea angustifolia seed germination rates from three harvest. dates under two different seed treatments

\begin{tabular}{|l|c|c|c|}
\hline Treatment & \multicolumn{3}{|c|}{ Harvest date } \\
\hline & September 18 & September 25 & October 3 \\
\hline Ethrel & $85 \%$ & $84 \%$ & $88 \%$ \\
\hline Control (no Ethrel) & $46 \%$ & $52 \%$ & $69 \%$ \\
\hline
\end{tabular}


In a study at CSIDC, the effect of seeding density and several other practices on final dry root yield was evaluated over several growing seasons. Generally, as seeding rate increased (with a corresponding increase in final plant population), dry root yield increased. The plant stand, as a percentage of seeding rate, was very low.

Producers will need to adjust the row spacing to allow aisles wide enough to accommodate the different types of equipment and management practices that will take place in the field.

\section{Seeding depth}

Echinacea requires some light to germinate; therefore seed must be planted at a shallow depth. Studies at CSIDC found that seed planted in the fall at a depth of $5 \mathrm{~mm}$ (1/4 in.) had similar stand establishment to seed spread on the soil surface in spring.

\section{Mulches}

Some producers have successfully direct seeded echinacea into plastic mulch. Plastic mulch can increase spring soil temperature and will also reduce the amount of in-row weeding needed, thereby reducing the competition between weeds and the crop for water, light and nutrients.

The mulch is put in place before planting. Holes must be punched into the mulch and seed placed in each hole. It is also recommended that an irrigation system be installed with the mulch. Producers should use caution when using plastic mulch as there is the potential for mulch to become trapped in the roots and become a contaminant.

Fall-seeded echinacea may benefit from the addition of 2 to $3 \mathrm{~cm}$ (3/4 to $11 / 5 \mathrm{in}$.) of clean straw mulch to provide some winter protection. Be sure to use clean, weed-free straw both to prevent the introduction of weed and volunteer seed and to reduce weeding labour costs. The straw should be removed in spring to facilitate germination.

\section{Organic considerations}

Organic producers should have documentation outlining their seeding practices and should ensure that all practices conform to the standards of their certifying body. Organic producers should also have clear documentation relating to their seed source.

\section{Transplanting}

Most echinacea produced in Alberta is grown from transplants produced in greenhouses. Using transplants has a number of advantages, including uniform plant stands. Care must be taken to maximize the survival of the transplants due to their high cost.

\section{Transplant characteristics}

Only healthy, high quality transplants should be used. Planting poor quality plants will result in a low survival rate and a loss of investment.

Transplants should be at least 10 weeks old with good root development and several true leaves. Overgrown transplants should not be trimmed down as the stress on the plant will increase the amount of time it takes to recover, reducing the rate of establishment.

Transplants should be shipped carefully. Wilted seedlings should not be planted as they are unlikely to establish properly due to a loss of root hairs.

Seedlings that are crowded, weak, spindly or leggy will be more susceptible to root rots and seedling blights. Diseased seedlings should not be planted as they are unlikely to survive and may spread the disease to other seedlings.

\section{Transplant type and production timing}

Transplants may be either greenhouse plugs or bare root seedlings (see Figure 8 - color section). Plugs tend to be of better quality and are more stable and likely to develop into a healthy mature plant. Bare root seedlings are less expensive and more readily available than plugs. 
Transplants are typically started in late winter or early spring, with a 10 -week-old transplant preferred. This method requires a heated greenhouse facility.

A study at CSIDC evaluated an alternative production schedule that may reduce the costs of production. Transplants were grown in a greenhouse in the late summer and fall under good growing conditions (adequate light and heat). Then, they were over-wintered as dormant plants in a strawcovered pit before being planted out in spring. The study found that survival was as much as 99 per cent higher with this production method than with other methods, such as spring-produced bare root seedlings.

For details on greenhouse production of transplants, see the section on Transplant Production.

\section{Planting date}

Echinacea transplants should be planted in the field by the end of May or mid-June. It is critical to allow as much time as possible for the plants to establish good, strong root systems in the field before frost occurs. It takes at least three weeks for roots to start growing into the soil from a plug. If the plants fail to establish before winter, the likelihood of winter injury and plant crown death will increase dramatically. Echinacea can regrow from the roots, but the new plants will be weak and of poor quality.

Transplants should not be planted in the fall, as they will not have sufficient time to establish.

\section{Plant spacing}

Planting density (the number of plants per unit area) will have a significant effect on echinacea plant survival, growth and development, as well as harvested yields and root quality. Spacing between the rows and between the plants within the rows are both important considerations.

Producers will need to adjust the row and plant spacing to accommodate the different types of equipment and management practices that will take place in the field. The calculation of total plant population per hectare (acre) should be adjusted for the aisles and alleyways in the field. Table 9 shows how plant populations (approximate) change with changes in spacing.

Research at CSIDC found that final dry root yields increased by 86 to 133 per cent (irrigated vs. dryland) when row spacing decreased from $30 \mathrm{~cm}$ (12 in.) to $15 \mathrm{~cm}$ (6 in.).

Table 9. Echinacea plant spacing vs. plant population densities

\begin{tabular}{|c|c|c|c|c|c|}
\hline $\begin{array}{l}\text { Row X plant } \\
\text { spacing (cm) }\end{array}$ & Plants/m² & Plants/ha* & $\begin{array}{l}\text { Row X plant } \\
\text { spacing (in.) }\end{array}$ & Plants/ $/ \mathrm{t}^{2}$ & Plants/acre* \\
\hline $60 \times 15$ & 11.1 & 111,000 & $24 \times 6$ & 1.0 & 43,500 \\
\hline $45 \times 45$ & 4.4 & 44,000 & $18 \times 18$ & 0.4 & 17,400 \\
\hline $30 \times 30$ & 11.1 & 111,000 & $12 \times 12$ & 1.0 & 43,500 \\
\hline $23 \times 23$ & 18.9 & 189,000 & $9 \times 9$ & 1.8 & 78,400 \\
\hline $15 \times 15$ & 44.4 & 444,400 & $6 \times 6$ & 4.0 & 174,200 \\
\hline $10 \times 10$ & 100.0 & $1,000,000$ & $4 \times 4$ & 9.2 & 400,700 \\
\hline $5 \times 5$ & 400.0 & $4,000,000$ & $2 \times 2$ & 36.2 & $1,576,800$ \\
\hline
\end{tabular}

Approximate plant numbers 
Studies at the Crop Diversification Centre South (CDCS) in Brooks, Alberta, examined a range of planting densities for their effect on yields of echinacea root, foliage and seed. The study concluded that as planting density decreased (wider spacing), foliage, root and seed production was reduced. It was recommended that a spacing of $30 \mathrm{~cm}$ (12 in.) between rows and $15 \mathrm{~cm}(6 \mathrm{in}$.) within the row would be most suitable for southern Alberta.

A study at $\mathrm{CDCN}$ also examined a range of planting densities for their effects on yield, quality and winter survival (see Figure 9). As planting density was increased, dry root yield increased; however, yields tended to plateau at the higher densities. It is likely that the cost of the additional plant material would not provide sufficient returns to justify the higher plant densities. High densities also had a negative effect on seed yield and winter survival (see sections on Seed Production and Over-wintering).

It is generally recommended that producers do not exceed a plant density of about 8.8 to 11 plants $/ \mathrm{m}^{2}$ (0.8 - 1.0 plants/ $\mathrm{ft}^{2}{ }^{2}$ ) or plant populations of 88,000 to 111,000 plants/ha $(35,000-45,000$ plants/acre $)$.

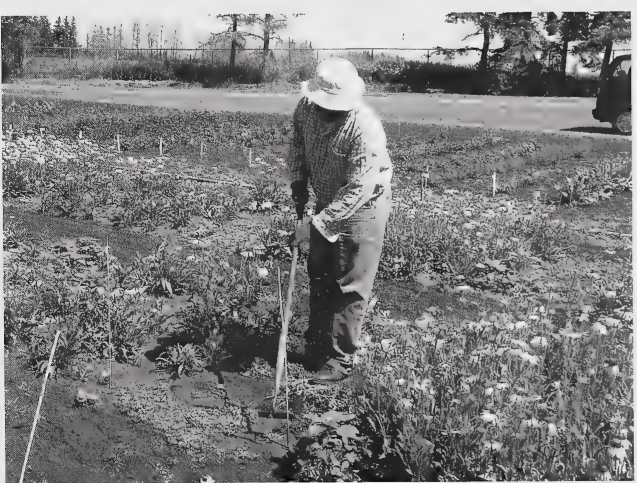

\section{Transplanting depth}

There is not a specific depth that transplants should be placed at. They should be planted deeply enough for the soil to completely cover the roots with good soil-to-root contact, but not so deeply that the leaves and growing points are covered with soil. Irrigation can allow somewhat shallower planting.

If producers are using mechanical transplanting equipment (see Figure 10), they should ensure the machine is calibrated properly and plants are being placed correctly. It is advisable to assign someone the task of checking planting depth and transplant position behind the planter so that errors can be corrected quickly.

\section{Transplant establishment and survival}

Transplants need to be handled with care to ensure good establishment. Stress of any kind at this stage can seriously reduce the likelihood of survival of the new plants. Producers should do all they can to ensure that all plant requirements are met.

Planting should be done in the cooler parts of the day or on cool, overcast days. Avoid planting in high temperatures and excessive winds, which result in elevated transpiration rates and moisture loss, leading to drought stress. Plants should be well watered befor planting and then watered in after planting.

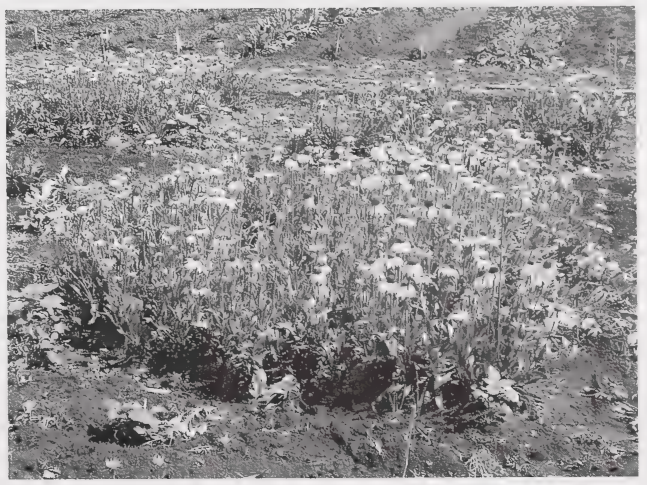

Photos Courtesy AAFRD - M. Mira 


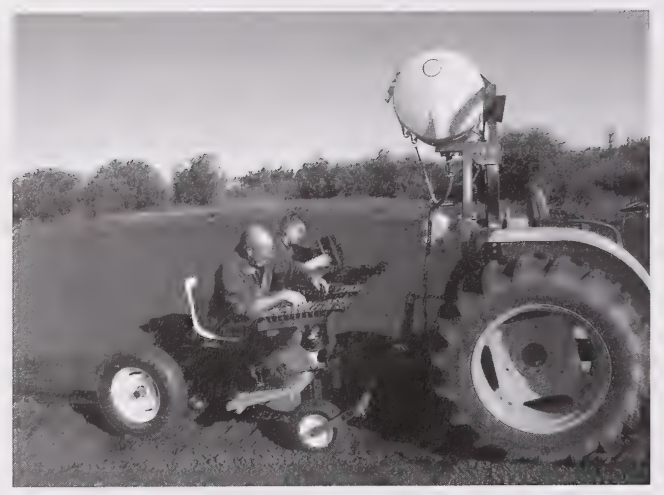

Photo Courtesy Phoenix Pharms

Figure 10. Transplanting equipment for planting echinacea

Occasionally, transplants may spend some time in the field before they are planted. In such situations, producers should ensure plants are supplied with water and kept in a sheltered location, out of direct sunlight and wind. They should be planted as soon as possible.

Applying a dose of liquid fertilizer when the transplants are watered in can significantly improve plant survival and establishment. A fertilizer with higher phosphorus will promote rooting.

During the first few weeks after planting, transplants should be supplied with sufficient water so that they don't dry out. It takes at least three weeks for a transplant's roots to grow into the surrounding soil.

\section{Planting bed design}

The design of a planting bed can help reduce problems related to harvest, environmental stress or weed management.

If an area is prone to flooding or the collection of water (even if temporarily), producers may want to consider a raised bed, to attempt to improve drainage and increase movement of water away from the crowns. Raised beds can also reduce the depth that a harvester has to dig.
Plastic mulch can be used to reduce in-row weeding requirements (see Figure 11). Usually mulch must be laid before transplanting, although some equipment can lay mulch and drip irrigation lines and transplants in a continuous operation. Equipment capabilities vary. Spacing and field layout may require adjustment if mulch is used.

\section{Organic considerations}

Organic producers should ensure that all practices used during transplanting conform to the standards of their particular certifying body. The use of a soluble fertilizer would not be permitted under organic production standards; however, growers can ensure that sufficient nutrients are present in the soil before planting.

\section{Fertility management}

Soil fertility has a marked effect on final harvested root yield and quality. Failure to provide adequate nutrients to the developing plants during the growth cycle will significantly affect the profitability of an echinacea operation.

Although producers can build up soil nutrient levels before establishing the crop, this approach may not necessarily provide sufficient nutrients for the critical stages of development for the entire life of the crop. Additional fertilizer applications may be required to supplement the nutrients supplied by the soil. The amount of nutrients to be applied should be determined by soil testing and knowledge of crop nutrient use. 

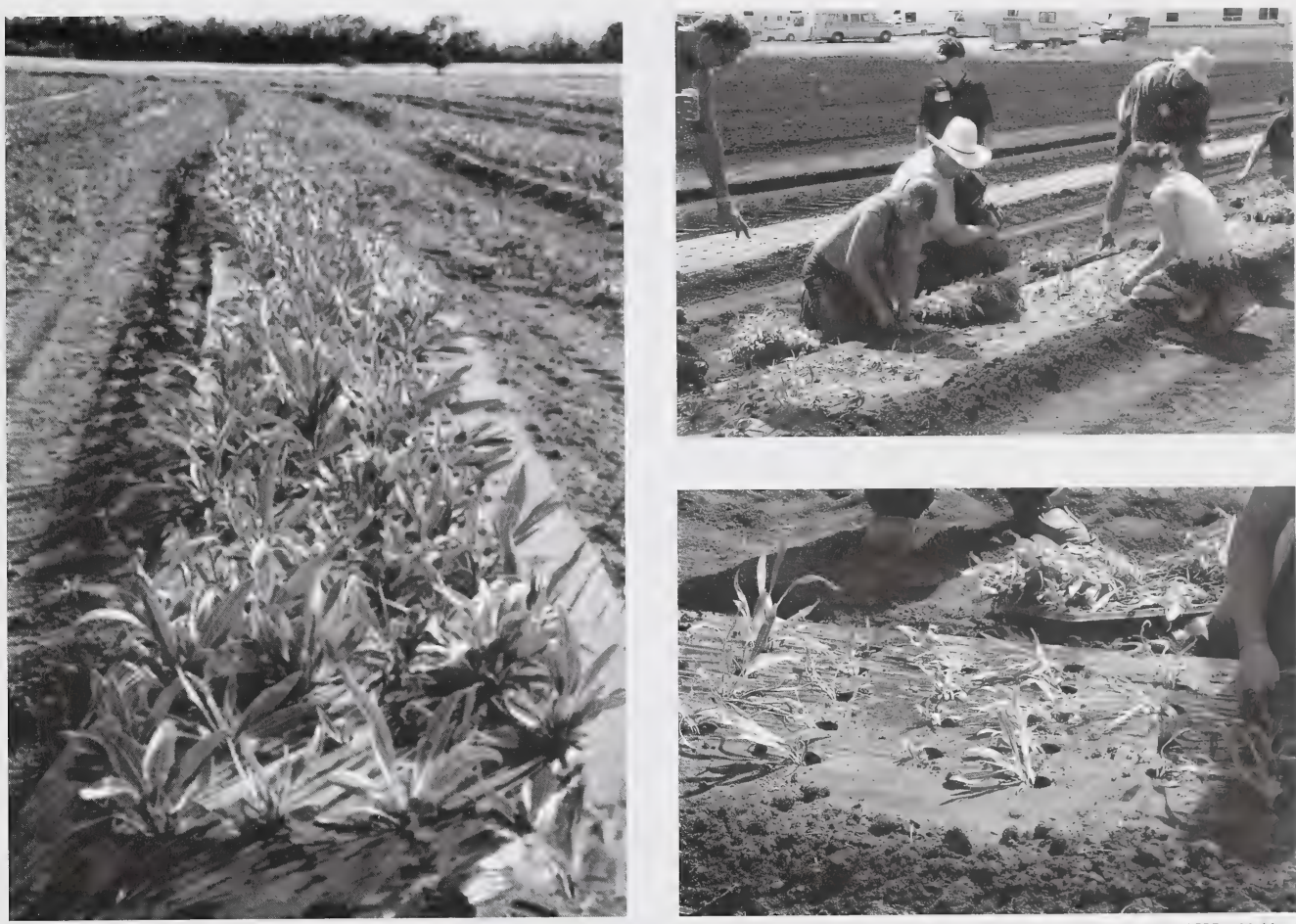

Photos Courtesy Monica Blaeser and AAFRD - M. Mirz

Figure 11. Transplanted echinacea in black plastic mulch

In a study at CSIDC, the response of echinacea to additions of nitrogen and phosphorus was

evaluated. Direct seeded echinacea yields increased by 17 per cent when $100 \mathrm{~kg} \mathrm{~N} / \mathrm{ha}$ (90 lb. N/acre) was applied as compared to $50 \mathrm{~kg} \mathrm{~N} / \mathrm{ha}$ (45 lb. N/acre). Yield response to phosphorus was also significant. Yields increased by 48 to 54 per cent when phosphorus rates were increased from $50 \mathrm{~kg}$ of phosphate $\left(\mathrm{P}_{2} \mathrm{O}_{5}\right)$ per hectare $\left(45 \mathrm{lb} . \mathrm{P}_{2} \mathrm{O}_{5} /\right.$ acre $)$ to

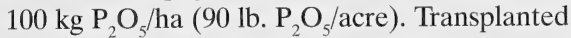
echinacea did not tend to respond to changes in fertility as dramatically as direct seeded echinacea. Generally, there was a strong response to phosphorus applications only when there were nitrogen applications.

It is generally recommended that fertility levels be maintained around $112 \mathrm{~kg} / \mathrm{ha}(100 \mathrm{lb}$./acre) of nitrogen, $56 \mathrm{~kg} / \mathrm{ha}$ (50 lb./acre) of phosphorus, 168 to $224 \mathrm{~kg} / \mathrm{ha}(150-200 \mathrm{lb}$./acre) of potassium,
22 to $34 \mathrm{~kg} / \mathrm{ha}(20-30 \mathrm{lb}$./acre) of sulphur and 8 to $10 \mathrm{ppm}$ of iron. Producers should build up and maintain nutrients at these levels based on yearly soil tests and fertilizer application. Nutrients can be supplied using different types of fertilizer. The nutrient contents of some common fertilizers are outlined in Table 10.

Do not apply excessive amounts of fertilizer at one time during the season. If possible, apply fertilizer in two or three split applications. Excessive rates of nitrogen will result in rapid growth that may lead to lower levels of bioactive compounds in the roots.

It is generally recommended that no fertilizer be added after mid-August. Late application of nitrogen fertilizers can result in reduced winter survival due to a reduction in plant acclimation (development of cold hardiness) and dormancy. 
Table 10. Nutrient analysis of some common conventional fertilizers

\begin{tabular}{|c|c|c|c|c|c|}
\hline & $N(\%)$ & $\mathrm{P}_{2} \mathrm{O}_{5}(\%)$ & $\mathrm{K}_{2} \mathrm{O}(\%)$ & $S(\%)$ & Other \\
\hline Anhydrous ammonia & 82 & 0 & 0 & 0 & \\
\hline Urea & 45 & 0 & 0 & $\begin{array}{c}0 \\
\text { (may have } 13-16 \% \\
\text { if sulphur-coated) }\end{array}$ & \\
\hline Ammonium nitrate & 34 & 0 & 0 & 0 & \\
\hline Calcium nitrate & 15 & 0 & 0 & 0 & $21 \%$ calcium $(\mathrm{Ca})$ \\
\hline Potassium nitrate & 13 & 0 & 44 & 0 & \\
\hline Ammonium phosphate & $11-18$ & $46-48$ & 0 & 0 & $0-1 \% \mathrm{Ca}$ \\
\hline Rock phosphate & 0 & $21-35$ & 0 & 0 & $\begin{array}{l}\mathrm{Ca} \& \mathrm{Mg} \text { (magnesium) } \\
\text { may be present in } \\
\text { undetermined amounts }\end{array}$ \\
\hline Potassium chloride & 0 & 0 & 60 & 0 & 0 \\
\hline Potassium sulphate & 0 & 0 & 52 & 16 & 0 \\
\hline Calcium chloride & 0 & 0 & 0 & 0 & $27-36 \% \mathrm{Ca}$ \\
\hline Gypsum & 0 & 0 & 0 & 18 & $22 \% \mathrm{Ca}$ \\
\hline Magnesium sulphate & 0 & 0 & 0 & $13-23$ & $10-17 \% \mathrm{Mg}$ \\
\hline Elemental sulphur & 0 & 0 & 0 & $90-100$ & \\
\hline
\end{tabular}

Adapted from Nutrient Content of Fertilizer Materials by Charles C. Mitchell, 1999.

A study at CSIDC evaluated the root yield response to fertilizer applied either as a single application in spring or as a split (spring and fall) application. Generally, there was little difference in response, but in some years, the split application increased yields.

\section{Organic considerations}

Organic producers may apply additional organic fertilizers during the growing season. As noted, organic fertilizers do not provide the instant release of a large quantity of plant-available nutrients that is typically available with conventional fertilizers. Producers may need to apply fertilizer a number of times or at strategic points in the season in an effort to replenish the nutrients used by the growing crop.
The nutrient contents of a number of organic fertilizer materials are listed in Table 11. Note that these are approximate values. Producers should always rely on a lab analysis to accurately determine the level of plant-available nutrients in a given fertilizer source. Also note that nutrient content might change over time through mineralization, degradation of organic matter and leaching.

\section{Irrigation}

Although Echinacea angustifolia can tolerate dry conditions, water still plays an important part in a successful crop. Adequate water is critical for newly planted seedlings to establish, grow, develop and thrive. Once plants are established, watering may not be as critical, but plants will benefit from water applications in drier seasons. 


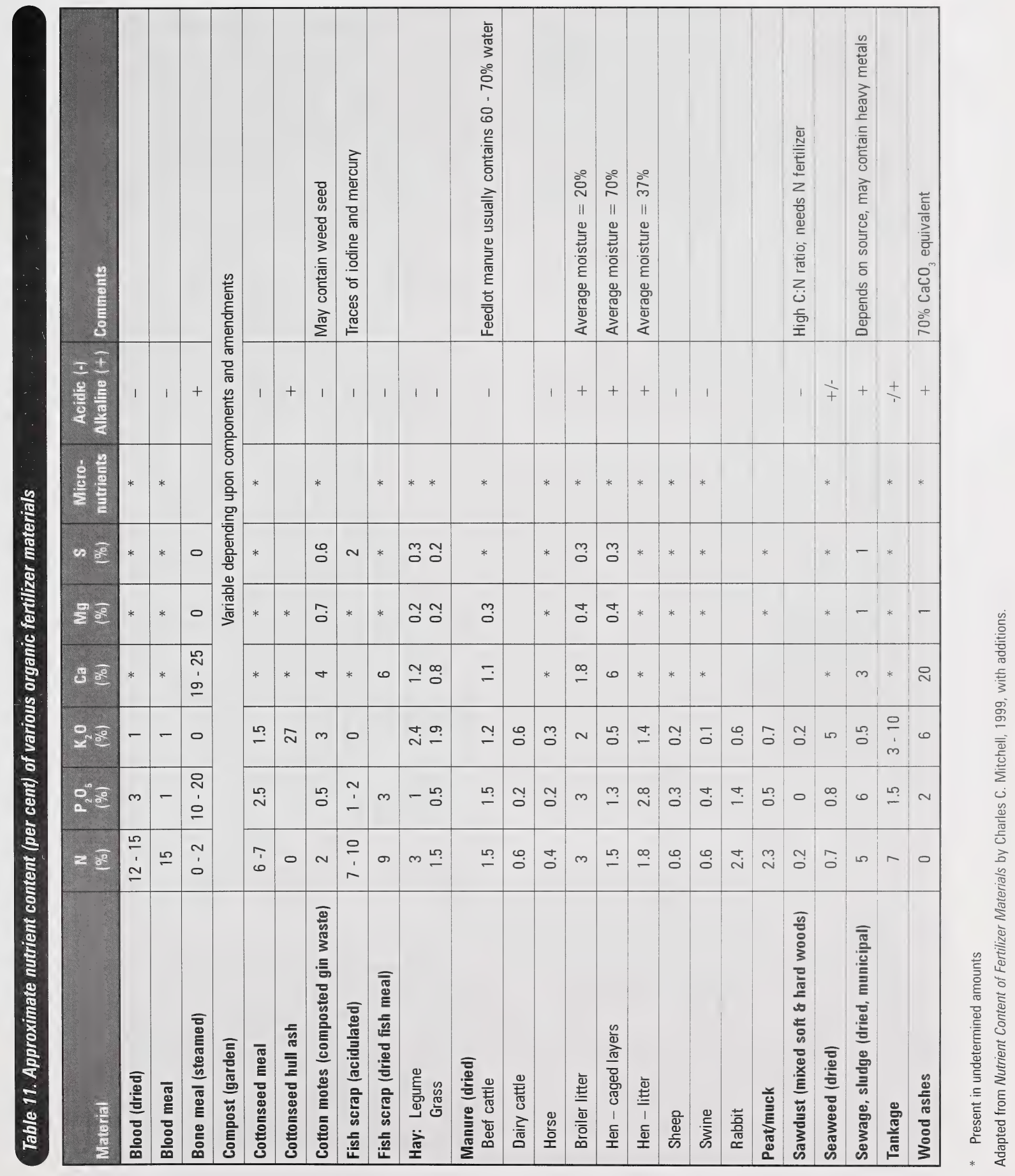


Irrigation is not always required every year in some locations, but for most echinacea operations, a producer's ability to irrigate can make a significant difference in plant survival and yield. In a study at CSIDC, it was found that during dry years, the response of echinacea plants (dry root yield) to irrigation was highly significant with irrigated yields up to two times greater than dryland yields. In years with better moisture, yields were not significantly different.

\section{Irrigation system options}

Irrigation systems differ in terms of method of delivery, efficiency and cost (initial capital cost and cost of operation). Producers should choose a system that is compatible with their water supply and production practices.

Producers who are planning to use plastic mulch will require a system that delivers water to the plants in the mulch. Typically, a drip irrigation system is used. A drip system consists of a commercially available tube or tape that delivers the water directly to the soil near the developing plants. This system must be installed before mulch application.

Drip systems must be managed properly to deliver water to meet crop needs. Because water is applied at lower flow rates than sprinkler irrigation, longer application times or more frequent applications may be required to supply a given amount of water. A properly sized filter is required to protect the drip system. These systems are quite efficient, as evaporative losses are usually lower than with aerial water applications.

Sprinkler irrigation is less efficient than drip irrigation, but sprinkler systems may be more readily available. Application rates tend to be higher within a shorter time. Sprinkler systems do require some thought to other field operations and will require a large pump system to supply sufficient water to the system.

Other methods may be used to supply water to a developing crop.
Costs for establishing an irrigation system will vary, depending on the type of system, the row spacing and delivery system density as well as other factors. The cost of establishing the first hectare (acre) is the most expensive due to the need for water source development, and pipe, pump and filter costs. Economy of scale has a significant effect on the installation costs of subsequently added irrigation systems. Producers should consult an irrigation supply company for system design and pricing.

\section{Irrigation timing and amounts}

Echinacea benefits from water applications during the establishment of young plants. Soil moisture levels should not be allowed to go below 50 per cent of plant-available water to prevent drought stress. The amount of water that should be applied at any one application will vary depending on weather conditions (wind, natural precipitation, sun, temperature), soil type, plant growth stage and irrigation system type.

Soils that have higher organic matter content or finer texture hold more moisture and hold the moisture longer whereas sandier soils will hold less moisture and dry out faster. Most echinacea is planted into sandier soils to facilitate root growth, harvest and post-harvest handling (washing).

\section{Other considerations}

Irrigation is not as simple as putting a pump on a nearby water body and applying water. Effective irrigation depends on having a suitable source of water (quality and quantity) and meeting the regulatory requirements to ensure the irrigation project will not cause damage to the environment.

\section{Water quality}

Water quality can have a significant effect on both plant health and soil quality. Poor quality water can negate the benefits of water application either in the short term by harming the plant with excess levels of different minerals (such as salts) or in the long term by creating saline conditions or poor soil structure (e.g. solonetzic soils). 
A water test is the only way of determining the suitability of a water source for irrigation. A test provides detailed information on the various mineral constituents of the water, which, when interpreted, will allow projections to be made as to the potential effect of the water on the soil and plants. In Alberta, water can be tested at a number of laboratories (see the Resources chapter).

Generally, water should have an electrical conductivity (EC) of less than $1 \mathrm{mS} / \mathrm{cm}$ and an adjusted sodium absorption ratio (SAR) of less than 30. Producers should also watch the levels of bicarbonates, chlorides and metal ions as well as any particulates or other impurities that may affect the suitability of water for irrigation. Some water sources may also contain a small amount of nutrients, which can be included when calculating crop nutrient management.

\section{Approval and licensing}

A water license must be obtained for all private irrigation projects, except for very small water diversions (less than $6250 \mathrm{~m}^{3}\left[220,717 \mathrm{ft}^{3}\right.$ or $1,374,807$ gal.]) from private dugouts.

A water license is not required for irrigating within an existing irrigation district, but producers must seek approval from the irrigation district for expanding irrigated acreage.

Alberta Environment is responsible for issuing water licenses. It may issue a water license for irrigation if the following applies:

- the land is classified as being irrigable

- the project is considered feasible

- sufficient water is available to meet the project requirements

The information needed to fulfil these requirements is met by completing the following steps.
1. Land classification - Land classification is the process where the proposed land to be irrigated is evaluated for general suitability for irrigation. Professional land classifiers look at soil structure, salinity, depth to bedrock and gravel, topography and internal drainage. Land classification is done by private consultants for a fee. For a list of private land classification consultants and more information on land classification in Alberta, see the Resources chapter.

2. Agriculture feasibility study - An agriculture feasibility study details the potential for effect from irrigation on the parcel of land. Such things as irrigation management, water source, water quality, pump site and field location, irrigation system type and flow requirements are all detailed in the feasibility stage. This step can be completed by the Irrigation Branch of Alberta Agriculture, Food and Rural Development or by private consultants. This is a fee-for-service step. Price per acre will vary. The speed at which this step is completed will also vary.

3. Department of Fisheries and Oceans review This step determines whether there will be any effect on wildlife or natural areas due to irrigation. Failure at this stage will result in no water license. This step is completed during the application to Alberta Environment.

After completing these steps, the producer submits an application to Alberta Environment, which may then grant and issue a license authorization. A final license for the project is issued once the project is constructed and all provisions set out in the authorization are met.

\section{Organic considerations}

Organic producers need to be aware of the potential for contamination of their water source (as do conventional producers) as the presence of contaminants may lead to the loss of certification. Contaminants might include pesticides, fertilizers, etc. 


\section{Pest management}

Compared to most traditional crops, echinacea is affected by relatively few disease, weed and insect pests. Nevertheless, failure to manage these pests can result in significant crop losses in certain situations. There are no fungicides, herbicides or insecticides registered for use on commercial echinacea; therefore, pests must be managed culturally (i.e. without chemicals).

\section{Diseases}

NOTE: Portions of the following are adapted from the Alberta Agriculture, Food and Rural Development publication Diseases of Echinacea on the Canadian Prairies, Agdex 620-2, April 1999.

Six major diseases may occur on echinacea in fields and greenhouses in western Canada. Each disease is described below with its causal agent, life cycle, disease symptoms and disease management practices. For general procedures to reduce the incidence of diseases in greenhouses, see the Managing Pests section in the Greenhouse Production Systems chapter.

\section{Aster yellows}

\section{Causal agent}

Aster yellows is the most common and destructive disease of echinacea. It is caused by a phytoplasma, which is a bacteria-like microorganism.

\section{Life cycle/transmission}

Phytoplasma bodies are spherical to egg-shaped or irregular in shape, surrounded by single membranes and lack cell walls. The aster yellows phytoplasma is transmitted primarily by insect vectors, namely leafhoppers (mainly Macrosteles phytoplasma) as well as by division of infected plants (vegetative propagation).

The aster yellows pathogen may over-winter or persist in perennial weed hosts, alternative host crops or native stands of echinacea.

\section{Discase symptoms}

- Young, emerging shoots may appear yellow or greenish-yellow (early spring).

- Leaves may appear reddish or purplish in the later stages of infections. (Note: the effects of frost and cold weather can cause similar symptoms, due to a lack of uptake of phosphorus.)

- Plants may be stunted.

- A proliferation of axillary shoots may appear resulting in a bunchy or "witch's broom" appearance.

- Roots may be malformed with a proliferation of secondary roots.

- Floral malformations may appear in mid-summer when plants reach flowering stage, including:

- virescence (greening)

- phyllody (conversion of floral parts to leaves)

- small, secondary, sterile floret issue from the original flower heads

Figure 12 (color section) shows some examples of Aster yellows symptoms.

Aster yellows is more difficult to identify in younger plants because the foliar symptoms may be confused with the symptoms of many other problems, such as root rots and nutrient deficiencies. Producers should look for patterns in the field or the presence of insects, which may indicate an aster yellows problem.

If the problem is seen in isolated plants or small patches of plants with no other obvious cause, aster yellows may be suspected. If the problem is field scale, then some other problem may be responsible. Producers should also compare affected plants with other potential hosts in the vicinity (e.g. weeds such as wild carrot, thistle, dandelion, or crops such as carrot, valerian, onion, etc.).

Aster yellows is typically identified using visual symptoms; however, the disease can be confirmed by laboratory testing (e.g. electron microscopy or polymerase chain reaction (PCR) techniques). Laboratory tests can be very costly, but they may make economic sense for some operations. 
Producers should consult a plant health diagnostic laboratory for assistance if necessary (see the Resources chapter for contacts).

\section{Discase effect}

Diseased plants are more susceptible to winterkill and infection from soil-borne pathogens. Due to floral deformities, seed production is significantly reduced.

Since echinacea is a perennial crop, the presence of aster yellows will result in a rapid increase in the number of infected plants, unless producers monitor for and control this disease.

\section{Management practices}

- Monitor fields regularly for plants with symptoms. Test suspect plants.

- Control or mow down perennial weeds that may harbour aster yellows, such as wild carrot, dandelion, thistle or wide-leaved plantain.

- Control leafhoppers with insecticides in the surrounding weeds or crops. Producers may also consider the use of trap strips, which attract specific pests and allow for control outside the crop.

- Plant echinacea well away from other aster yellows-susceptible crops such as alfalfa, clover, canola, lettuce, celery, carrots and asters.

- Grow leafhopper-repellent crops such as yarrow, garlic, mint or tansy with the echinacea. These might be planted around the periphery of the crop or between the rows.

- Remove and destroy plants that show typical symptoms of aster yellows.

- Select healthy plants for vegetative propagation.

Some development and breeding work for aster yellows resistance is currently underway at CDCS. Figure 13 (color section) shows aster yellows-free plants among infected plants.

\section{Sclerotinia stem and root rot}

\section{Causal agent}

The fungus Sclerotinia sclerotiorum can infect a wide range of host crops, including echinacea. Sclerotinia can cause a range of different symptoms depending on the timing and point of infection.

\section{Life cycle/transmission}

Sclerotinia can infect plants in several ways. Sclerotinia produces hard, irregular-shaped sclerotia, or resting bodies, on plant surfaces or within stem tissues. These sclerotia can survive in the soil for a time and will germinate and infect plant parts. Sclerotia can also form spore-producing structures, which release aerial ascospores that infect above-ground plant parts, such as stems, leaves and flower stalks. Ascospores can be carried some distance on the wind to infect healthy plants.

\section{Disease symptoms}

- Dark brown to black lesions on stems at and/or above the soil line.

- Bleached leaf petioles or dead leaves.

- Disintegration of infected stem and petiole tissues with only the fibrous tissues remaining intact, resulting in a frayed appearance and stem breakage.

- Rotting of roots.

- Under moist soil conditions, a white mycelium may be produced on infected plant parts.

- Black, irregular sclerotia may form on root surfaces and crown areas after plant death. Sclerotia may also be found inside the stem after the plant has been killed.

- Leaves become brown, dry and brittle.

- Rapid wilting of adult plants, with drooping of flower heads. The whole plant may collapse (see Figure 14 - color section). 


\section{Management practices}

- Avoid over-fertilizing with nitrogen, which promotes lush, susceptible growth.

- Maintain a long crop rotation (more than three years), and avoid previous crops such as canola, sunflower, beans or other susceptible crops. Cereals, grasses or corn are suitable rotation crops.

- Be aware of susceptible crops growing adjacent to or near echinacea fields, and monitor the crop accordingly. Remove infected plants/plant parts before sclerotia formation.

- Ensure a healthy planting with balanced fertility and adequate air circulation.

- Orient rows parallel to prevailing winds to promote good air circulation in the plant canopy.

- Remove infected plant debris at the end of the growing season, if practical.

- There are no chemical control options registered for echinacea.

\section{Damping-off/seedling blight}

\section{Causal agent}

This disease may be caused by a number of different fungal pathogens, including Rhizoctonia solani and various species of Pythium, Fusarium and Alternaria.

\section{Life cycle/transmission}

Contaminated soil/growing media combined with cool, damp conditions can lead to the development and spread of damping-off (the condition when the plants die before they are able to emerge from the soil). Slow or weak plant growth can increase the incidence of seedling blight (the condition when the seedlings die after emergence).

\section{Disease symptoms}

- Seeds may fail to germinate, and when the problem is caused by Pythium, a white, fluffy mycelium may develop on infected plant parts.

- Seedling leaves may suddenly start to wilt and wither.
- Root tips show blackening, and roots and stem may start to brown.

- Cotyledons shrink and young leaves twist and then seedlings wilt and collapse.

- Lower stems of seedlings appear discoloured with the affected stems having a smaller diameter or pinched appearance (when the problem is caused by Rhizoctonia).

Figure 15 (color section) shows some examples of damping-off symptoms.

\section{Management practices}

- Do not over-water.

- Ensure the growing medium drains well and is properly aerated.

- Ensure that growing media and germination trays are sterile and free from contaminants.

- Do not reuse infected soil.

- Avoid cool growing conditions and overcrowding plants.

- Do not over-stratify seeds, as this procedure may pre-dispose seedlings to infection.

- No chemical controls are registered for echinacea.

\section{Fusarium root and crown rot}

\section{Causal agent}

This disease may be caused by several Fusarium species, including Fusarium oxysporum, F. solani, $F$. avenaceum and $F$. equiseti.

\section{Life cycle/transmission}

This disease is spread during vegetative propagation of roots and crowns. The fungus enters roots and crowns via wounds. Wet soil conditions may encourage the spread of this disease. Some of these species of Fusarium are quite common in soil and may be present in new fields. 


\section{Disease symptoms}

- Discoloured lesions on plant crowns.

- Roots may become truncated (stubbed off or cut off abruptly) and may disintegrate.

Figure 16 (color section) shows examples of these symptoms.

\section{Management practices}

- Avoid injuring roots during cultivation.

- Use healthy plants for propagation.

- Do not reuse growing medium (if propagating vegetatively).

\section{Botrytis blight}

\section{Causal agent}

This disease is caused by the fungus Botrytis cinerea, which is a very common pathogen with a very wide host range.

\section{Life cycle/transmission}

Cool, wet conditions promote the development of this disease. Botrytis produces profuse amounts of unicellular, smooth-walled and roughly oval spores. Spores are spread by the wind or by water splashing. The disease also spreads through host tissues with the rate of spread determined by environmental conditions.

\section{Disease symptoms}

- Water-soaked lesions of various sizes may occur on leaves.

- Infection of the petiole and stem leads to collapse of the whole leaf.

- Grey mould on dead and dying leaves, stems and blossoms.

- Longitudinal lesions on the stem.

- Large lesions often split leaves or form holes in the centre.

- Microsclerotia may form on dead or dying plant parts.
Figure 17 (color section) shows a plant infected by Botrytis blight.

\section{Disease effect}

Botrytis does not usually kill echinacea plants; however overall plant productivity may be reduced, especially if young plants or flowers are infected. Under cool, wet conditions, disease development and spread can be very rapid.

Management practices

- Avoid over-fertilizing with nitrogen, which promotes lush, susceptible growth.

- Remove infected plant material and debris.

- Ensure adequate spacing, and orient rows parallel to prevailing winds to promote good air circulation between plants. Consideration must be given for plant spacing over the 3- to 4-year growth cycle.

- In greenhouses, avoid water condensation and ensure adequate ventilation.

- No chemical controls are registered for echinacea.

\section{Alternaria leaf spot}

\section{Gausal agent}

Alternaria leaf spot is caused by various Alternaria species.

\section{Life cycle/transmission}

Alternaria can infect the leaves and result in large lesions under moist conditions. Young shoots and small flowering heads may be infected. Seed can become infected, allowing spread of this disease. Roots and crowns may also be affected.

\section{Disease symptoms}

- Small, dark brown to black spots may develop on the leaves.

- Dark lesions tend to follow the midrib in seedling leaves. 
- Small spots may grow together to form large lesions, which appear oblong with a lightcoloured centre surrounded by dark, necrotic tissue.

- Lesion centres may fall out to create holes in the leaves.

- Lesions on the stem may result in stem collapse and die-back.

- Root rot and leaf spots of young seedlings may result from seed-borne infection.

Figure 18 (color section) shows the lesions on the leaves.

\section{Management practices}

- Sterilize seeds with a 1 per cent bleach solution for 3 to 5 minutes, and then, rinse with sterile water before stratification or seeding.

- Gather up and destroy infected crop debris at the end of the growing season, if practical.

- No chemical controls are registered for echinacea.

\section{Insect pests}

There are few insect pests of economic importance in echinacea. Leafhoppers, particularly the aster leafhopper (Macrosteles quadrilineatus), can spread the aster yellows pathogen. Other insect pests (aphids, lygus bugs, stink bugs, thrips) may be found on echinacea, but the damage they cause is usually

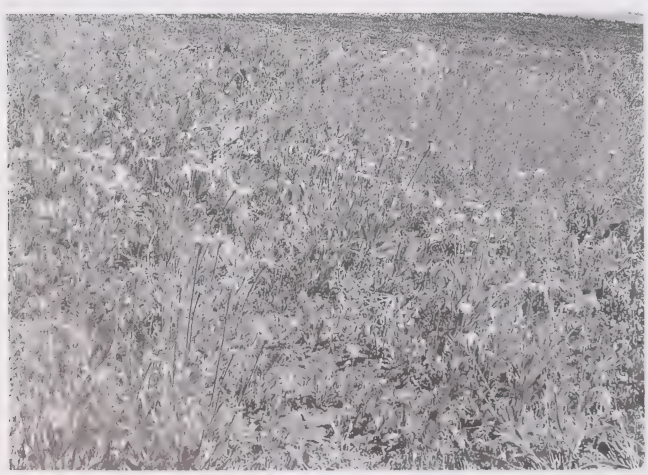

negligible. Some pests, such as aphids, may be managed culturally; however, in most cases, beneficial natural predators will keep populations in check. Grasshoppers do not tend to damage echinacea plants although some feeding may take place.

For procedures to control insects in greenhouses, see the Managing Pests section in the Greenhouse Production Systems chapter.

\section{Vertebrate pests}

Echinacea is not typically a prime choice for vertebrate pests such as deer and other ungulates. Gophers may pose a problem in some areas. Birds may be a problem when flower heads are mature, as they will eat some of the seed. A number of nonlethal devices can minimize vertebrate pest predation.

\section{Weed management}

Many different types of weeds, particularly perennial weeds, can be problematic in echinacea fields (Figure 19). Weed management is a significant labour cost and time commitment.

Weeds need to be managed constantly. Perennial weeds should be controlled as much as possible in the years before crop establishment. All other weeds should be removed, if possible, and seed production should be minimized.

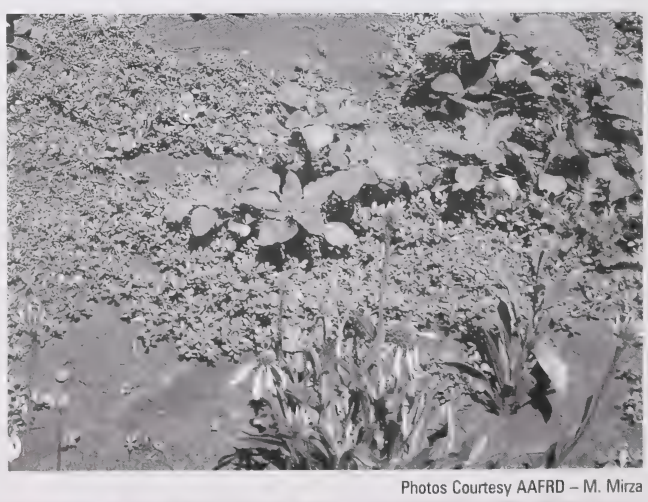

Figure 19. Weedy echinacea fields 
Weeds within the plant row must be controlled by hand. Weeds between the rows may be controlled using mechanical methods. Row spacing may be adjusted to allow for the use of different tillage equipment.

Using black plastic mulch can reduce in-row weeding labour and competition from weeds. Some adjustments may need to be made to field layout and design. Producers should be careful to ensure that no plastic mulch becomes trapped in the roots as plastic would be considered a foreign material and therefore a contaminant.

Weedy areas adjacent to the field should be mowed to prevent introduction of weeds. These areas also provide potential alternate hosts for insect pests and disease.

Regular mowing can also gradually deplete food resources of perennial weeds, which may eventually reduce perennial weed spread.

Proper cleaning of tillage equipment can reduce the spread of weeds. Rhizomes and weed seeds may be introduced or spread to new fields if they are not removed from implements.

Proper composting can reduce the levels of weed seeds in animal manure that may be applied to fields.

Herbicides may be used in waste areas or in preplanting applications; however, no herbicides are registered for use in the echinacea crop itself.

Off-type plants or non-pure species of echinacea can be considered weeds. Roguing (scouting for and removing undesirable plants) should be carried out regularly.

\section{Nutrient deficiencies}

Nutrient deficiencies can occur in echinacea. Magnesium deficiency will appear as interveinal chlorosis, with leaf veins remaining dark green in lower, mature leaves. Similar symptoms in younger leaves point to iron deficiency. Some deficiencies can be resolved through foliar applications of soluble fertilizers.

\section{Organic considerations}

As there are no registered pesticides for the control of weeds, diseases or insects in echinacea, the pest control methods used for non-organic operations are similar to those for organic operations. Cultural practices are available to control most diseases; natural predators are used to control insect pests, and cultural and mechanical practices are used to control weeds.

Nutrient deficiencies cannot be remedied by the application of foliar fertilizers in organic production systems; therefore, nutrients must be supplied by careful management of soil fertility.

\section{Over-wintering}

\section{Winterkill}

Winterkill is a major concern in echinacea plantings in Alberta, and serious crop loss can occur as a result. Winterkill may cause partial or complete plant death. Plants may also be weakened and become more susceptible to pathogen attack. If the crown area is killed, some regeneration may occur from the roots, but it will be late and will result in poor quality plants.

Winterkill can occur as a result of several different processes or a combination of factors. The main contributors to plant injury and death are excessively low temperatures, rapidly changing temperatures and desiccation (drying) stress.

Desiccation of crown and other plant tissues may occur if too much water is moved out of plant cells by continued or increased transpiration due to winds or prolonged freezing conditions. Water loss in the plant is continuous, even in winter when plants are dormant.

Plants may also be killed due to the formation of ice layers, either in the root zone or over the plant crown, which creates an anaerobic stress (lack of oxygen). If snowmelts occur and a layer of ice forms over the crowns and roots, an extended period with a lack of air may lead to cell and tissue death. At the same time, the loss of the air pockets in the snow pack reduces the snow's insulation value. Thus, the 
plants are potentially exposed to greater extremes in temperature and some tissue damage may occur. If the soil becomes saturated due to melting snow and then freezes, root injury may occur.

Plant growth and re-mobilization of water due to prolonged above-zero mid-winter temperatures may also lead to a reduced tolerance to cold conditions, resulting in damage from subsequent freezing night temperatures. Sudden drops in temperature may lead to water freezing inside the cells, disrupting cellular function and leading to tissue death.

Some research suggests plant density can affect winter survival. Studies at $\mathrm{CDCN}$ revealed that winter survival decreased as plant densities increased (Table 12).

\section{Improving winter survival}

The survival of any native or hardy plant is closely linked to its ability to acclimate, or shut down growth processes and prepare for winter. The degree of winter hardiness and subsequent survival varies between plant species and is affected by climatic or environmental conditions and signals as well as cultural practices. The amount of stress (cold, drought, other) that a plant can endure during winter relates to the degree of initial acclimation during the fall.

Ideally, a plant will experience environmental signals, such as changing day length, high day/night temperature shifts and cooler temperatures or frosts, which will allow it to gradually shift from active growth to the channelling of resources to over-wintering tissues, such as the roots and crown. Fall rains, warm fall temperatures or excessive nitrogen all slow or prevent acclimation by keeping the plant active and growing. Failure to acclimate will result in insufficient carbohydrate accumulation to sustain the plant and excessive water content in the cells.

Acclimation and cold hardiness can be maintained to varying degrees, depending on the plant species. Most plants should hold their cold hardiness as long as night temperatures stay cool and warm conditions are not prolonged.

\section{Practices to improve winter survival}

Producers can use various practices to improve the winter survival of echinacea by reducing desiccation and temperature stress.

- Make sure the crop is adequately hydrated but not overly wet before winter freeze-up. One of the greatest contributors to winterkill or winter injury is a lack of water. However, producers will need to find the balance between too much and too little water. Excessive water applied in fall, when the plants should be shutting down, can stimulate growth and slow the acclimation process. Also, a mild drought stress will help trigger dormancy.

Table 12. Effect of plant densities on winter survival of Echinacea angustifolia

\begin{tabular}{|c|c|c|c|c|}
\hline Plant spacing* (cm) & Plant spacing* (in.) & \multicolumn{3}{|c|}{ Plant survival (\%) } \\
\hline & & 2002 & 2003 & 2004 \\
\hline $45 \times 45$ & $18 \times 18$ & 100 & 80 & 42 \\
\hline $30 \times 30$ & $12 \times 12$ & 100 & 75 & 35 \\
\hline $23 \times 23$ & $9 \times 9$ & 100 & 70 & 35 \\
\hline $15 \times 15$ & $6 \times 6$ & 100 & 65 & 20 \\
\hline $10 \times 10$ & $4 \times 4$ & 100 & 68 & 22 \\
\hline $5 \times 5$ & $2 \times 2$ & 100 & 58 & 8 \\
\hline
\end{tabular}

Spacing between rows $\mathrm{x}$ spacing between plants within rows 
- Provide shelter from winds. Drying winds can accelerate water loss from the plants, so shelterbelts or other shelter options can be helpful.

- Maintain or increase snow cover. One of the best insulators is snow. A University of Alaska study found that soil temperatures below a layer of snow about $0.5 \mathrm{~m}$ ( $20 \mathrm{in}$.) deep can differ by as much as 15 to $25^{\circ} \mathrm{C}\left(59-77^{\circ} \mathrm{F}\right)$ from the air temperatures. Practices that provide shelter, like using annual species seeded between the rows of echinacea (e.g. annual sunflowers, fall rye, etc.) as temporary shelterbelts, can trap snow and reduce evaporation and sublimation of the snow cover.

- Apply a straw cover. Some producers attempt to increase winter survival by using straw to cover and insulate their plants. This practice is similar to use of straw for winter protection in strawberry and garlic plantings. Straw cover provides a buffer to temperature changes and helps plants remain dormant as temperatures change.

The straw should be applied as late as possible, at ground freezing (November) or after 7 to 15 frosts. If it is applied too early, light will be blocked, and proper photosynthesis will not occur, preventing adequate carbohydrate accumulation. Straw should be applied to a depth of at least $20 \mathrm{~cm}(8 \mathrm{in}$.).

Ensure that the straw cover, once applied, is not displaced or disturbed. Protection from wind with permanent or temporary shelterbelts is recommended.

Flax straw is considered to be a better insulator than wheat straw as it is more rigid and contains more air spaces in the stem. Straw must be clean and free from weed and crop seeds. Producers should carefully select their straw source, paying close attention to weed populations and previous production practices (e.g. herbicides used, weed levels of the field, etc.). Producers may request that straw be combined twice, but this option may not be possible or may be hard on machinery.

Straw fumigation using injected ammonia can reduce weed seed viability and levels of pathogens.

However, some producers have found that fumigated straw may be less rigid after treatment.
To fumigate, straw is tarped with plastic (Figure 20), and ammonia gas is injected at the rate of 2 per cent of the straw's dry weight. For example, a $27 \mathrm{~kg}$ (60 lb.) bale of wheat straw with 20 per cent moisture has a dry weight of $27 \times 0.8=22 \mathrm{~kg}$ ( $48 \mathrm{lb}$.) Therefore, the amount of ammonia to inject into the bale would be $22 \times 0.02=0.44 \mathrm{~kg}(1 \mathrm{lb}$.) of ammonia gas, which would calculate to $20 \mathrm{~kg} / \mathrm{t}$ (42 lb./ton) of straw. Straw fumigation requires adequate heat to disperse the ammonia, so it should take place in late summer or early fall.

- Use thermal blankets. On a small scale, the use of nursery thermal blankets or other insulators may also be effective.

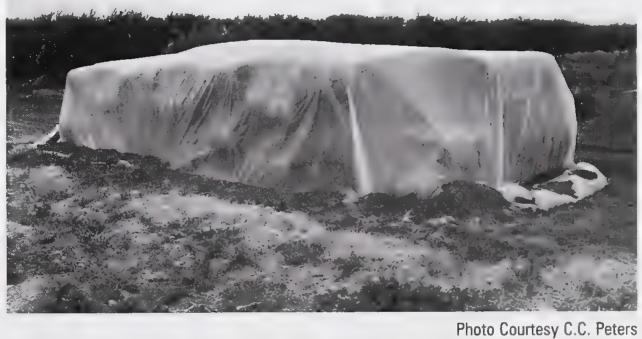

Figure 20. Straw bales tarped with plastic

\section{Organic considerations}

Some of the options to enhance winter survival need to be adjusted to comply with organic production standards. For example, straw would have to be from an organic source, and straw fumigation may not be allowed.

\section{Estimating plant populations}

The overall productivity and economic viability of an echinacea operation are determined by the final, dry weight yield of the harvested root. The plant population at establishment may not be the same as the plant population after three growing seasons. Although a field may look lush and full, plants will often compensate for missing plants with increased aboveground growth. 
Take a close look at the plants at different points during the season to track the number of plants remaining.

One way to estimate the plant population for a whole field is to count plant numbers in randomly selected areas across the field. If the plant numbers vary greatly from area to area, increase the number of counts to provide a more accurate overall estimate.

\section{Seed harvest}

While the main focus of echinacea production is on harvesting the mature root, which has the highest levels of bioactive compounds, echinacea seed is a valuable commodity vital to establishing new plantings.

Echinacea seed prices vary greatly, depending on market conditions. Prices can be as high as $\$ 990 / \mathrm{kg}$ ( $\$ 450 / \mathrm{lb}$.), if the seed is of good quality with a documented purity, botanical identity and history.

Seed can provide some economic return early in the production cycle, but its value should not be overestimated in preliminary business plan calculations. Seed yields and prices vary considerably, and market demand is generally very low.

It is estimated that 0.4 ha ( 1 acre) of echinacea can produce, on average, enough seed in two years to

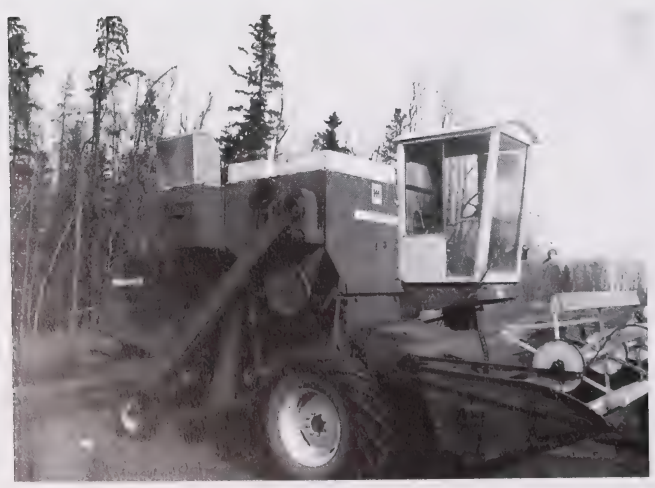

plant 121 ha (300 acres) at $0.75 \mathrm{~kg} / \mathrm{ha}(1.6 \mathrm{lb} . / \mathrm{acre})$ of pure live seed.

\section{Collection}

Echinacea seed is generally collected in the second year of growth. Some seed is produced in the first year, but it is typically of low viability and therefore of poor quality.

Seed should be collected from the mature cones when the seed is ready to drop out with gentle shaking. Mature cones have the base of the stem turning brown and the seeds starting to shed (Figure 21 - color section). Harvesting immature cones is not recommended as immature cones must be dried and then crushed to release seed, which may damage the seed and result in poor germination.

Echinacea cones have been successfully harvested mechanically with a small plot combine. Combine settings have to be worked out carefully to optimize threshing and seed separation with minimal damage to the seed. Other equipment may be modified to permit mechanical harvest of seed cones (Figure 22).
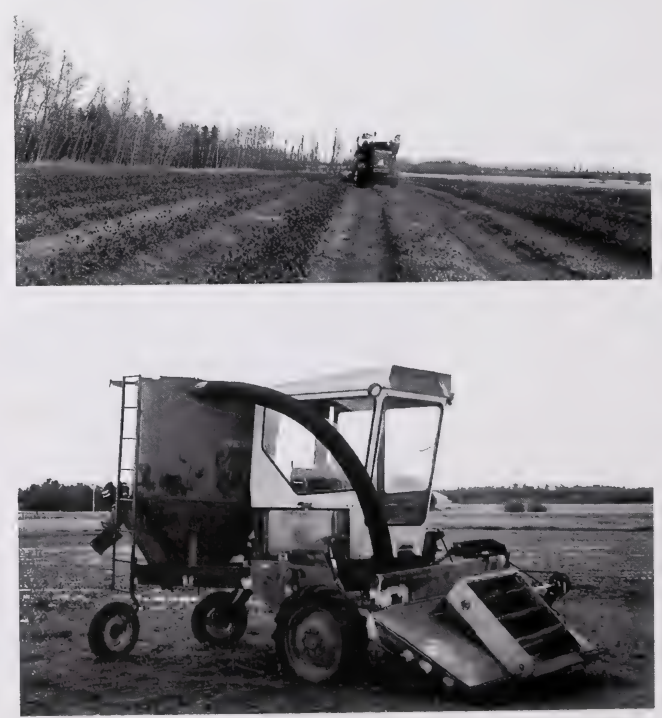

Photos Courtesy Monica Blaeser and AAFRD - K. Piquette 


\section{Cleaning}

Seed cleaning involves the separation of seed from the cones and debris.

Commercial seed cleaners can be used to clean seed. Alberta Agriculture, Food and Rural Development's Centre for Agri-Industrial Technology (CAIT) in Edmonton also has equipment for seed cleaning (Figure 23) (see the Resources chapter).
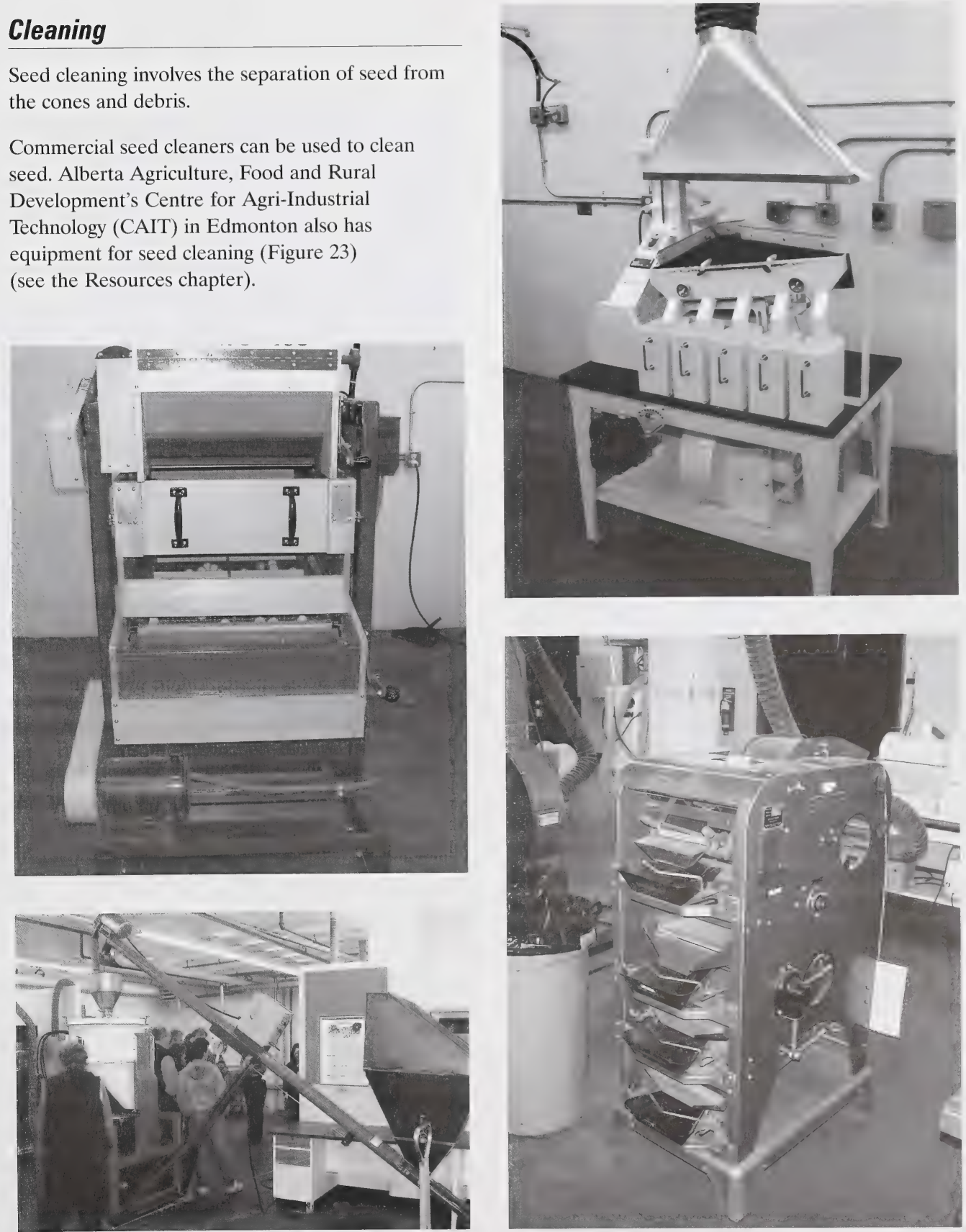

Photos Courtesy AAFRD - R. Spencer

Figure 23. CAIT's seed cleaning equipment a. air screen machine (top left) b. impact dehuller with feeding auger (bottom left) c. gravity separator (top right) d. dockage tester (bottom right) 


\section{Seed numbers per gram}

Seed numbers per gram can vary with the planting and the year the seeds are harvested. On average, there are between 50 and 100 good seeds per cone with a range in seed weight. Approximately 4 cones will yield 1 gram of seed.

Remember that a lower number of seeds per gram does not mean that seed quality is better.

Germination tests should be used to determine seed quality.

\section{Seed production per hectare}

The amount and quality of seed collected from a hectare (or acre) of echinacea will vary depending on a number of factors.

- Plant density varies with the initial planting density and the number of plants that have survived. Studies at CDCN found that seed yield increased as plant density increased, although seed yield peaked and dropped off when plant densities were higher than 29 to 38 plants $/ \mathrm{m}^{2}$ (2.7 to 3.5 plants/ft. ${ }^{2}$ ), as shown in Figure 24 . The final plant population needs to be estimated to estimate the total number of cones.

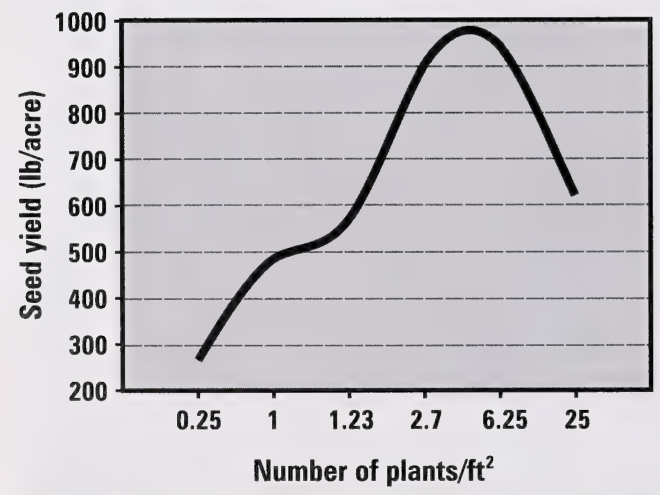

Adapted from CDCN data

Figure 24. Effect of plant density on seed yield of. second year Echinacea angustifolia
- Number of cones per plant varies depending on the plant's age and the stand's health and vigour, as influenced by fertility management practices. It is possible to have up to 10 cones per plant, but an average of 5 is more likely.

- Seed quality and viability depends on the health of the crop.

Research has shown that the seed number to cone weight ratio varies between 10 to 30 per cent. It is safer to use the low end of the range when making estimates.

\section{Traceability}

Seed quality is determined, in large part, by the purity of the seed. Seed producers must be able to certify that the seed they are selling is pure, without any contamination by off-type species or weed seeds. Producers should be able to provide detailed information on their field, the source crop and their crop production practices.

When selling seed, producers should keep a small, representative sample of each seed lot. Samples should be clearly numbered, labelled and properly stored, with all pertinent information relating to the production of the sample documented.

\section{Organic considerations}

Organic seed producers must be able to clearly demonstrate, with records, that their seed was produced according to the standards of their certifying body. Organic and conventional seed samples should be kept separate.

Generally, organic producers are required to use organically produced seed if it is available, although this requirement may depend on the specific certifying body. Some exceptions may be made if it can be demonstrated that no organic source is available. 


\section{Color Section}

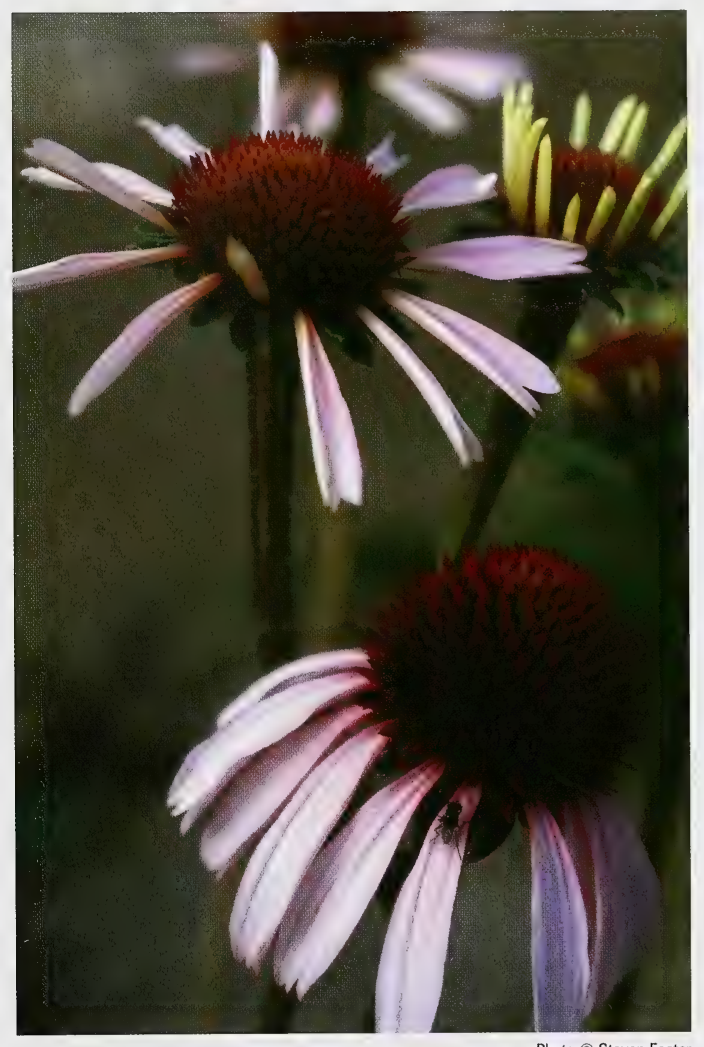

Figure 2A. Flower heads of Echinacea angustifolia

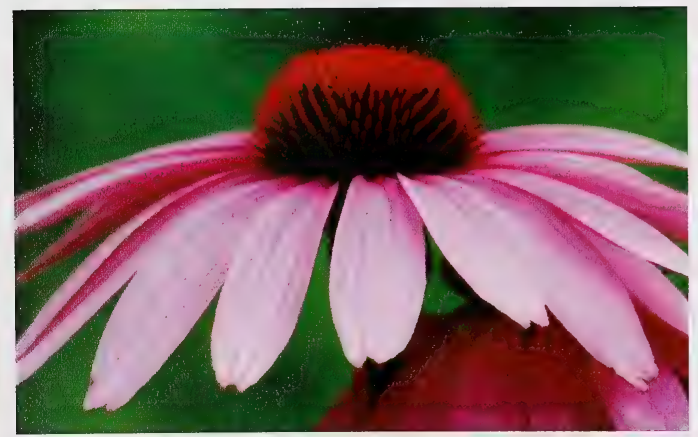

Figure 2C. Flower heads of Echinacea purpurea

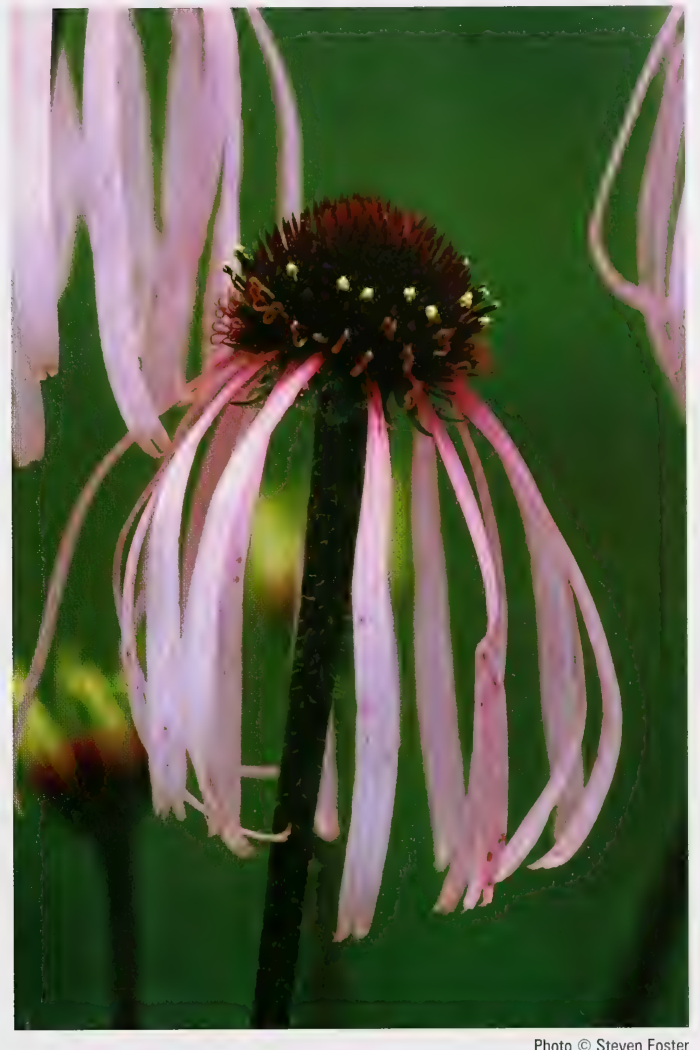

Figure 2B. Flower heads of Echinacea pallida

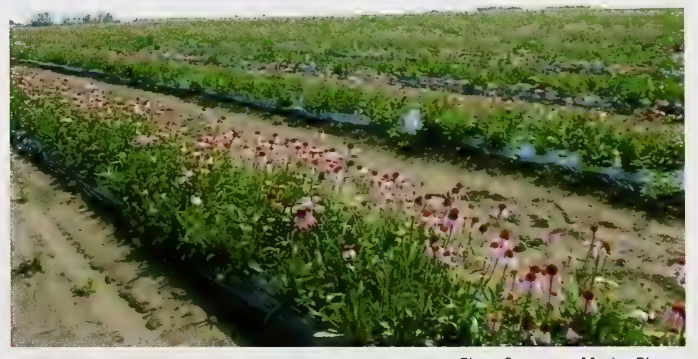

Figure 4. Second-year Echinacea angustifolia field 


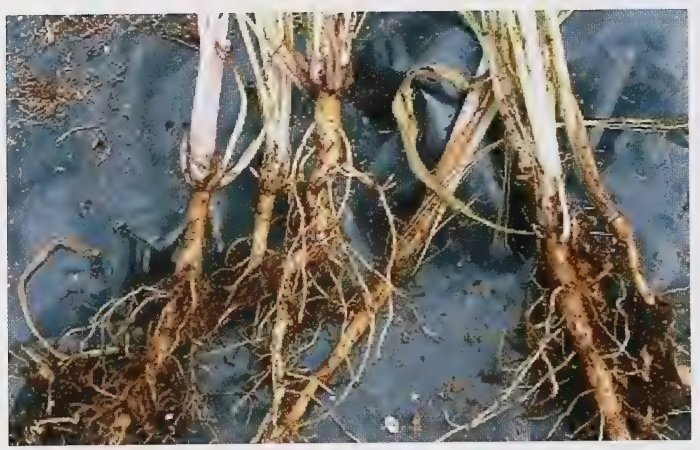

Figure $\mathbf{8 A}$. Echinacea greenhouse transplants - bare root seedlings

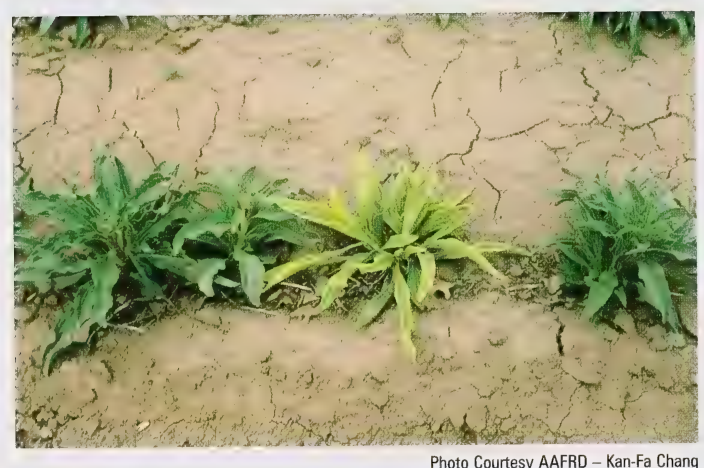

Figure 12A. Symptoms of Aster yellows in Echinacea angustifolia - yellowing

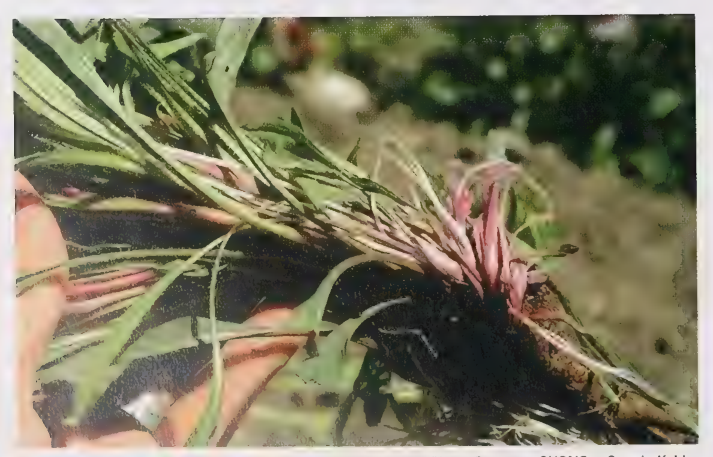

Photo Courtesy CHSNC - Connie Kehler

Figure 12C. Symptoms of Aster yellows in Echinacea angustifolia - proliferation of shoots "witches broom"

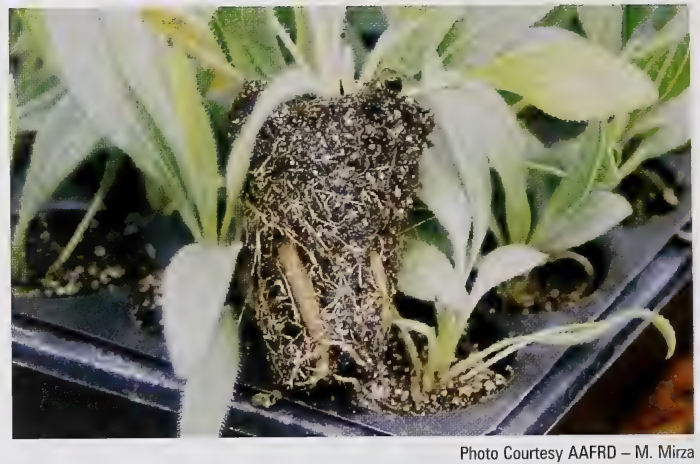

Figure 8B. Echinacea greenhouse transplants - plugs

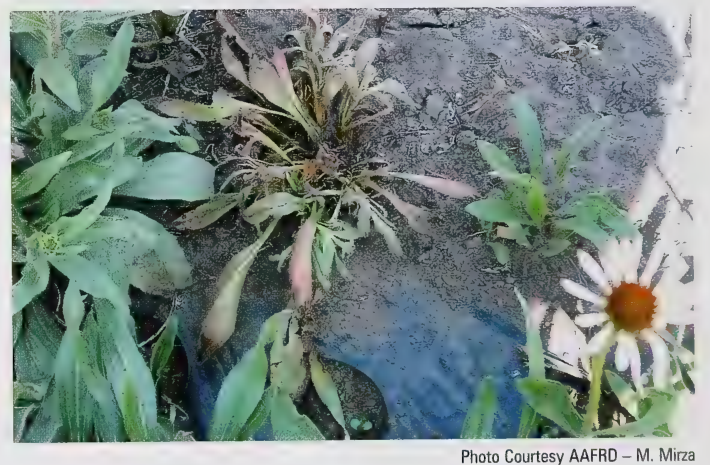

Figure 12B. Symptoms of Aster yellows in Echinacea angustifolia - reddening

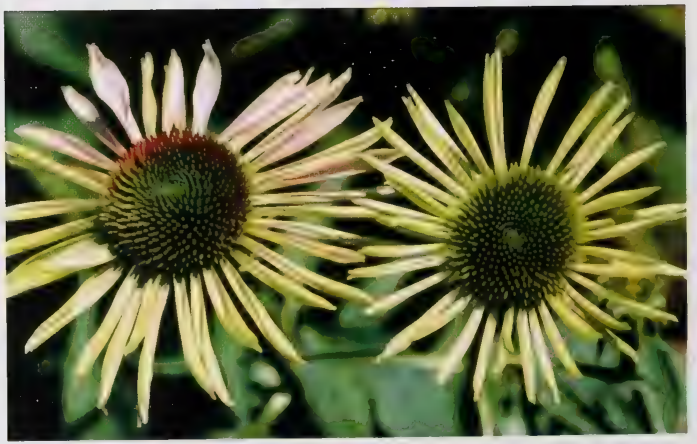

Photo Courtesy AAFRD - Kan-Fa Chang

Figure 12D. Symptoms of Aster yellows in Echinacea angustifolia - floral virescence 


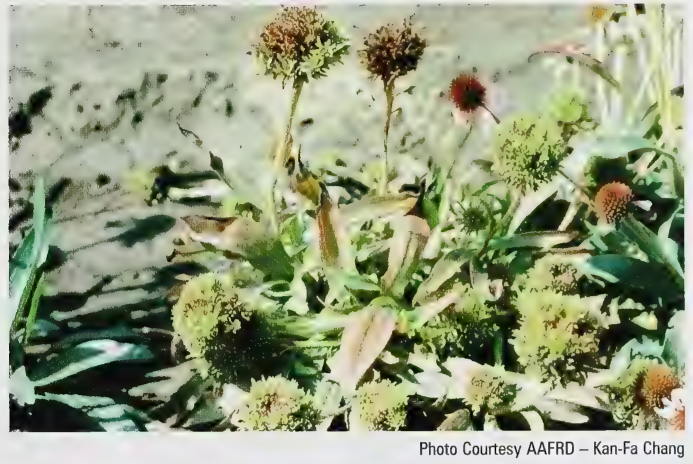

Figure 12E. Symptoms of Aster yellows in Echinacea angustifolia - floral virescence

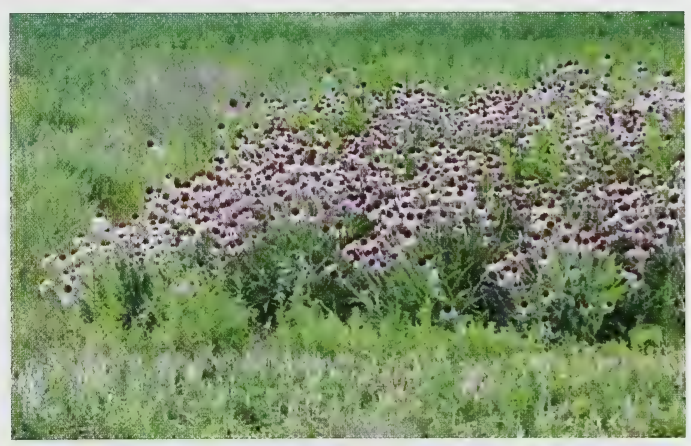

Photo Courtesy AAFRD - M. Bandara

Figure 13A. Aster yellows nursery

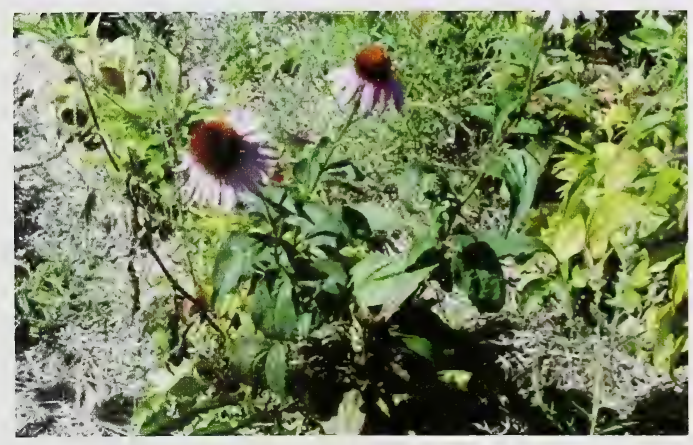

Figure 13C. Healthy echinacea plant among infected plants

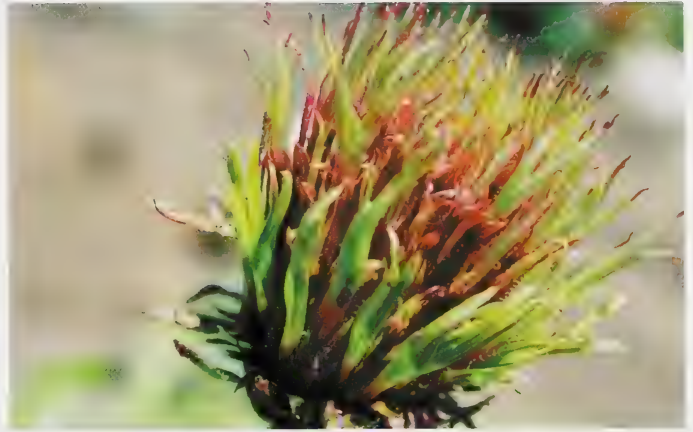

Photo Courtesy CHSNC - Connie Kehler

Figure 12F. Symptoms of Aster yellows in Echinacea angustifolia - phyllody

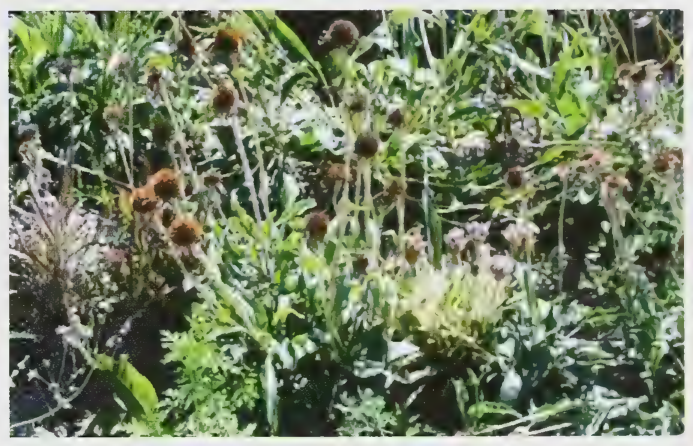

Photo Courtesy AAFRD - M. Bandara

Figure 13B. Aster yellows-infected plants 


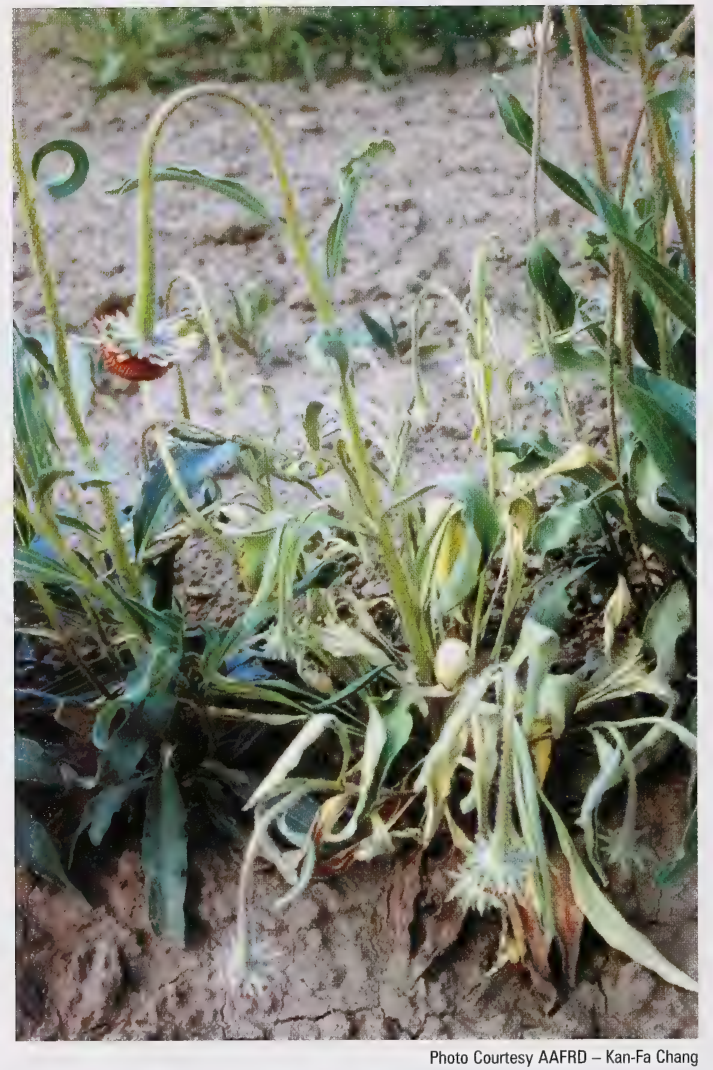

Figure 14. Symptoms of Sclerotinia sclerotiorum in Echinacea angustifolia - note bleaching of leaves and rapid wilting of plant and drooping of flower heads

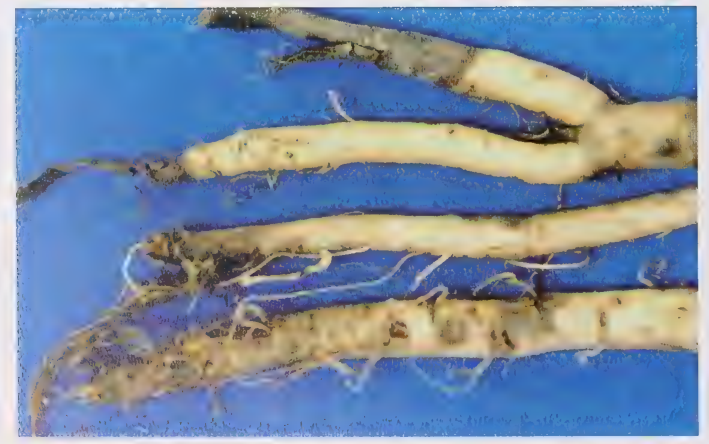

Photo Courtesy AAFRD - Kan-Fa Chang

Figure 16. Symptoms of root rot in Echinacea angustifolia lesions and root breakdown

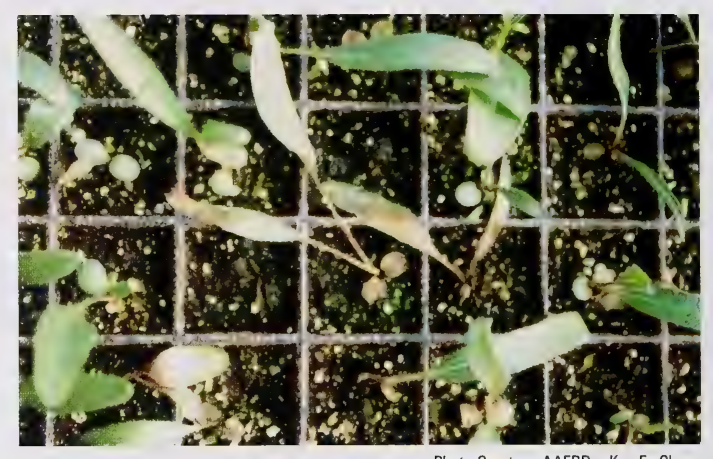

Photo Courtesy AAFRD - Kan-Fa Chang

Figure 15. Symptoms of damping-off in Echinacea angustifolia wilting/withering of leaves, collapse of seedlings

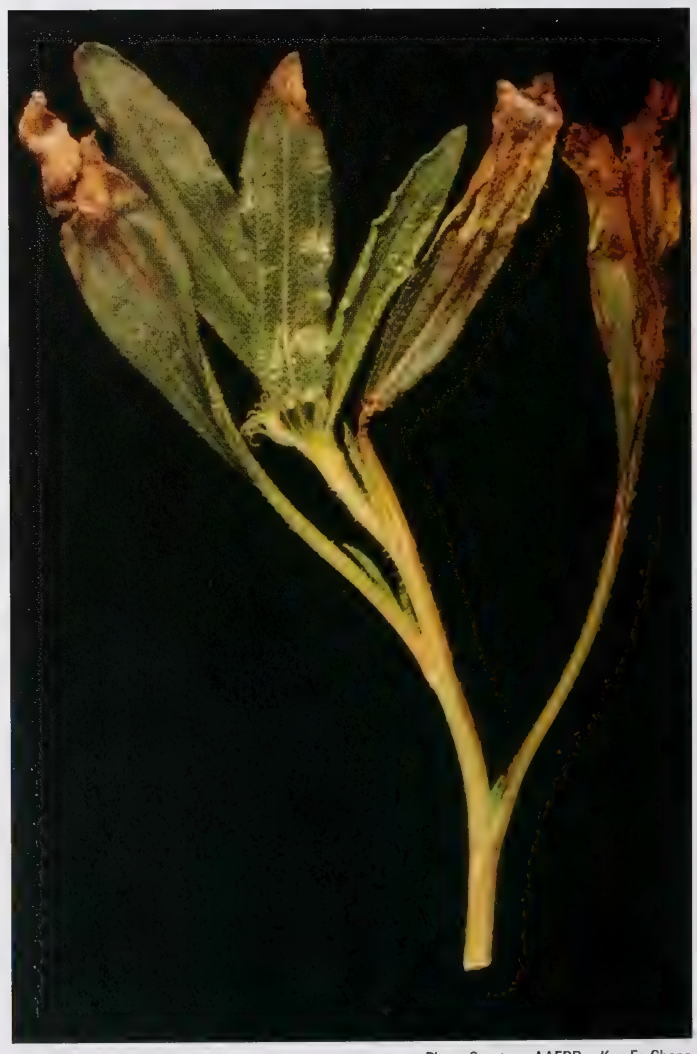

Photo Courtesy AAFRD - Kan-Fa Chang Figure 17. Symptoms of Botrytis cinerea on Echinacea angustifolia 


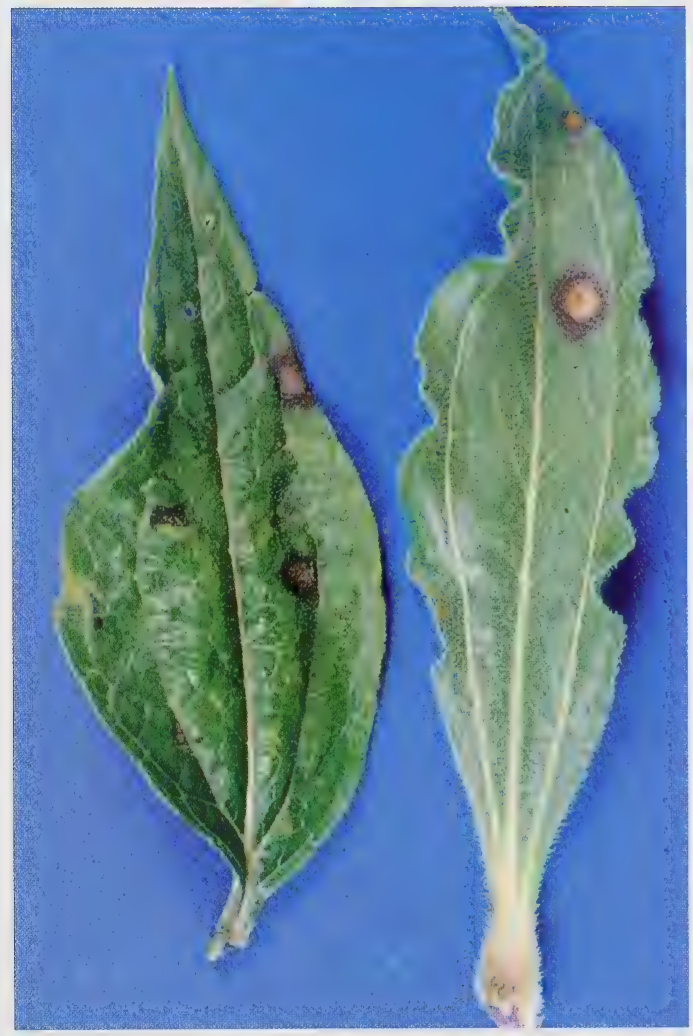

Figure 18. Alternaria leaf spot lesions on Echinacea angustifolia

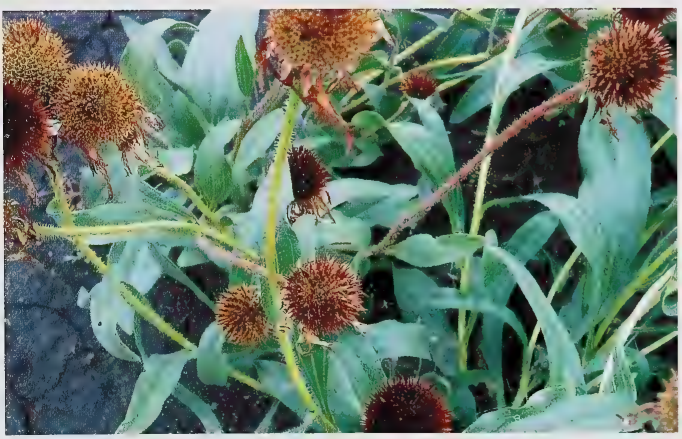

Photo Courtesy AAFRD - M. Mirza

Figure 21C. Mature seed cones - note browning of stem base

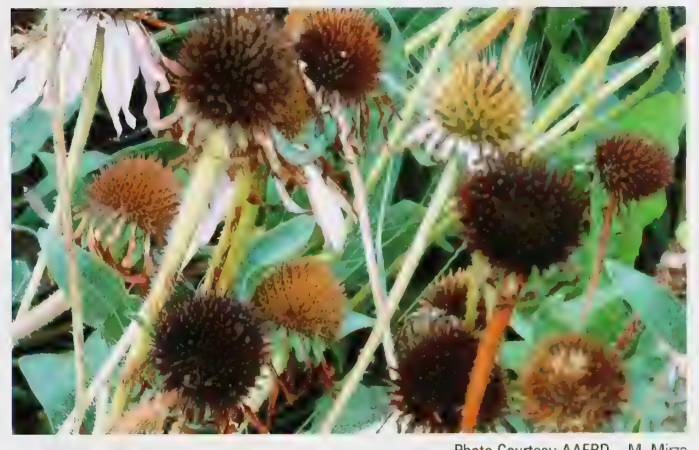

Figure 21A. Mature seed cones of $\mathrm{E}$. angustifolia

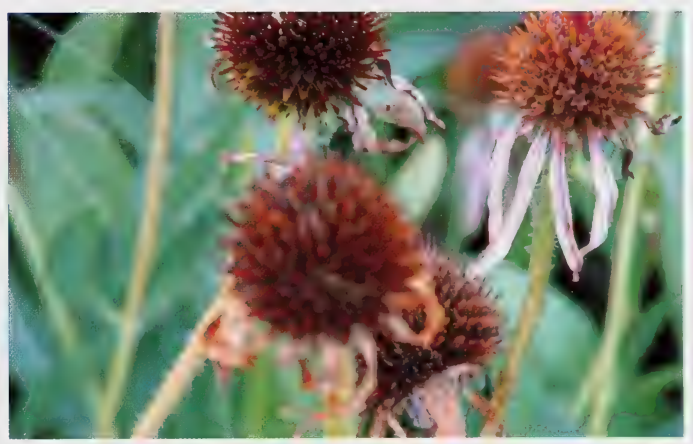

Photo Courtesy AAFRD - M. Mirza

Figure 21B. Mature seed cones - close up

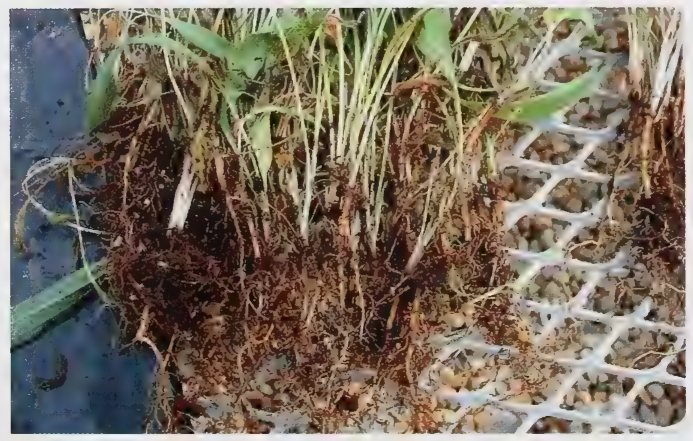

Photo Courtesy AAFRD - M. Mirza

Figure 32A. Echinacea greenhouse seedlings - crowded bare root seedlings 


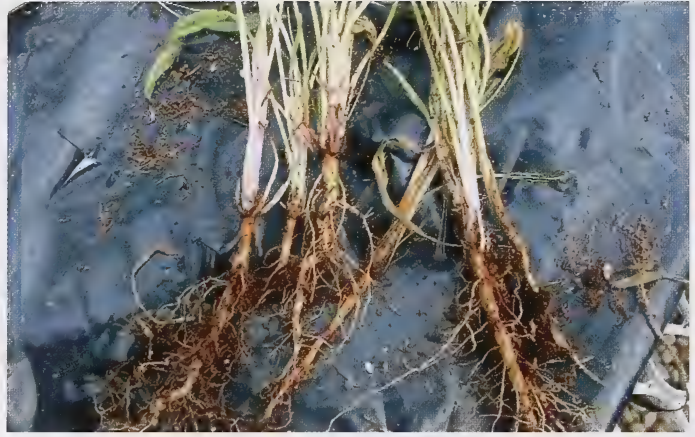

Photo Courtesy AAFRD - M. Mirza

Figure 32B. Echinacea greenhouse seedlings - good bare root seedlings

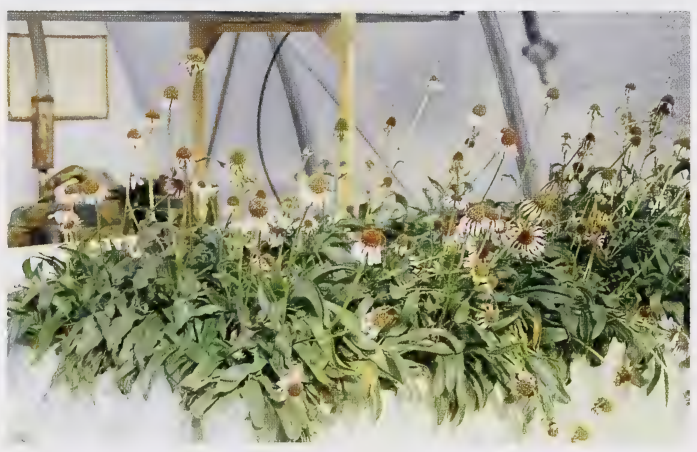

Figure 34A. Aeroponic echinacea growth system - growth channel

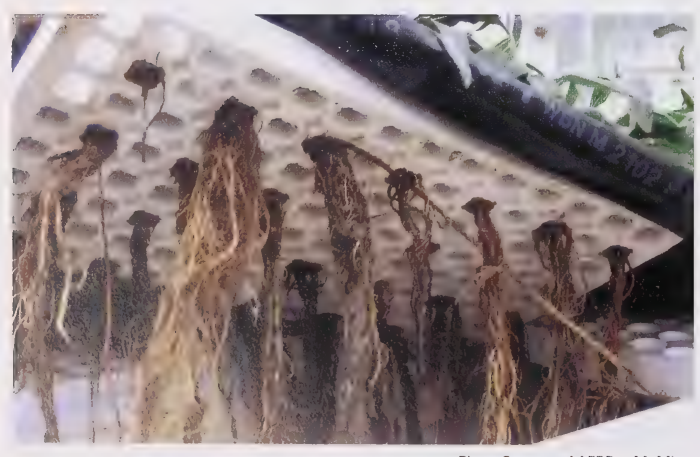

Figure 34B. Aeroponic echinacea growth system - root system within channel

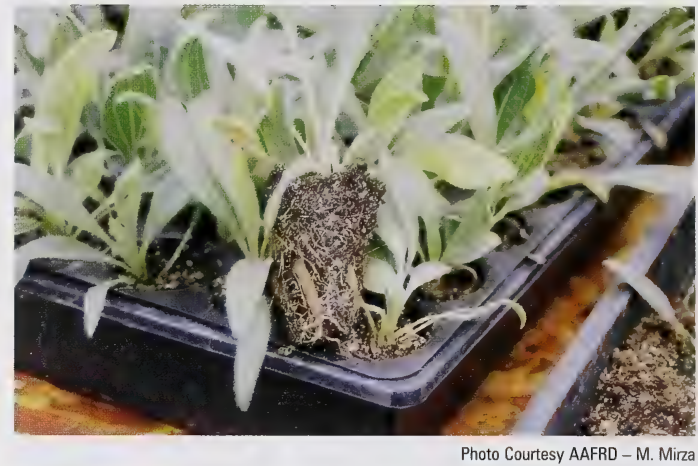

Figure 32C. Echinacea greenhouse seedlings - plugs in 128-cell tray

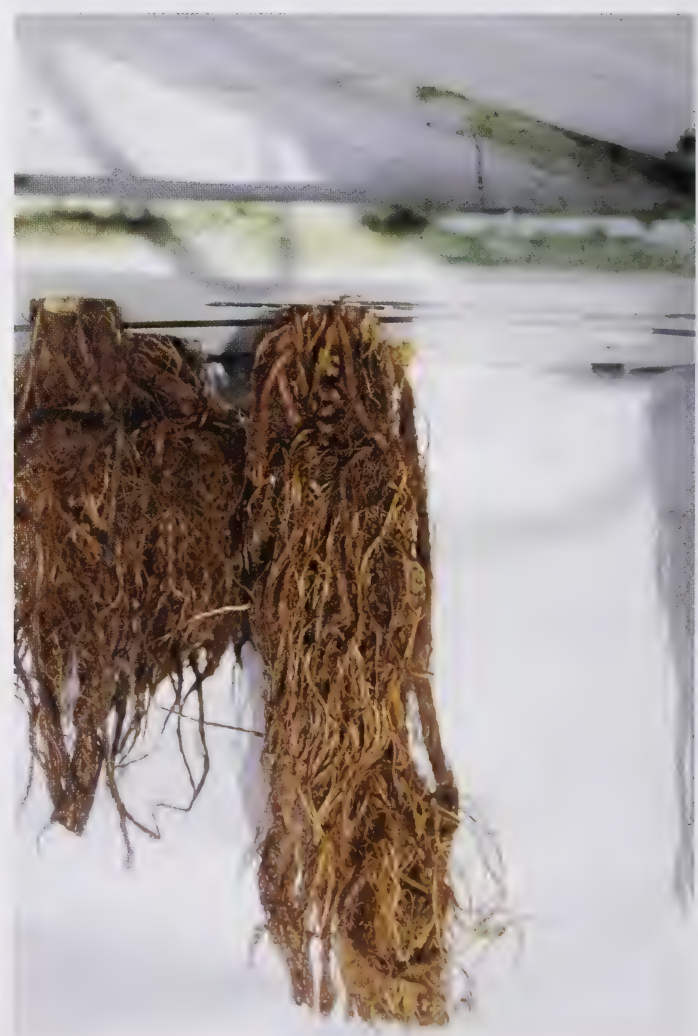

Photo Courtesy AAFRD - M. Mirza

Figure 34C. Aeroponic echinacea growth system - root system within channel 


\section{Root harvest}

\section{Timing}

The timing of root harvest is based on two factors: the root weight and the levels of bioactive compounds, such as echinacoside, in the roots.

Echinacea root is typically dug when plants have grown for three growing seasons, although root may be left until the fourth year, if necessary. This approach allows for plants to generate sufficient root mass and bioactive compounds to make harvest worthwhile. Harvest in an earlier year may result in roots with higher levels of bioactive compounds, but root yields will suffer. Studies at CSIDC found that dry root yields increased by 32 to 49 per cent when roots were harvested in the third year rather than the second year.

Contrary to some of the research findings, some producers have found that quantities of bioactive compounds in the second year can be excellent and if root weights are good, then harvest at this stage may be a viable option. Root weights depend on many factors, such as location, climate and growing conditions. Results may vary from crop to crop.

Roots may be dug either in the spring or the fall. It is generally thought that there is no significant variation in bioactive compounds between fall- and spring-harvested roots. However, some growers have found that active compounds are highest when the roots are harvested in the spring as plants begin to bloom.

In the fall, plants should be harvested after the plants have gone to seed and have had several hard frosts and started to die back.

Roots should be dug when temperatures are above $10^{\circ} \mathrm{C}\left(50^{\circ} \mathrm{F}\right)$.

\section{Deciding when to harvest}

The following is one way to decide when to harvest roots:

1. Dig, clean and dry a sample of roots each year, including the second year.
2. Use that sample to determine the root weight and to estimate the overall potential root yield from the field. If the root weight is low, the plants may be left in the field for another year.

3. If the root weight is high, then have the sample analyzed to measure the levels of those bioactive compounds that are important to the buyer. Some buyers buy roots based on echinacoside levels; others buy based on alkamide levels or a combination of echinacoside and alkamide levels.

4. If the levels of bioactive compounds are low, the plants may be left in the field for another year. If the levels are high, the plants may be harvested.

Similarly, roots may be sampled at various times during the year (e.g. spring vs. fall) to determine the levels of bioactive compounds. Over time and with experience, producers may find they can achieve a certain benefit by careful timing of the root harvest.

\section{Equipment}

There is no set piece of equipment for harvesting echinacea roots. Many producers have adapted potato diggers (see Figure 25) or other field equipment (Figure 26). Some have designed their own equipment, often consisting simply of a cutting blade that vibrates, mounted on an angle.

Critical characteristics of any digger include the following:

- Digs to a depth of at least $30 \mathrm{~cm}$ (12 in.). However, the actual depth needed will be determined by the root growth, so greater depth may be useful.

- Minimizes damage to roots, particularly the fine feeder roots and the taproot because the bioactive compounds are present at higher levels in those parts. Figure 27 shows an example of the damage that can occur due to improper equipment.

- Loosens soil and lifts roots slightly. 

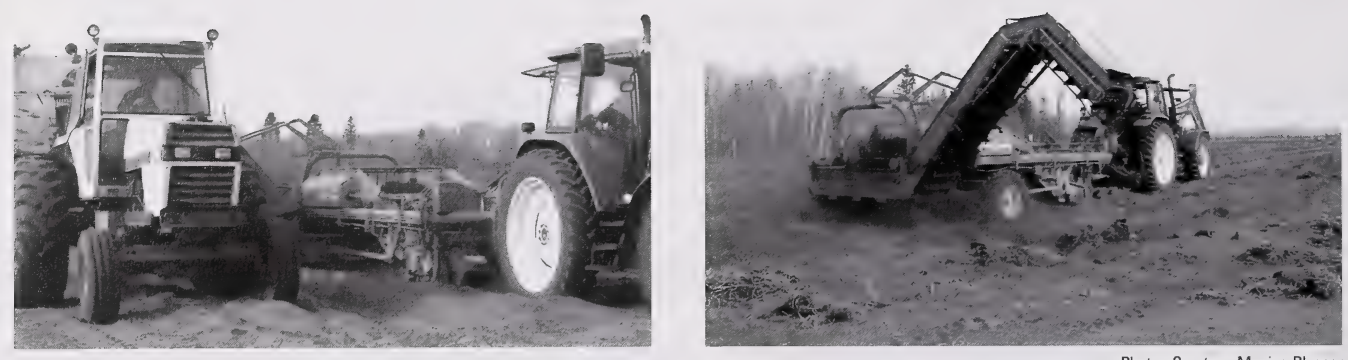

Photos Courtesy Monica Blaeser
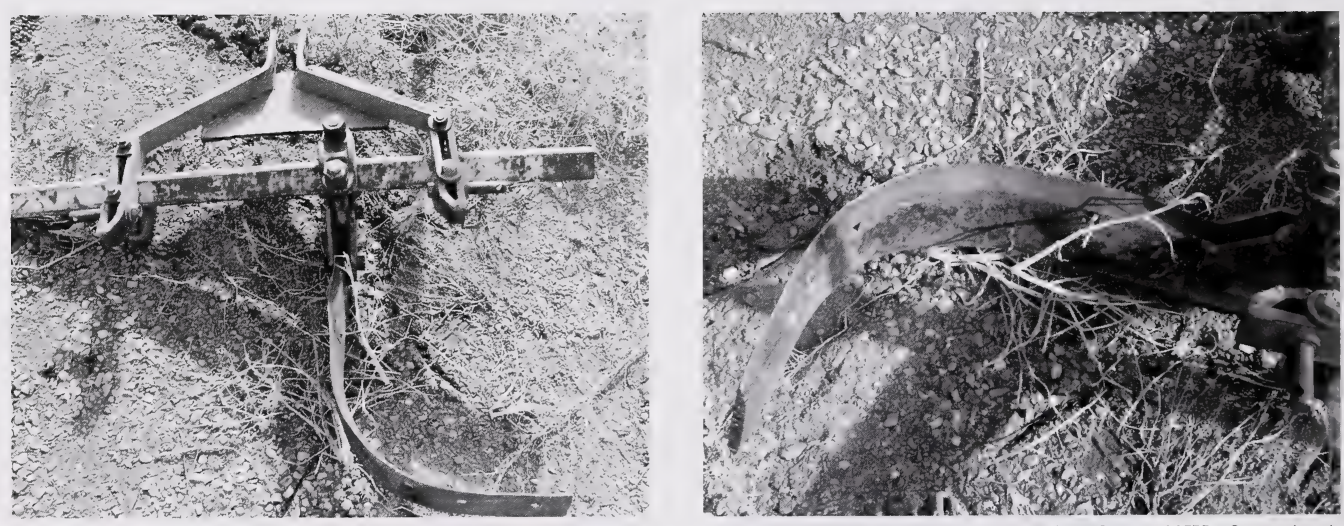

Photos Courtesy AAFRD - Stewart Jangula

Figure 26. J-Blade digger implement for digging echinacea root

Some growers prefer to remove the plant tops before harvesting, so the plants will go through the harvester more easily. About 2.5 to $5 \mathrm{~cm}$ (1 to $2 \mathrm{in}$.) of the stem may be retained, to prevent injury to the crown. After the roots have been dug and sorted, but before washing and drying, any stem tissue should be removed, to facilitate drying.

\section{Root cleaning, drying and storage}

Roots should be handled as gently as possible in all post-harvest stages to prevent the loss of fragile parts of the root. Be especially careful with the small, feeder roots and the root's bark; a University of Saskatchewan study has shown that those parts contain the highest levels of echinacoside and other bioactive compounds. 

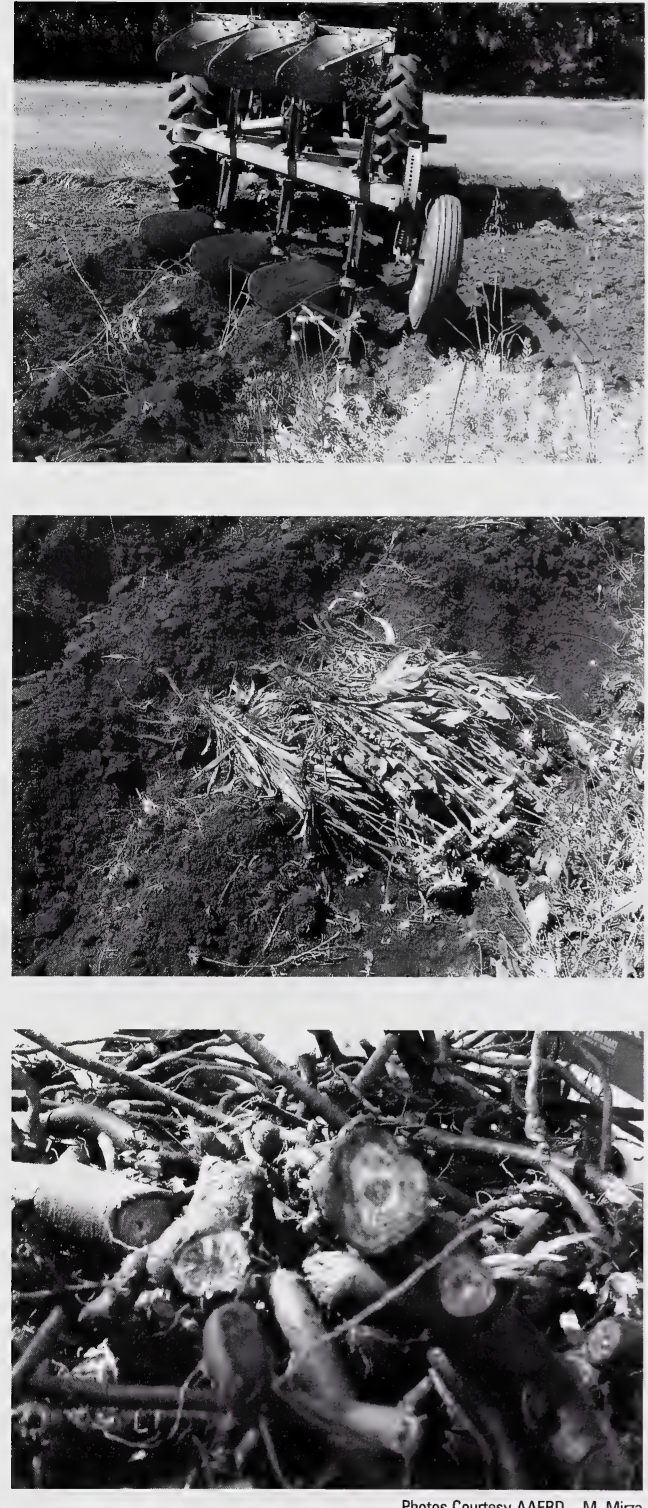

Figure 27. Echinacea harvester that did not work, with the resulting badly cut roots

\section{Cleaning}

As much dirt as possible should be cleaned off the harvested roots. Any soil left on the roots will be a starting point for mould development during storage. The roots must also be free from other contaminants, such as foreign plant material.

Until they can be washed, keep the harvested roots in a cool, shady place to prevent moisture loss before washing. Do not allow the roots to be in direct sunlight or to freeze or thaw because these conditions will cause the bioactive compounds to break down.

Roots should be washed thoroughly in cold water (see Figure 28). Wash water should be of potable quality (free from moulds, mycotoxins,

microorganisms and other contaminants). Roots may be soaked for 10 to 15 minutes to loosen dirt, but soaking for longer than this time may reduce the levels of bioactive compounds.

Take care not to remove or knock off the small, feeder roots or the root's bark during washing. A high-pressure washer may be used to remove dirt in areas of root branching, but be very careful. If the pressure is too high or exposure to the water is too long, the root's outer bark may peel.

After washing, the roots should be soaked in a 1 to 2 per cent solution of hydrogen peroxide for 5 to 10 minutes and then taken to the dryer. (See Appendix $\mathrm{C}$ for details on hydrogen peroxide use.)

\section{Drying}

For roots to be stored and for the harvest quality to be maintained, the roots must be dried. Roots must also be dry when submitted for sampling and analysis (see the Sample Analysis section).

One kilogram $(2.20 \mathrm{lb}$.) of fresh root will yield around $0.25 \mathrm{~kg}(0.55 \mathrm{lb}$.) of dried root. 

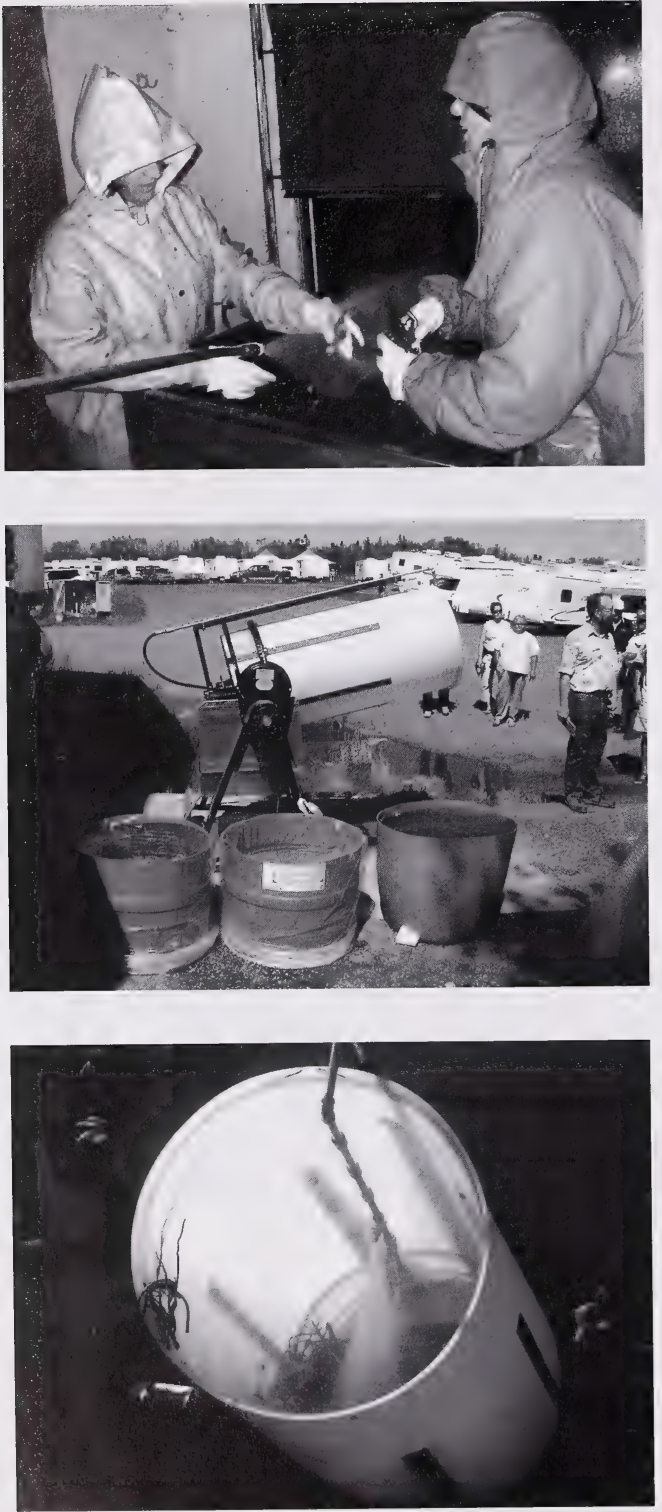

Photos Courtesy Monica Blaeser and AAFRD - R. Spencer Figure 28. Cleaning echinacea roots
The key to good drying is air movement, not heat. Echinacoside is a very heat-sensitive compound and will degrade and volatilize if exposed to excessive temperatures. A study at the University of Saskatchewan found that drying times decreased as temperature was increased above room temperature, but the echinacoside content of roots was reduced by 28 per cent or 45 per cent if roots were dried at $30^{\circ} \mathrm{C}\left(86^{\circ} \mathrm{F}\right)$ or $60^{\circ} \mathrm{C}\left(140^{\circ} \mathrm{F}\right)$, respectively. When roots were dried at room temperature, echinacoside levels were preserved.

The preferred drying method is to use a dryer at a temperature under $30^{\circ} \mathrm{C}\left(86^{\circ} \mathrm{F}\right)$ with constant air movement and minimal light.

Roots should not be thickly stacked as a thinner pile will allow faster drying and maintain quality. Bulk drying in sacks will not be successful due to high bulk volume.

The rate of drying is affected by root size. Larger roots should not be stacked as this practice will slow drying and may increase microbial development.

During drying, roots should not be exposed to bright, direct sunlight which can reduce the amount and quality of echinacoside and other bioactive compounds. Roots can be dried in a sheltered location in darkness or some indirect light.

Roots should be dried to a moisture content of around 10 to 12 per cent (see box on Determining Root Moisture Content for details).

Do not over-dry the roots. Roots are considered to be dry when a fingernail does not leave an imprint on the fattest root and the root snaps easily with no resistance. 


\section{Determining root moisture content}

Estimating root moisture content to determine when drying is finished can be difficult. The following procedure can be used to make an estimate of moisture content.

1. Weigh 100 grams of washed roots.

2. Put the roots in a microwave at high power for 5 minutes.

3. Record the new weight (e.g. 50 grams).

4. Microwave the roots for another 5 minutes and record the weight (e.g. 15 grams).

5. Repeat the procedure until no more weight is lost. At this point, you will have a completely dried root.

Freshly harvested Echinacea angustifolia roots have an average moisture content of about 85 per cent. Based on this estimate, $100 \mathrm{~g}$ of roots should be dried to about 20 to $22 \mathrm{~g}$, for a moisture content of about 10 per cent.

Based on the average moisture content of the roots, producers can estimate the amount of weight loss that will be required to achieve the target final moisture content.

\section{Storing}

Short-term - Roots may be stored in the short term, before washing and drying, in a cool, dry environment free from frost and not in direct sunlight.

Long-term - Properly dried roots may be stored for extended periods in breathable bags (such as a nylon mini-bulk bag) in a clean, dry, cool, rodent-free and insect-free storage area with a stable temperature and good air circulation. Roots should be stored in low light or dark conditions.

The roots should be checked every few months for mould. Diseased material should be removed to prevent the disease from spreading to other roots.

Under good conditions, properly dried whole roots may be stored successfully for some time. A reduction in potency may occur in processed root (i.e. cut, chopped or powdered) as bioactive compounds are oxidized over time.

\section{Sample analysis}

Dried root should be submitted to a laboratory to determine the levels of the desired bioactive compounds. This information is critical in the successful marketing of echinacea root as the levels of bioactive compounds influence the root's value.

A sample typically consists of 100 grams of dried root. The sample should not be frozen.

When submitting a sample, keep and document a random sample of the entire lot. Randomization is key, as this approach will give a good average of the whole lot.

At this time, the only lab in Alberta that tests for levels of bioactive compounds (including echinacoside, alkamides, isobutylamides) is EnviroTest Labs (see the Resources chapter).

Some buyers and manufacturers may require additional analysis for microorganisms, pesticide residues and heavy metals. This analysis is to satisfy Good Manufacturing Practice raw material specifications, which must meet or exceed Natural Health Product Directorate (NHPD) regulations. These regulations are provided in detail on the NHPD website (see the Resources chapter).

\section{Harvesting other plant parts}

While echinacea production focuses primarily on harvesting mature root, which has the highest levels of echinacoside and other bioactive compounds, there may be a small market for other plant parts, such as the leaves, stems or flowers. For example, the mature flower (before seed maturation) has some ornamental value as a cut or dried flower. Echinacea herb harvested at the time of flowering in spring may also have a small market.

Producers should explore the potential for sales of different plant parts during the course of their market research. Producers should not overestimate the value of these parts when making economic calculations. 


\section{Economic Analysis}

Echinacea production requires a significant investment with a limited potential for returns before harvesting the root in the third or fourth year. Producers need to realistically assess their costs, cash flow, potential root and seed yields as well as the likely prices from root and seed sales. They should have a clear understanding of the financial risks involved and develop strategies to address those risks.

The following analysis focuses mainly on the economics of field production of echinacea root. The analysis is intended as a general guide only. Each operation must develop its own analysis based on its own specific production targets, practices, costs and market prices. As well, producers should perform financial analyses regularly as costs, prices and yield estimates change. By tracking their economic situation, they will be better able to assess the effects of their current practices and adjust their operation to be more economically viable.

\section{Yield potential}

A key aspect in assessing the economic outcome of an echinacea operation is estimating the potential yields of seed and root. In the following tables, yield estimates for root are based on 100,000 healthy plants per hectare. The basic assumption is also made that 30 to 40 plants produce $0.45 \mathrm{~kg}(1 \mathrm{lb})$ of dried root.

However, actual seed and root yields can vary significantly depending on the number of surviving plants and the health of the plants. For example, some researchers estimate that the survival rate of echinacea plants is about 60 to 65 per cent, which would have a significant effect on yields.
Producers will need to develop realistic projections for seed and root yields based on their own conditions. In the Field Production Systems chapter, the Over-wintering section describes how to estimate plant populations.

Two major factors affecting yields are initial planting density and winterkill. These factors strongly influence the final plant population and may also affect root weight and quality. Agronomic factors such as fertility management, irrigation and pest control are also important in maximizing yields and quality of roots and seeds.

\section{Plant density and yields}

With increasing plant density, the competition among plants for water, nutrients and light increases. Increased competition can reduce the productivity and levels of bioactive compounds for individual plants, although the overall production from the field can be increased. Planting density can be manipulated by changing between-row spacing and/or within-row spacing.

Various studies have assessed the effects of plant density on root yields. Research at $\mathrm{CDCN}$ found that as plant density increased, dry weight root yield per square metre also increased (Figure 29).

However, the amount of yield increase slowed as plant populations surpassed 50 plants $/ \mathrm{m}^{2}$ (approx. 4.5 plants/ $\left./ \mathrm{ft}^{2}\right)$.

In studies at CDCS, dry root yields of transplanted echinacea tended to decrease slightly as plant density increased. For three-year-old plants, differences in between-row spacing did not appear to affect root yield as much as within-row spacing. In studies on direct seeding rates at CSIDC, dry root yield increased as seeding rate increased in dryland and irrigated echinacea. Wider row spacing slightly increased dry root yield. 


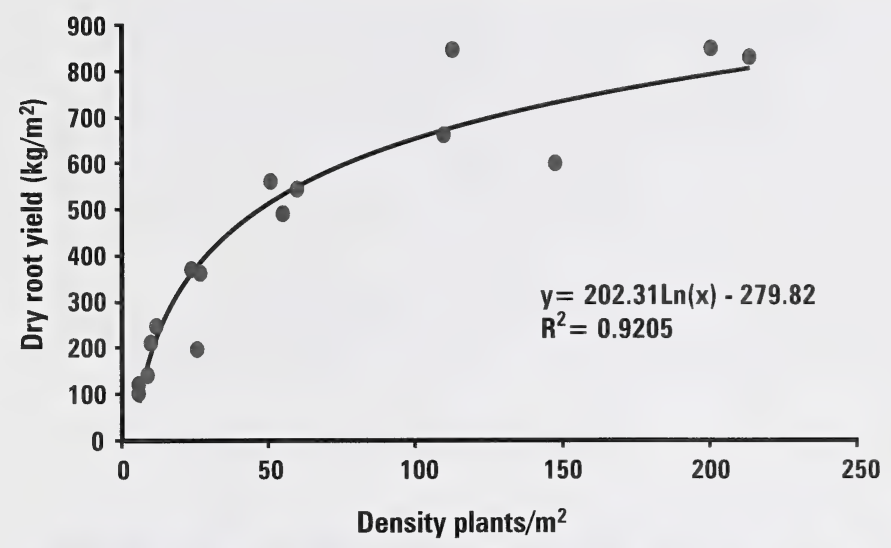

Figure 29. Relationship between planting density and dry weight root yield of Echinacea angustifolia in a greenhouse at CDCN

In the Field Production Systems chapter, the Seed Harvesting section discusses the effects of plant density and other factors on seed production per hectare.

Planting density may also affect aboveground biomass (foliage and stems) in addition to root yields and active compounds.

\section{Winterkill and yields}

Producers need to do as much as possible to reduce the risk of winterkill. The section on Over-wintering in the Field Production Systems chapter describes several methods to minimize winterkill.

\section{Capital investment requirements}

The sample capital budget, shown in Table 13, reflects the capital investment required for a 1-ha echinacea operation. Obviously, if the crop is produced in conjunction with an existing farm operation, little or no capital investment is needed in most cases.

\section{Gross margin}

The gross margin from a business must provide funds for interest, overhead and other indirect expenses as well as return for living expenses. If the
Table 13. Example of capital investment per hectare for an echinacea operation

\begin{tabular}{|l|c|}
\hline Gapital itom & $\$ /$ ha \\
\hline Land & $\$ 2,500$ \\
\hline Buildings & $\$ 3,500$ \\
\hline Machinery & $\$ 8,750$ \\
\hline Total & $\$ 14,750$ \\
\hline
\end{tabular}

gross margin is negative, then it is not recommended to start producing echinacea.

Table 14 lists some of the most common costs in echinacea production. A number of assumptions are related to these cost estimates:

- The producer grows his/her own transplants. The cost is estimated at 3 cents per plug (not including capital costs for the greenhouse).

- Seed cost for producing plugs is estimated at $\$ 600$ per $\mathrm{kg}$, assuming that certified seed is used for better germination.

- Currently, the seed market for Echinacea angustifolia is very soft. For the purposes of this crop budget, seed value is estimated at $\$ 100$ per $\mathrm{kg}$. Seed is harvested in Years 2, 3 and 4. 
- Echinacea root is generally harvested in Year 3 or 4 . For Tables 14,15 and 16, the assumption is that the root is harvested in Year 4.

- Wholesale price for dried Echinacea angustifolia root has ranged from $\$ 20$ to $\$ 62$ per $\mathrm{kg}$ over the last 8 to 10 years. For this budget, the price is estimated at $\$ 30$ per $\mathrm{kg}$.

- Labour for a 1-ha operation is estimated at 829 hours, distributed over four years, with major expenses for planting and weeding in Year 1 and harvesting in Year 4. Labour cost is estimated at $\$ 10.50$ per hour.

- Costs for site preparation, irrigation, storage and transportation of root and seed products have not been included.

- Costs such as fertilizer, fuel, oil and lube, machinery repairs and maintenance, taxes and insurance as well as miscellaneous expenses in Tables 14 and 15 are all estimates and can vary significantly from one operation to another.
- As noted, yield estimates for seed and root are based on 100,000 healthy plants per hectare at the end of four years. These yields represent conservative estimates of total yield.

Producers will need to develop their own set of assumptions for their own operations to create realistic financial projections. The budgets in Tables 14 and 15 are provided as a general guide only. For example, if the plant survival rate were near to the 60 to 65 per cent level found by some researchers, then the gross margin at the end of four years would be much lower than shown in Table 14.

Table 15 provides a year-by-year breakdown of the gross margin budget in Table 14 .

\section{Table 14. Example of gross margin for 1-ha echinacea operation (4-year crop cycle).}

\begin{tabular}{|l|c|c|c|}
\hline Estimated gross sales & Yield & Price & Sales (\$) \\
\hline Seed & $90 \mathrm{~kg}$ & $\$ 100 / \mathrm{kg}$ & 9,000 \\
\hline Root (dried) & $550 \mathrm{~kg}$ & $\$ 30 / \mathrm{kg}$ & 16,500 \\
\hline Total sales (\$) & & & $\$ 25,500$ \\
\hline Direct costs (\$) & Quantity & Price & Costs (\$) \\
\hline Seed & $1.25 \mathrm{~kg}$ & $\$ 600 / \mathrm{kg}$ & 750 \\
\hline Plugs & 100,000 & $\$ 0.03 /$ plug & 3,000 \\
\hline Planting & 130 hours & $\$ 10.50 /$ hour & 1,365 \\
\hline Fertilizer & & & 2,090 \\
\hline Fuel, oil and lube & & & 2,190 \\
\hline Machinery, repair and maintenance & & & 1,425 \\
\hline Weeding (labour) & 235 hours & $\$ 10.50 /$ hour & 2,468 \\
\hline Harvesting and cleaning of seed (labour) & 214 hours & $\$ 10.50 /$ hour & 2,250 \\
\hline Harvesting, cleaning and drying of roots & 250 hours & $\$ 10.50 /$ hour & 2,625 \\
\hline Taxes and insurance & & & 1,000 \\
\hline Miscellaneous expenses & & & 1,025 \\
\hline Total direct costs (\$) & & & $\$ \mathbf{2 0 , 1 8 8}$ \\
\hline Gross margin (\$) & & & $\$ 5,313$ \\
\hline
\end{tabular}


Table 15. Example of echinacea establishment budget (1-ha operation, 4-year crop cycle)

\begin{tabular}{|c|c|c|c|c|c|}
\hline & Year $1(\$)$ & Year $2(5)$ & $\operatorname{Year} 3(\$)$ & Yoar $4(\$)$ & Acetinulatod talal (\$) \\
\hline \multicolumn{6}{|l|}{ Yield (dried) } \\
\hline Seed & 0 & $30 \mathrm{~kg}$ & $30 \mathrm{~kg}$ & $30 \mathrm{~kg}$ & \\
\hline Root & 0 & 0 & 0 & $550 \mathrm{~kg}$ & \\
\hline \multicolumn{6}{|l|}{ Sales } \\
\hline Seed@\$100/kg & 0 & $\$ 3,000$ & $\$ 3,000$ & $\$ 3,000$ & $\$ 9,000$ \\
\hline Root@@ @30/kg & 0 & 0 & 0 & $\$ 16,500$ & $\$ 16,500$ \\
\hline Total sales (\$) & & $\$ 3,000$ & $\$ 3,000$ & $\$ 19,500$ & $\$ 25,500$ \\
\hline \multicolumn{6}{|l|}{ Direct costs } \\
\hline Seed & 750 & 0 & 0 & 0 & 750 \\
\hline Plugs & 3,000 & 0 & 0 & 0 & 3,000 \\
\hline Planting & 1,365 & 0 & 0 & 0 & 1,365 \\
\hline Fertilizer & 1,100 & 320 & 320 & 350 & 2,090 \\
\hline Fuel, oil and lube & 740 & 350 & 350 & 350 & 2,190 \\
\hline Machinery, repair and maintenance & 600 & 250 & 250 & 325 & 1,425 \\
\hline Weeding, annual & 1,250 & 375 & 375 & 467 & 2,468 \\
\hline Harvesting and cleaning seeds & - & 750 & 750 & 750 & 2,250 \\
\hline Harvesting, cleaning and drying roots & 0 & 0 & 0 & 2,625 & 2,625 \\
\hline Taxes and insurance & 250 & 250 & 250 & 250 & 1,000 \\
\hline Miscellaneous & 250 & 250 & 250 & 275 & 1,025 \\
\hline Total direct costs (\$) & $\$ 9,305$ & $\$ 2,545$ & $\$ 2,545$ & $\$ 5,792$ & $\$ 20,188$ \\
\hline Gross margin $(\$)$ & $\$(9,305)$ & $\$ 455$ & $\$ 455$ & $\$ 13,708$ & $\$ 5,313$ \\
\hline
\end{tabular}

\section{Gross margin sensitivity analysis}

Table 16 demonstrates changes in gross margin in Year 4 of echinacea production as the yields and the blended prices vary for seed and echinacea root (dried).

This echinacea budget shows that a combined yield of $580 \mathrm{~kg} / \mathrm{ha}$ ( $30 \mathrm{~kg}$ for seed and $550 \mathrm{~kg}$ for root) priced at $\$ 33.62 / \mathrm{kg}$ would provide a gross margin of $\$ 13,708 /$ ha in Year 4. However, the accumulated gross margin for production after four years would be around $\$ 5,313 /$ ha. Of course, these values will be different if a different set of assumptions is used.

\section{Financial risk management}

When managers look at an investment, three essential elements must be considered:

1. the opportunity must be profitable ("will it pay?")

2. affordable ("can I afford it?")

3. desirable ("do I want to do it?")

Managers must also assess the economic and financial risk in their decision making. 
Table 16. Sensitivity of gross margin to the blended market price for seed and dried root

\begin{tabular}{|l|c|c|c|c|c|}
\hline Blended price $(\$ / \mathrm{kg})$ & \multicolumn{6}{|c|}{ Yield of seed and dried root $(\mathrm{kg} / \mathrm{ha})$} \\
\hline & $\mathbf{4 8 0}$ & $\mathbf{5 3 0}$ & $\mathbf{5 8 0}$ & $\mathbf{6 3 0}$ & $\mathbf{6 8 0}$ \\
\hline 25.00 & 5,091 & 6,787 & 8,708 & 10,854 & 13,113 \\
\hline 30.00 & 7,059 & 9,198 & 11,608 & 14,288 & 17,091 \\
\hline 33.62 & 8,483 & 10,944 & 13,708 & 16,774 & 19,971 \\
\hline 35.00 & 9,027 & 11,610 & 14,508 & 17,721 & 21,069 \\
\hline 40.00 & 10,995 & 14,021 & 17,408 & 21,155 & 25,047 \\
\hline 45.00 & 12,963 & 16,433 & 20,308 & 24,588 & 29,025 \\
\hline
\end{tabular}

A key aspect of economic risk is cash flow. Producers need to develop realistic cash flow projections to get a good understanding of their financial situation. By looking at various production and marketing scenarios, they may be able to find strategies to improve the cash flow of their operation.

\section{Cash flow projections}

Cash flow must be looked at separately from revenue and expenses to assess the viability of the enterprise. Table 17 shows an example of a 10-year cash flow projection based on the enterprise budget (Table 14). In this strategy, the root is harvested in Year 3. Harvesting in Year 3, rather than Year 4, is one way to reduce the risk of seed and root losses due to winterkill. An equity level of 70 per cent is assumed due to the risk involved with echinacea production.

Other assumptions in Table 17:

- The producer purchases plugs from a greenhouse operation at $\$ 0.10$ per plug.

- Direct costs include plugs, planting, fertilizer, fuel, oil, lube, machinery repair and maintenance.

- Indirect costs include taxes, insurance and miscellaneous.
- Labour costs are separated from direct costs because labour forms such an important component of the total costs for echinacea production. Labour costs include weeding and root harvesting, cleaning, drying and storing.

- Labour totals 560 hours/ha, distributed over three years with major expenses for planting and weeding in Year 1 and harvesting in Year 3. Labour cost is estimated at $\$ 10.50$ /hour.

- Costs for site preparation, irrigation, storage and transportation of root and seed products are included.

This analysis shows that annual net cash flows are negative except in the years when the root is harvested. Cumulative net cash flows are negative except in the harvest years until Year 10.

Higher upfront operating capital would help to maintain the operation's viability. Generally, upfront capital should cover any negative shortfall during the first two years of an operation, but in this scenario, the negative shortfall in Year 1 is quite high.

Higher prices for echinacea root would improve viability. Production and marketing strategies that reduce input costs and/or generate income between root harvests would also help. 


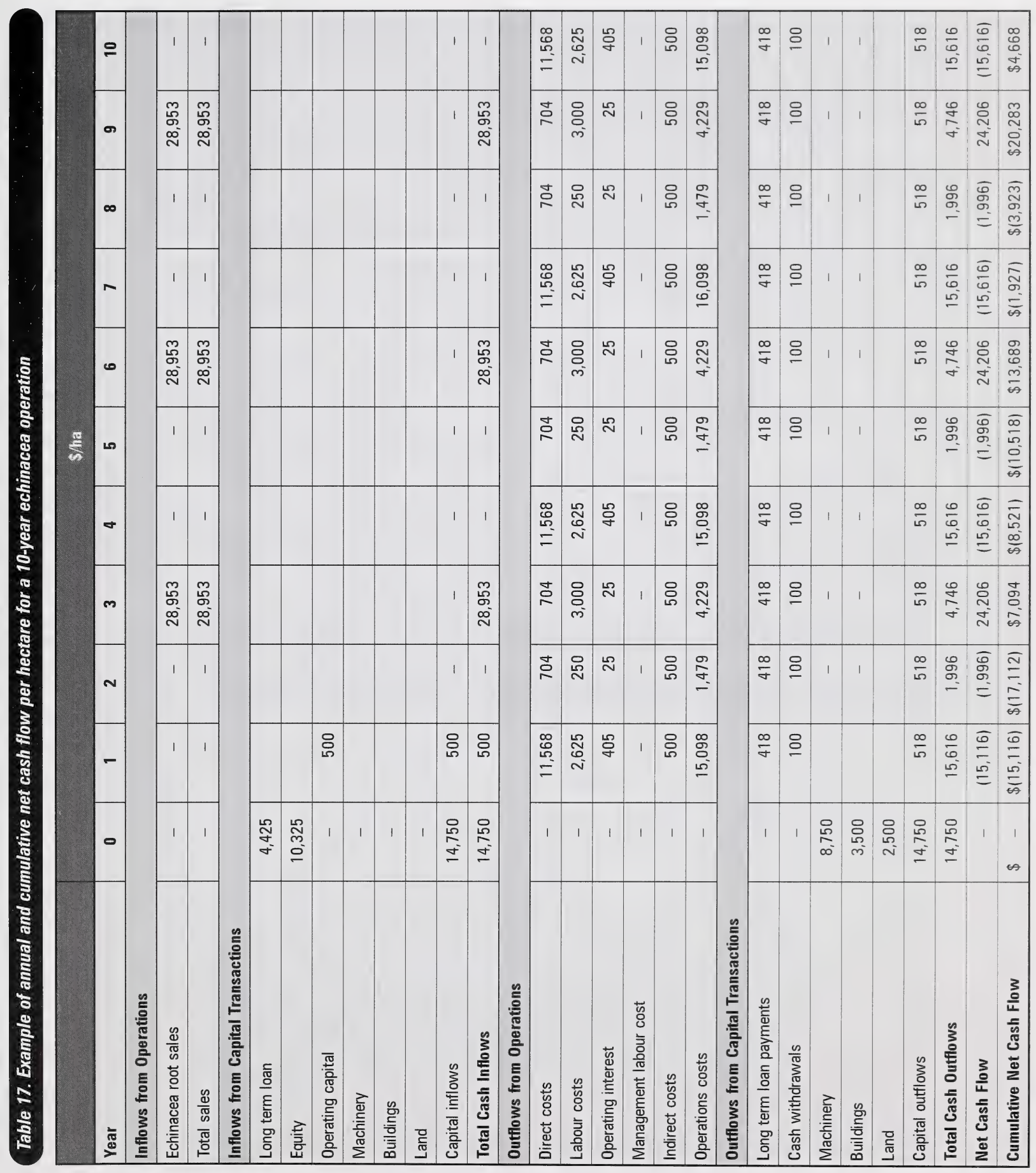




\section{Risk management strategy: a five-year rotation}

An alternative risk management strategy, shown in Table 18, involves five fields and a rotation that provides consistent income in future years. The rotation includes a two-year respite from echinacea production to replenish the soil fertility

(e.g. application of manure/compost, production of a green manure crop) and to provide an opportunity for controlling any weeds that are difficult to manage when the field is in echinacea. Rotating out of echinacea can also break disease or insect pest cycles.

The assumptions for each rest year are as follows:

- weed control costs (including herbicides, spraying equipment operation and/or labour) equal $\$ 22.00 /$ ha.

- green manuring costs (including seed, inoculant, tillage, seeding and discing) equal \$100.13/ha.

- maintenance costs (including fertilizer, machinery operations and labour)
Based on this five-year rotation, Table 19 presents the cash flow for the 5-ha enterprise.

Using this five-year rotation, the cash flow is now positive in the seventh year. Higher upfront operating capital would still be necessary to ride out the first two years of high negative cash flow as the rotation is started.

\section{Risk management strategy: reduce the cost of plugs}

Another strategy to improve cash flow is to reduce the cost of plugs. It is assumed that the manager purchases plugs from a greenhouse operation at $\$ 0.10$ per plug. Harvesting seed, beginning in the third year of the operation, and growing echinacea plants on site can reduce the cost of plugs to $\$ 0.03$ per plug.

\section{Table 18. Example of alternative rotation for a 5 -ha echinacea operation over 10 years}

\begin{tabular}{|c|c|c|c|c|c|}
\hline & Field \#1 & Field \#2 & Field \#3 & Field \#4 & Field \#5 \\
\hline & 1 ha & 1 ha & 1 ha & 1 ha & 1 ha \\
\hline Year 1 & Planting & & & & \\
\hline Year 2 & Maintenance & Planting & & & \\
\hline Year 3 & Production & Maintenance & Planting & & \\
\hline Year 4 & Rest year & Production & Maintenance & Planting & \\
\hline Year 5 & Rest year & Rest year & Production & Maintenance & Planting \\
\hline Year 6 & Planting & Rest year & Rest year & Production & Maintenance \\
\hline Year 7 & Maintenance & Planting & Rest year & Rest year & Production \\
\hline Year 8 & Production & Maintenance & Planting & Rest year & Rest year \\
\hline Year 9 & Rest year & Production & Maintenance & Planting & Rest year \\
\hline Year 10 & Rest year & Rest year & Production & Maintenance & Planting \\
\hline
\end{tabular}




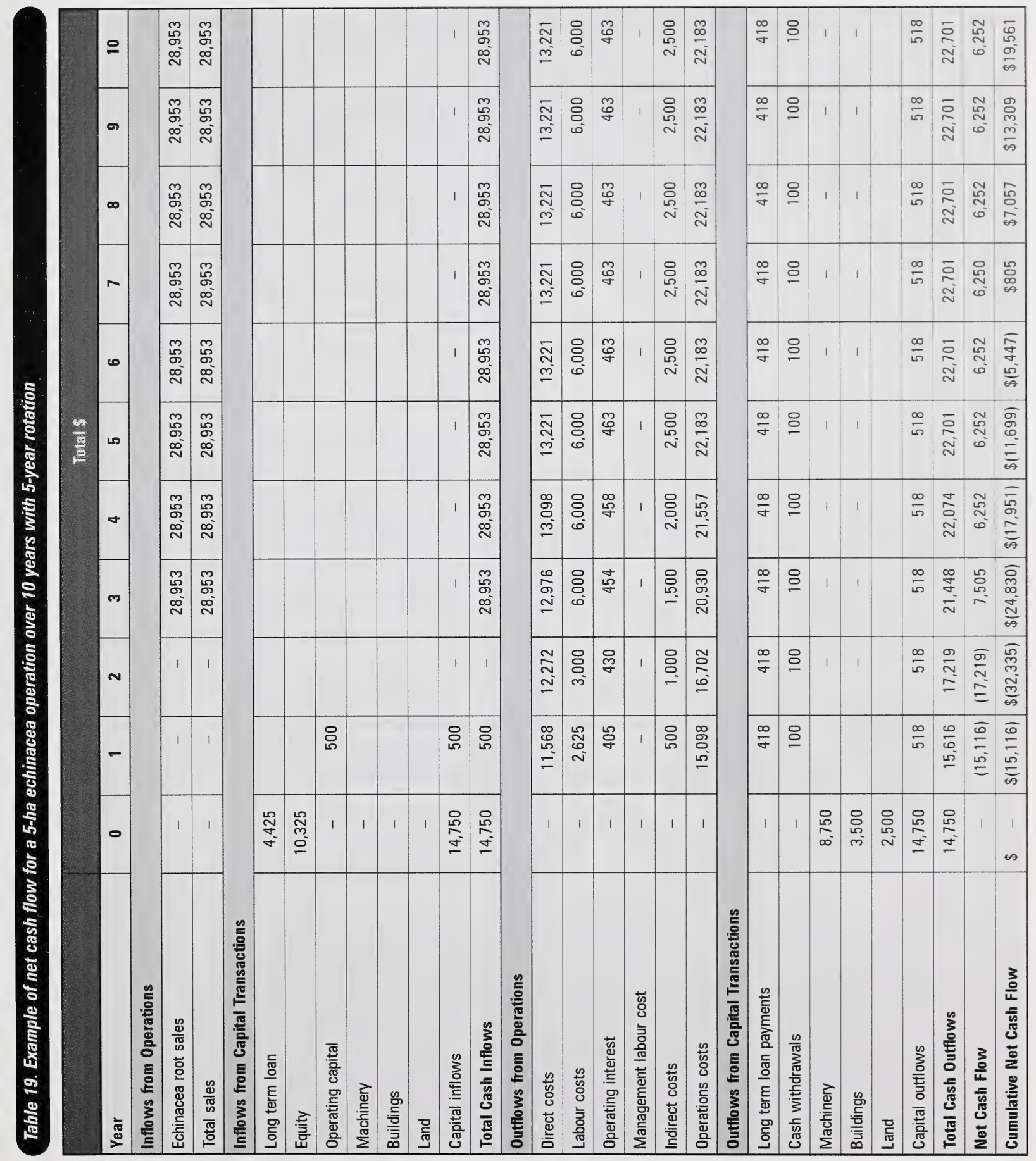


The analysis shown in Table 20 assumes the following:

- The five-year rotation described above is followed.

- Plugs are purchased in the first three years. After the third year, seed harvested from the crop is used to grow plugs on-site. An equivalent value of $\$ 600 / \mathrm{kg}$ for certified seed is used.

- The analysis does not include the greenhouse capital costs or the operating costs for producing the plugs.

Based on these assumptions, the results in Table 20 show a positive cash flow by the fifth year.

\section{Discounted cash flow}

Investments are usually made anticipating financial gain. Measuring profitability in an enterprise requires using the net present value method, which accounts for the time value of money. That is, a dollar today is worth more than a dollar to be received a year from now.

If the net present value is less than zero, the investment should be rejected. A positive net present value means that the investment pays better than the opportunity cost of capital and should be accepted.

The analysis shown in Table 21 assumes the same 5-year rotation and a discount rate of 13.62 per cent to account for risk and inflation.

This analysis shows that the net present value is negative, and the investment should be rejected. If the investment is accepted, there will be an economic cost.

\section{Break even analysis}

Producers must sell at a price that will cover their costs. In the short run, the selling price must cover their direct costs, so they can stay in business. In the long run, the selling price must cover economic costs. Table 22 shows the direct, indirect and economic costs to produce echinacea root in the 3-year (Table 17) and 5-year rotations (Table 19).

Table 23 shows the break even yields needed to cover the costs in Table 19. Again, to stay in business, producers must cover direct costs in the short run. In the long run, the average yield must cover economic costs.

\section{Table 22. Example of direct, indirect and economic costs to produce echinacea root}

\begin{tabular}{|l|c|c|}
\hline & 3-year rotation $(\$ / \mathrm{kg})$ & 5-year rotation $(\$ / \mathrm{kg})$ \\
\hline Direct costs & $\$ 20.79$ & $\$ 21.17$ \\
\hline Direct + indirect costs & $\$ 23.42$ & $\$ 25.31$ \\
\hline Economic costs & $\$ 24.73$ & $\$ 27.50$ \\
\hline
\end{tabular}

Table 23. Break even root yields to cover direct, indirect and economic costs

\begin{tabular}{|l|c|c|}
\hline & 3-year rotation (kg/ha) & 5-year rotation (kg/ha) \\
\hline Direct costs & 707.5 & 720.5 \\
\hline Direct + indirect costs & 797.1 & 861.4 \\
\hline Economic costs & 841.8 & 935.9 \\
\hline
\end{tabular}




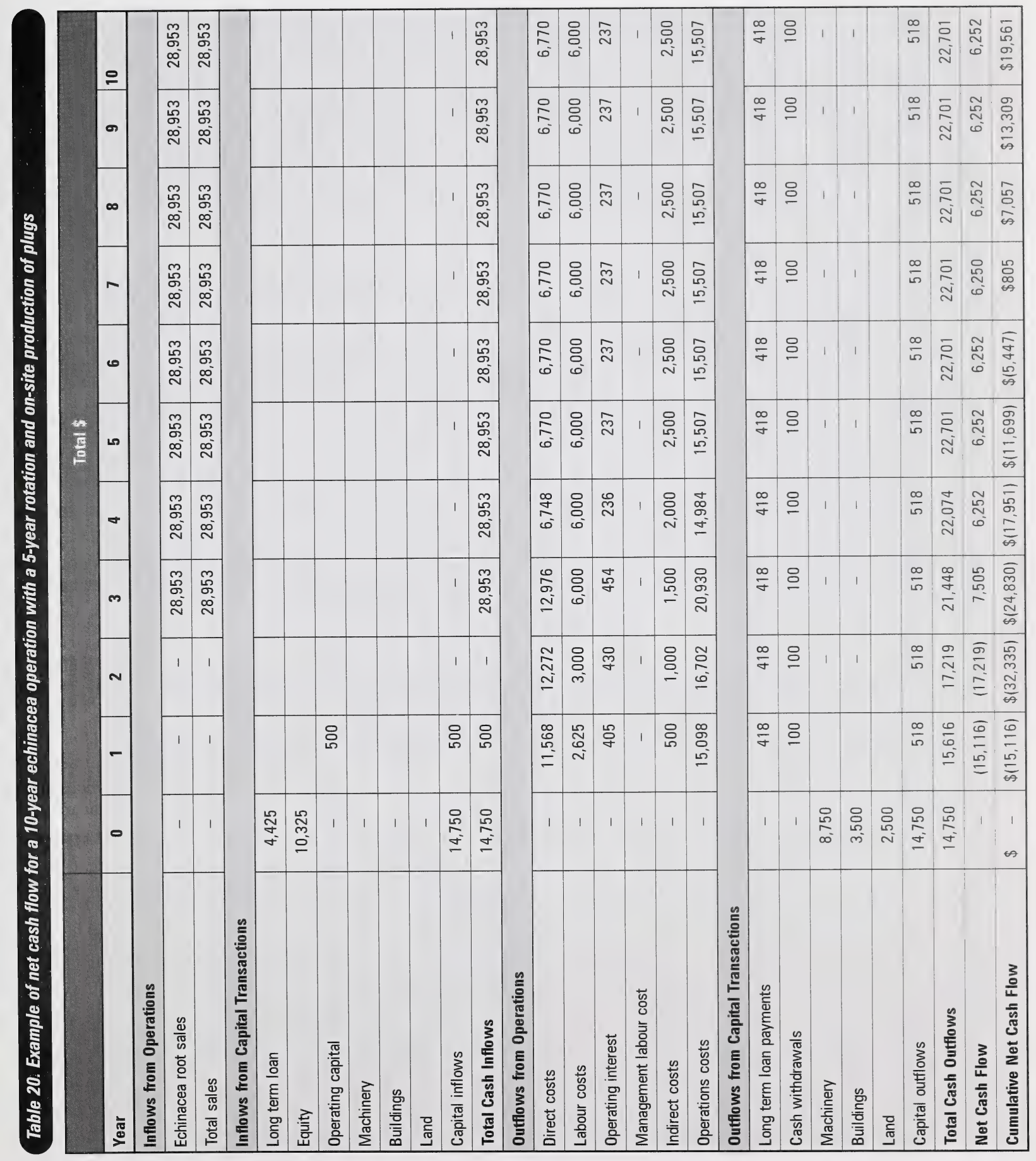




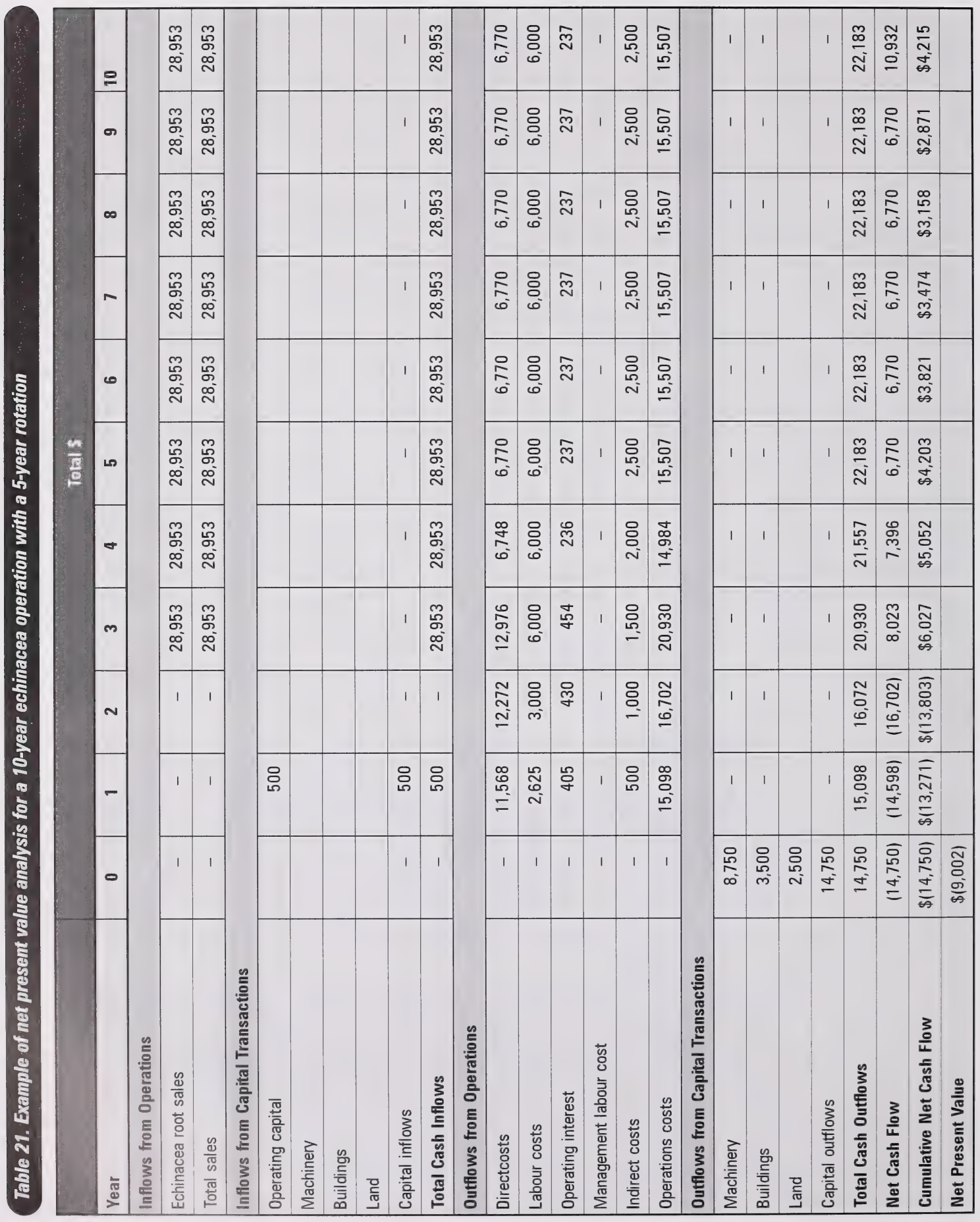




\section{Sensitivity analysis}

The following two sensitivity analyses explore aspects of market pricing and production performance.

Table 24 shows the effects of changes in echinacea prices on gross operating profit at various production levels for a 5-year rotation. All other costs are held constant.
Table 25 shows the effect of changes in echinacea prices on return to management (returns over economic costs) at various production levels within a 5-year rotation. All other costs are held constant.

\section{Table 24. Sensitivity of gross operating profit to market prices for echinacea root}

\begin{tabular}{|c|r|r|r|r|r|r|}
\hline Markat price $(\mathbf{S} / \mathrm{kg})$ & \multicolumn{7}{|c|}{ Yisid (kghij) } \\
\hline & \multicolumn{1}{|c|}{$\mathbf{7 0 0}$} & $\mathbf{7 5 0}$ & \multicolumn{1}{c|}{$\mathbf{8 0 0}$} & \multicolumn{1}{c|}{$\mathbf{8 5 0}$} & \multicolumn{1}{c|}{$\mathbf{9 0 0}$} & \multicolumn{1}{c|}{950} \\
\hline$\$ 15.00$ & $(\$ 14,624)$ & $\$(13,874)$ & $\$(13,124)$ & $\$(12,374)$ & $\$(11,624)$ & $\$(10,874)$ \\
\hline 20.00 & $(11,124)$ & $(10,124)$ & $(9,124)$ & $(8,124)$ & $(7,124)$ & $(6,124)$ \\
\hline 25.00 & $(7,624)$ & $(6,374)$ & $(5,124)$ & $(3,874)$ & $(2,624)$ & $(1,374)$ \\
\hline 30.00 & $(4,124)$ & $(2,624)$ & $(1,124)$ & 376 & 1,876 & 3,376 \\
\hline 35.00 & $(624)$ & 1,126 & 2,876 & 4,626 & 6,376 & 8,126 \\
\hline 40.00 & 2,876 & 4,876 & 6,876 & 8,876 & 10,876 & 12,876 \\
\hline$\$ 45.00$ & $\$ 6,376$ & $\$ 8,626$ & $\$ 10,876$ & $\$ 13,126$ & $\$ 15,376$ & $\$ 17,626$ \\
\hline
\end{tabular}

Table 25. Sensitivity of returns to management for echinacea root

\begin{tabular}{|c|r|r|r|r|r|r|}
\hline Markat prico (\$\$/kg) & \multicolumn{7}{|c|}{ Yiald (kg/ha) } \\
\hline & \multicolumn{1}{|c|}{$\mathbf{7 0 0}$} & \multicolumn{1}{|c|}{$\mathbf{7 5 0}$} & \multicolumn{1}{c|}{$\mathbf{8 0 0}$} & \multicolumn{1}{c|}{$\mathbf{8 5 0}$} & \multicolumn{1}{c|}{$\mathbf{9 0 0}$} & \multicolumn{1}{c|}{950} \\
\hline$\$ 15.00$ & $\$(16,796)$ & $\$(16,046)$ & $\$(15,296)$ & $\$(14,546)$ & $\$(13,796)$ & $\$(13,046)$ \\
\hline 20.00 & $(13,296)$ & $(12,296)$ & $(11,296)$ & $(10,296)$ & $(9,296)$ & $(8,296)$ \\
\hline 25.00 & $(9,796)$ & $(8,546)$ & $(7,296)$ & $(6,046)$ & $(4,796)$ & $(3,456)$ \\
\hline 30.00 & $(6,296)$ & $(4,796)$ & $(3,296)$ & $(1,796)$ & $(296)$ & 1,204 \\
\hline 35.00 & $(2,796)$ & $(1,046)$ & 704 & 2,454 & 4,204 & 5,954 \\
\hline 40.00 & 704 & 2,706 & 4,704 & 6,704 & 8,704 & 10,704 \\
\hline$\$ 45.00$ & $\$ 4,204$ & $\$ 6,454$ & $\$ 8,704$ & $\$ 10,954$ & $\$ 13,204$ & $\$ 15,454$ \\
\hline
\end{tabular}




\section{Financial benchmarks}

Variability in costs, yields and prices can cause fluctuations in returns. Typical budgets and cash flows assume fixed prices and yields when calculating returns. However, by using financial modelling that incorporates distributions for prices, yields and costs, it is possible to estimate some essential financial benchmarks. Table 26 provides a set of assumptions for modelling, and Table 27 shows an example of how these assumptions can be used to look at possible financial outcomes. In the particular scenario shown in Table 27, the 2 per cent inflation rate is applied to the direct costs (but not to the other costs or the sales price). Other scenarios could be run that apply the inflation rate to other costs or the sales price.
The results in Table 28 indicate that return over direct costs and earnings before taxes are positive over the 10-year time frame. Standard deviation is a measure of risk. A high standard deviation compared to the mean equals high risk.

As shown by the high standard deviation, earnings before taxes are highly variable. This variability is due to the effect of labour costs because labour costs are the only costs subtracted from return over direct costs. Watching labour costs will be essential to ensure positive earnings before taxes. The average net present value is quite negative, indicating that profitability is a concern with the price and yield distributions. Finally, the modified internal rate of return (MIRR) is positive, but the standard deviation is high, and the return could become negative within the time period.

\section{Table 26. Assumptions for financial modelling}

\begin{tabular}{|l|c|c|c|}
\hline & Minimum & Most likely & Maximum \\
\hline Price $(\$ / \mathrm{kg})$ & 20.00 & 30.00 & 35.00 \\
\hline Yield $(\mathrm{kg} / \mathrm{ha})$ & 756 & 1,000 & 1,200 \\
\hline Direct costs $(\$)$ & 13,500 & 16,000 & 17,500 \\
\hline Labour costs $(\$)$ & 5,500 & 6,000 & 8,000 \\
\hline Indirect costs $(\$)$ & 900 & 1000 & 1,100 \\
\hline Fixed costs $(\$)$ & 4,000 & 5,281 & 6,000 \\
\hline
\end{tabular}

\section{Table 28. Results of financial benchmark modelling}

\begin{tabular}{|l|c|c|}
\hline Benchmark & Mean & Standard deviation \\
\hline Return over direct costs & $\$ 7,304$ & $\$ 1,423$ \\
\hline Earnings before taxes $(\$)$ & $\$ 1,054$ & $\$ 1,487$ \\
\hline Net present value $(\$)$ & $\$(25,431)$ & $\$ 5,588$ \\
\hline Modified internal rate of return & $0.3 \%$ & $2.9 \%$ \\
\hline
\end{tabular}




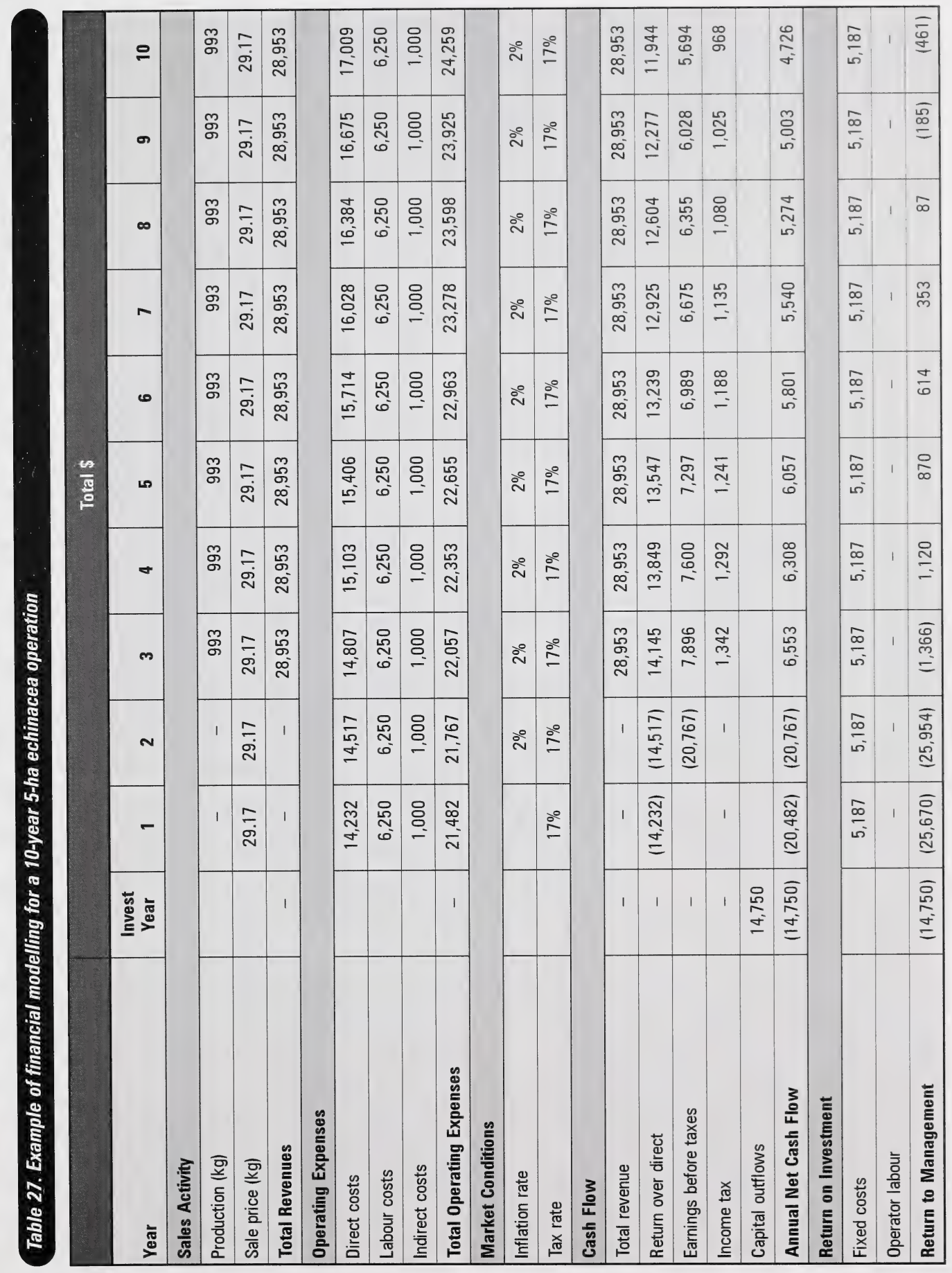




\section{Business and Marketing}

\section{Marketing vs. business}

Marketing involves research, both of the industry and the prospective consumers, as well as selling the product. Market research should be done before developing a business plan because that research will determine the direction and focus of the business.

A business is developed based on a potential market to meet the demands of the consumer/buyer. Business includes the day-to-day activities involved with generating a product or service. It also encompasses marketing activities, such as new product research or continuous contact with buyers to allow for refinement and adjustment of products and activities.

\section{Value of market research}

Market research is a multi-step process with the overall purpose of collecting information. It is designed to give an individual or company the information needed to make decisions about whether or not to proceed, where to focus activities and what adjustments need to be made to improve feasibility. It is also used to gather information about the people who may buy product.

Market research answers some fundamental questions about the market arena:

- Who will buy the product?

- What requirements do the different potential customers have?

- Who is the end user of the product (not necessarily the buyer of the product)?

- Who else is producing a similar product? Who is the competition?

- Who might be an ally in the market?
- Is there anything unique about the product that may add value or improve saleability?

- Do any marketing constraints exist?

- What is the market size and is there capacity for a new business to enter this market?

Conducting market research is essential to the success of an operation. Producers cannot expect to simply produce a product with no consideration of where it may be sold or whether there is any demand for the product. Market research helps producers find the information needed to develop sound marketing and business strategies.

Market research can help producers evaluate their operation including production costs and management decisions. Used in connection with cost of production information, research will help producers determine whether their operation is feasible or if adjustments need to be made.

Market research can also provide ideas on how to increase returns by identifying value-added opportunities or other options for increasing the value for a particular product. Producers must decide whether they will market a raw product or add some type of processing, which can encompass many forms.

\section{Conducting market research}

Market research should be carefully planned and documented, as it comprises a critical component of an overall business plan.

Market research can be either indirect (based on information that already exists) or direct (based on information that is gathered directly from the market). Direct market research may involve some cost. 
Doing market research follows an orderly series of steps:

1. Clearly define the product or service.

2. State the need being met by the product.

3. State the objective of the market research. What information is needed? What decisions will be made based on the research?

4. Review the information already in hand. Organize and analyze the existing information.

5. Collect additional information, if needed. Start with indirect research, then move on to more targeted direct research.

6. Organize and analyze the collected information. Ensure all pertinent questions have been answered. Resolve any contradictions or information gaps.

7. Make decisions based on the collected information.

8. Observe and evaluate the results of any decisions. Adjust activities or gather more information to clarify the results.

\section{How to market}

Echinacea producers are responsible for marketing their own products. As noted, before planting a crop, they need to do the research necessary to understand their potential markets.

Producers may not be able to find a fixed buyer, but they need to be aware of where the potential outlets for their product are. Echinacea may be sold directly to a customer or may be sold to a processor, broker, cooperative or some other source. Producers should recognize the differences in price that can be found through sales to different outlets.

Producers who are active marketers will increase their sales options and may have better returns. Marketing is a skill that must be developed; not all individuals are good at it. Producers may want to consider a partner or someone who has dedicated responsibility for marketing product. Producers may also want to consider using a third party, such as a broker or a cooperative sales agreement with other producers.
Producers should consider all options when it comes to marketing. The Natural Health Products Industry Canada: Industry \& Suppliers Guide is an annual directory of companies in the Natural Health Products industry (available from www.contactcanada.com).

\section{Market requirements}

Marketing is critical to the success of an echinacea operation; therefore, producers should devote a significant amount of energy and thought to what is required by the buyers. For example, producers need to identify which of the bioactive compounds are desired by their potential buyers, which parts of the plant provide those compounds, and how to maintain and improve the levels of those compounds during production, harvesting, cleaning, storage and transportation.

Producers need to know certain basic details about their product to meet buyers' needs. For example, they need to know the exact quantity (weight) of product they have and the quality (identity, purity and chemical analysis) of each lot, and they must understand what the buyers are demanding (form, quality, active ingredients, etc.). Buyers will not buy "guesses," but require specific products.

\section{Selling root, seed and/or herb}

When selling to a broker, company or any customer, it is important to present the product at the best quality possible. This focus is not only to make the immediate sale, but also to foster a relationship that could lead to a more permanent arrangement in the future, such as contracts or growing agreements.

The best scenario is to know what the buyer requires before echinacea is planted. The different species have different phytochemical characteristics or active marker compounds. It is important to know whether the buyer is looking for echinacoside, alkamides, chicoric acid, etc. What is the quality trait that determines value in the buyer's mind? 
The buyer will request a sample of the herb, root or seed. It is important to provide as much documentation as possible. Generally, the more information that can be provided to a buyer, the better the chance to sell the product and foster repeat business. This documentation could include the following:

- proof of organic certification (if applicable/ available)

- proof of botanical identification (also includes a seed sample and voucher specimens)

- lab analysis documentation (levels of bioactive compounds, freedom from contaminants such as microorganisms, heavy metals or pesticide residues)

- bacteriological analysis

If the buyer is looking for a certain percentage of a particular bioactive compound in the root, it is critical that the analysis of a representative sample be sent to the buyer, not just the best root. Some buyers may only be interested in the look and feel of a sample, while others may want an analysis. A bit of extra effort and information will not be wasted.

When sending a sample of the herb, root or seed to a buyer, producers should ensure it is a representative sample. Transport the sample in a way that will provide a clean, dry, cool, dark environment to preserve product quality. Make sure the sample is in a clearly marked, breathable bag with the producer's name and contact information and the product's botanical identity on the outside. Keep an identical sample of the product supplied for comparison in future, if required. Be sure to keep a copy of everything sent so that if there are any discrepancies, there is supporting documentation.

\section{General requirements}

The following are some common requirements that echinacea buyers ask for:

- Most (85 per cent) buyers want whole dried root. Some buyers may want chopped or minimally processed root.

- Most buyers want a high echinacoside content, typically higher than 1.2 to 1.5 per cent. Some buyers will only buy based on price, with little or no consideration of quality.

- Some buyers want a minimum of 4 per cent total alkamides.

- Although organic product does not always bring a price premium, buyers often seek organic product. Organic production may strengthen the product's marketability.

To be successful, producers should attempt to match their management practices to meet these common requirements. In addition, producers need to meet the specific requirements of their own buyers.

Producers should have all possible information about their product, so that they can answer any questions that a potential buyer might have.

\section{Value-added options}

In the past, producers grew and sold a commodity as a raw product at prices sufficient to generate adequate returns. In the current economic arena, many producers discover that some degree of valueadding, or processing, can increase the value of their product and can make their operation more profitable.

Value-adding can take many forms, ranging from minimal processing of a raw product (such as chopping or bagging) to the production of a processed product (such as a tincture, pill, infusion, etc.) for sale (Figure 30). Production, harvesting, cleaning, drying and freezing are not considered to be processing. 
Producers should remember that current regulations (see Natural Health Products Regulations chapter) do not allow for "backyard" or "kitchen" processing to create a product. Once processing begins, processing procedures must be standardized and the finished products licensed, including a site and product license.

When considering value-added options, producers should carefully consider all the costs involved in developing, packaging and marketing value-added products, and whether value-adding is a feasible option for their operation.

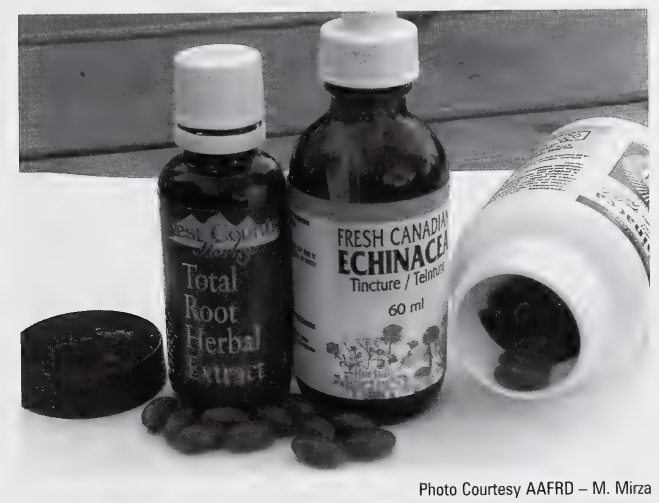

Figure 30. Processed echinacea pills and tincture 


\section{Greenhouse}

\section{Production Systems}

Some echinacea growers include greenhouse production as part of their operation. Usually, they produce greenhouse plugs or bare root seedlings for transplanting into fields. Some recent research suggests that greenhouse production of roots may also be a viable option.

Greenhouse technology has made significant advances, allowing producers to successfully grow plants within a controlled environment. Producers may control or optimize plant growth using moisture deficits and carbon dioxide $\left(\mathrm{CO}_{2}\right)$ enrichment, and control insects and diseases by managing temperature. Producers may also grow plants at a much higher density than in fields due to the ability to closely manage the nutrient supply. These factors, combined with the reduced influence of external climatic factors, make it attractive to consider growing echinacea under controlled conditions.

This chapter describes greenhouse production practices for good quality bare root seedlings and plugs. It also outlines the experimental option of greenhouse production of echinacea root.

\section{Transplant production}

Plants need a good quality, well-drained growing medium, good fertility, moisture, light and other conditions to grow into healthy and good quality seedlings. Poor techniques such as little or no light, excessive plant densities or poor quality growing media will result in weak, spindly plants and an increased risk of damping-off of seedlings.
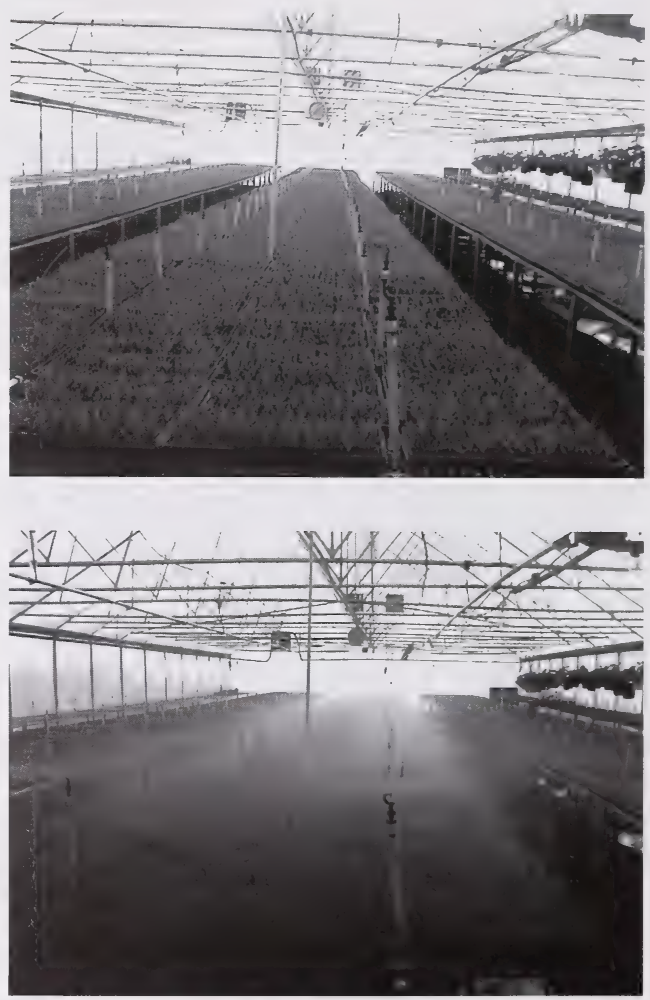

Photos Courtesy Monica Blaeser

Figure 31. Echinacea plugs being grown in the greenhouse 


\section{Production timing}

Transplants are usually grown in late winter or early spring in a heated greenhouse, so the transplants are ready for spring planting.

A study at CSIDC grew transplants in a greenhouse in the late summer and fall. The seedlings were then over-wintered as dormant plants in a straw covered pit before being planted out in spring. This experimental approach could potentially be more cost-effective because the transplant survival rates were quite high and because a heated greenhouse would not be necessary. Producers interested in this approach should begin with a very small trial because there are still many unknowns.

\section{Growing medium}

A good growing medium for echinacea seedlings is essential. It is important to understand the function of a growing medium and the contribution of its component parts to the overall quality. It is not enough to simply throw together a mix of the material that might happen to be on hand.

Producers should develop a standardized process or mixture to ensure the production of a uniform, quality seedling and transplant every time.

Functions of a growing medium:

- To anchor and support the plant. Echinacea does not require vertical support as do vine-like crops (e.g. cucumbers or tomatoes) because the contact between the plants will provide some support, in addition to the support that comes from the roots in the medium.

- To store minerals and water. Echinacea requires a range of nutrients throughout the growth cycle as well as sufficient water. A good quality medium will hold sufficient nutrients and water to supply the plant over a short period without retaining an excess of salts or water.

Remember that the growing medium also serves as a home for many living organisms that will affect the health of the roots. If "good" microbes become dominant, then "bad" microorganisms are held in check. If the reverse is true, then root health will deteriorate and plant loss may occur.
A growing medium is a very dynamic environment. The constituents of growing media are in a constantly changing relationship with each other. Management practices like watering and fertilizing change the balance in root zones, resulting in a constantly changing environment.

A growing medium consists of three phases or parts:

1. The solid phase consists of all organic and inorganic materials. This part is normally 50 per cent of the total volume of the medium.

2. The liquid phase is comprised of the moisture in the growing medium. In an ideal medium, the liquid phase is 25 per cent of the total volume.

3. The gaseous phase makes up the remaining volume. It contains all the gases, primarily carbon dioxide, oxygen and nitrogen. Several other gases are present in minute amounts.

The relative amount of each of the phases in the medium greatly affects plant growth. If the liquid phase increases too much compared to the gas phase, the growing medium becomes waterlogged, which is not good for echinacea growth.

Poor drainage of a medium causes waterlogging. A growing medium that has a large volume of fine particles is easily over-watered. This situation can happen when producers try to use field soil in containers. A well-designed growing medium has good drainage.

If the medium is very porous, the gas phase will be out of balance with the liquid phase. Such a growing medium does not have enough water-holding capacity and will require very frequent irrigation. For example, the successful cultivation of echinacea in perlite or other inert materials will require constant drip irrigation.

\section{Roles of growing medium components}

Each component of a growing medium plays a specific role. A specific medium need not contain all possible components as some may be substituted for one another. 
- Sphagnum moss peat - Fibrous peat has a high water-holding capacity. A cubic foot of peat moss weighs between 44 and $59 \mathrm{~kg}$ (97 and $130 \mathrm{lb}$.) when thoroughly saturated with water. This water-holding capacity is of great value in designing a good growing medium for echinacea. Peat moss has a large volume of pore space as well as high organic matter with good nutrient exchange capability. Most of the peat moss from Alberta has an acidic $\mathrm{pH}$, necessitating the addition of dolomite lime to raise the $\mathrm{pH}$ level to around 6.0.

- Other peats - Although sphagnum moss is commonly used, there are also hypnum, reed and sedge mosses. These mosses tend to be much more decomposed than sphagnum peat moss, which can create drainage problems. If these mosses are used as a part of a growing medium, they can cause problems with the growth of echinacea. It is recommended that producers use sphagnum peat.

- Manure - Manure contains large amounts of organic matter, which is why many echinacea producers may like to use it either as a part of a growing mix or to prepare a manure tea to fertilize plants. If using manure, have it tested to determine its nutrient content and ensure it is well composted and free from contaminants (harmful microorganisms, etc.). Manure use is discouraged in echinacea transplant production because the manure can contain very high amounts of soluble salts like potassium, sodium and chloride. Echinacea angustifolia requires relatively low levels of nutrients compared to some other crops.

- Sawdust - Sawdust is commonly used for the production of several greenhouse vegetable crops. Up to 30 per cent can be mixed with peat moss to grow mature echinacea plants. Because of its non-uniform texture and size, sawdust should not be used in the production of young echinacea seedlings. As the crop progresses, the decomposition of sawdust will result in a demand for nitrogen by the decomposing microorganisms, which may affect echinacea growth.
- Sand - Sands can be useful in a soil mix. If using sand, take care because not all sands are the same. Sands need to be free from disease, weed seeds and other soil particles (e.g. silt). Use deep-mined white mountain sands, which are mainly silica. They are usually free of diseasecausing organisms, insects and weed seeds. These sands are called "sharp sands" because the particles have flat sides. They do not pack down to reduce the pore space of the mix. Ocean sand is not recommended because of its very high salt content. Sands with some silt particles will not drain properly, resulting in disease problems. Also remember that sand is generally alkaline, which must be considered for $\mathrm{pH}$ control.

- Perlite - Perlite is commonly used as a part of the growing mix for echinacea. Plants can also be grown exclusively in perlite. It is an inert material and is used with peat moss to improve the pore space of the growing mix. Its rough surface permits it to provide good drainage without being droughty.

- Vermiculite - Vermiculite is used in growing mixes because of its excellent water-holding capacity, buffering capacity and cation exchange capacity. It also contains potassium, calcium and magnesium, which can be used by echinacea. Use horticultural grade vermiculite to make a growing mix.

- Styrolite - Expanded polystyrene is available under the trade name Styrolite. It is an inert material and is used to add pore space in peatbased media. Up to 20 per cent by volume is recommended and can replace perlite in a mix.

- Dolomite lime - Dolomite lime is a mixture of calcium and magnesium carbonate and is used to neutralize the acidity of peat moss. It also slowly supplies some calcium and magnesium to echinacea plants.

- Wetting agent - Peat has water-repellent properties, so the addition of a wetting agent is recommended. If moisture applications are uneven or if the medium dries out between watering, peat may become difficult to rewet. Adding a wetting agent into the medium will help to prevent this problem. As echinacea is normally grown on a drier moisture regime, a wetting agent is recommended. 
Producers do not have to build a custom soil-less medium. Commercially prepared mixes are also satisfactory for seedling growth and plant production. It is important to know and understand the chemical characteristics of the growing medium being used. It is recommended that producers get a detailed chemical analysis done on their mixes to know their starting point.

\section{Water-holding capacity and air porosity of medium}

A good growing medium for the growth and development of echinacea seedlings should have sufficient water and air space to promote rooting. Echinacea does not like waterlogged conditions. Water-holding capacities and air porosities can vary between different mixes, depending on the ratio of their different components. It is recommended that a medium for echinacea production should have a water-holding capacity between 40 and 50 per cent and an air porosity of 15 to 25 per cent.

Table 29 gives approximate values of per cent porosity and water-holding capacity in different media.

Table 29. Effect of growing medium components on air porosity and water-holding capacity

\begin{tabular}{|l|c|c|}
\hline Growing medium & Air space $(\%)$ & Water-holding capacity $(\%)$ \\
\hline Coarse peat moss & 28 & 67 \\
\hline Perlite & 42 & 42 \\
\hline Sand & 7 & 30 \\
\hline Peat - perlite $1: 1$ & 28 & 50 \\
\hline Peat - vermiculite $1: 1$ & 19 & 58 \\
\hline Peat - perlite - vermiculite $1: 1: 1$ & 23 & 53 \\
\hline Vermiculite & 33 & 39 \\
\hline Soil & 5 & 54 \\
\hline Sand - peat $1: 1$ & 15 & 43 \\
\hline
\end{tabular}




\section{Measuring air porosity and water- holding capacity in a growing medium}

The water-holding capacity and air porosity of a growing medium will have a significant effect on the growth and development of echinacea. The following method is an easy way to calculate these values.

\section{Materials needed}

- one $15-\mathrm{cm}$ (6 in.) pot

- growing mix

- graduated cylinder marked in millilitres

- good quality masking tape

- two plastic trays, $7.5 \mathrm{~cm}$ (3 in.) deep

- container for water

- pencil and paper

\section{Procedure}

1. Measure the volume of the pot.

- Close the drainage holes by taping them shut. It is important to do this properly as any leakage and loss of water will result in incorrect calculations. At least one of the holes should be covered from the outside of the hole, to allow for opening later on.

- Fill the pot with water to within $1.25 \mathrm{~cm}$ ( $1 / 2$ in.) of the top. Mark the fill line on the outside of the pot with a marker.

- Carefully pour the water into the graduated cylinder. Record the amount of water in millilitres. This is the volume of the pot.

2. Dry the inside of the pot. Do not remove any tape.
3. Fill the pot with dry growing medium to the water line. Pack the medium as if potting a plant.

4. Using the graduated cylinder to measure the water, carefully pour water on the medium until it is thoroughly wet. Peat is difficult to wet. Use warm water with a few drops of soap to improve the wettability. Record the amount of water used.

5. When the medium is saturated, there will be a thin film of water on top of the medium. Stop adding water, and record the total amount of water used.

6. Once the medium is thoroughly wetted, remove the tape from one hole while holding the pot over the plastic pan. The water draining from the pot must be collected. DO NOT THROW THIS WATER AWAY.

7. After collecting all the water that drains from the pot, measure it in the graduated cylinder. This water is called gravitational water. Its volume is equal to the pore space filled with air in the medium.

8. Calculate the percentage air space:

Percentage air space $=$

volume of drained water in millilitres (gravitational) $\times 100$

total volume of pot in millilitres

9. Water-holding capacity is the water retained by the growing medium. The difference between the total amount of water added and the water drained is the water-holding capacity of the growing medium. 


\section{Other growing media}

Echinacea can be germinated in various types of growing media other than the peat-based soil-less media discussed above provided the media are managed properly.

One example is rockwool, an inert growing medium that is reasonably free of disease-causing organisms. Rockwool germination cubes $2.5 \mathrm{~cm} \times 2.5 \mathrm{~cm}$ (1 in. $x 1$ in.) or larger can be used.

Regardless of the type of medium used, producers should consider the same factors that determine the quality of the medium, such as porosity, water- and nutrient-holding capacity and freedom from pathogens and other contaminants.

\section{Suggested growing mix}

The following is a good growing mix for echinacea seedlings:

- sphagnum peat moss, medium grade (not too coarse or too fine): 50 per cent by volume

- vermiculite: 25 per cent by volume

- perlite or Styrolite: 25 per cent by volume

- dolomite lime: 3 to $5 \mathrm{~kg} / \mathrm{m}^{3}$

- super phosphate: $0.5 \mathrm{~kg} / \mathrm{m}^{3}$

- calcium nitrate: $0.2 \mathrm{~kg} / \mathrm{m}^{3}$

- wetting agent: $100 \mathrm{~mL}$

This medium can be used for small plug volumes through to larger plugs. It is recommended that a coarse peat moss be substituted when growing mature plants.

Up to 10 per cent of good quality, sandy loam soil can be mixed with the above formula. Soil can provide some buffering capacity and will also provide some trace minerals. It is important to ensure that any added soil is pasteurized to prevent the introduction of disease-causing organisms. Bone meal (if available) can be added instead of calcium nitrate, and blood meal or fishmeal can supply some nitrogen required for early plant growth.

\section{Growing containers}

Seedlings can be germinated and grown in various types of containers, including flats or bedding plant plug trays. Plug trays with 72 to 200 cells can be used (see Figure 32 - color section). The size of the container is determined by the size of transplant desired for field planting. It is recommended that plants be at least 8 to 10 weeks old for planting in the field.

Many producers germinate seeds in open flats rather than cell packs. They broadcast the seed on the surface of the tray. Then, they pull the plants apart as bare root seedlings for either planting into a field or transplanting into individual containers. Over-seeding is a common problem in this system.

Producers who decide to produce bare root seedlings should take care to avoid over-seeding. Over-seeding often results in significantly reduced seedling survival. The incidence of seedling death due to root diseases is high because plants are usually touching each other and aeration is poor. If a root disease appears, adjacent plants are easily infected. Over-seeded trays often produce weak, spindly, thin plants due to the amount of competition between the seedlings. Over-seeding can also result in increased production costs due to higher seed costs and greater seedling losses.

The use of bedding plant plug trays, cell packs or rockwool cubes to germinate and grow transplants will tend to improve the quality of greenhouseproduced plants.

\section{Germination}

Some consideration needs to be given to improving germination rates of echinacea seed. For information, see the section on Treatments to Improve Germination in the Field Production Systems chapter.

\section{Environmental factors}

After germination, young seedlings of Echinacea angustifolia grow slowly. Careful management of the growing environment is critical in the production of quality transplants. 
Producers should maintain night temperatures between 18 and $20^{\circ} \mathrm{C}\left(64\right.$ and $\left.68^{\circ} \mathrm{F}\right)$ and day temperatures between 20 and $22^{\circ} \mathrm{C}\left(68\right.$ and $\left.72^{\circ} \mathrm{F}\right)$. Relative humidity should be held between 60 and 80 per cent.

Supplemental lighting will be required if plants are being grown in January and February. A 400-Watt high pressure sodium (HPS) lamp positioned about $6 \mathrm{ft}$. above the plants will deliver sufficient light for young seedlings. On a small scale, basement windows are not enough to provide adequate light to echinacea plants. If the true leaves start to elongate rapidly and remain very narrow, this growth indicates there is not enough light for the plants.

Initially, the growing medium should be kept continually moist for the very young seedlings. Once the true leaves start emerging, watering should be reduced. The surface should be allowed to dry out slightly between waterings. Plants are being kept too wet if algae start growing on the soil surface. Using 30 to $50 \mathrm{ppm}$ of hydrogen peroxide in the water will reduce algal development.

If using rockwool cubes, the best way to water is when the weight of a block drops to around 60 per cent of the saturated weight. If it is difficult to weigh the blocks, then water the plants when the surface of the rockwool cube starts drying out slightly.

\section{Fertility management}

In peat-based media, fertilization should start when true leaves begin developing. In rockwool, fertilization should start when true leaves are barely emerging.

The following fertilizer mix is used as a constant feed program and should be administered with each watering:

- calcium nitrate (15.5-0-0): $25 \mathrm{~g} / 100 \mathrm{~L}$

- potassium nitrate (13-0-46): $25 \mathrm{~g} / 100 \mathrm{~L}$

- monopotassium phosphate (0-53-34): $20 \mathrm{~g} / 100 \mathrm{~L}$

- magnesium sulphate: $20 \mathrm{~g} / 100 \mathrm{~L}$

- iron chelate (13\%): $1.5 \mathrm{~g} / 100 \mathrm{~L}$
- manganese chelate (13\%): $0.4 \mathrm{~g} / 100 \mathrm{~L}$

- copper chelate (14\%): $0.1 \mathrm{~g} / 100 \mathrm{~L}$

- zinc chelate (14\%): $0.1 \mathrm{~g} / 100 \mathrm{~L}$

- $\operatorname{borax}(15 \%): 0.13 \mathrm{~g} / 100 \mathrm{~L}$

- molybdenum: $0.02 \mathrm{~g} / 100 \mathrm{~L}$

(The set of three numbers (e.g. "15.5-0-0") given for some of these fertilizers indicates the percentage of nitrogen, phosphorus and potassium in the fertilizer.)

The $\mathrm{pH}$ of this nutrient solution should be adjusted to 6.0 using phosphoric acid (see box for $\mathrm{pH}$ correction formulae).

Echinacea angustifolia does not require high amounts of nitrogen. Studies found that higher amounts of nitrogen delay flowering and can result in some reduction in fresh and dry shoot and root weight.

\section{Correcting $\mathrm{pH}$}

The management of $\mathrm{pH}$ in the growing medium and nutrient solution is critical in any greenhouse. In Alberta, water must usually be acidified, as opposed to being made more alkaline. Adding acid to the feed solution will lower the $\mathrm{pH}$.

The amount of acid that must be added to a solution depends on the amount of bicarbonates in the water. A water analysis by a laboratory will determine the bicarbonate level. Neutralizing the bicarbonates decreases the $\mathrm{pH}$. Sixty-one parts per million is equal to 1 milliequivalent of bicarbonate. Seventy millilitres of 85 per cent phosphoric acid or $76 \mathrm{~mL}$ of 67 per cent nitric acid is required to neutralize 1 milliequivalent of bicarbonate in every $1000 \mathrm{~L}$ of water. 


\section{Calculating ppm}

Different fertilizers can be interchanged for fertilizer applications (assuming they are equal in solubility, quality and compatibility). The analysis of each fertilizer needs to be considered, but the parts per million (ppm) contribution of the fertilizer can be calculated.

Basically, 1 ppm equals 1 milligram of substance per litre of water. So, 1 gram per litre equals $1000 \mathrm{ppm}$.

Using the grade (analysis of the specific nutrient in per cent, e.g. $10 \% \mathrm{~N}$ ) of the fertilizer, one can calculate the number of grams of fertilizer needed to get a specific ppm:

\section{Desired ppm $x$ litres of water $=$ grams of fertilizer grade of fertilizer $\times 10$}

Grams of fertilizer $x$ fertilizer grade $x \quad 10=p p m$ litres of water

The basic rule of thumb is that $100 \mathrm{~g}$ of a fertilizer in $100 \mathrm{~L}$ of water will give ppm equal to 10 times the grade of the fertilizer.

It is important to note that the grades of phosphorus or potassium must be converted from the oxide form of phosphorus and potassium (phosphate $\left(\mathrm{P}_{2} \mathrm{O}_{5}\right)$ and potash $\left(\mathrm{K}_{2} \mathrm{O}\right)$ ) to actual phosphorus and potassium. Convert $\mathrm{P}_{2} \mathrm{O}_{5}$ to phosphorus by multiplying by 0.43 , and convert $\mathrm{K}_{2} \mathrm{O}$ to potassium by multiplying by 0.83 .

\section{Water quality}

Water quality is very important in growing echinacea in greenhouse systems, especially in aeroponic and hydroponic systems where plants are grown without soil. Water quality varies greatly with the source. Both the chemical quality and microbiological quality are important.

\section{Chemical quality}

Water naturally contains dissolved minerals that can be used by echinacea plants. A chemical analysis will provide this information and allow appropriate decisions to be made.

Basically, water is classified as hard or soft. Hard water contains significantly higher amounts of calcium and magnesium in a carbonate form. Such water supplies can be used to grow echinacea; however, fertility programs must be adjusted to take into consideration the calcium content. If the calcium content exceeds 200 ppm, calcium nitrate cannot be used as a source of nitrogen; therefore, ammonium nitrate must be relied upon as the nitrogen source. Ammonium forms of nitrogen cannot be used in aeroponic systems (systems where roots are misted with a nutrient solution) because of its toxicity.

Replacing calcium with sodium can chemically soften hard water, but softened water is not suitable for the production of echinacea.

Soft water is the term used when sodium is present in large quantities. If it is over $100 \mathrm{ppm}$, then such water is not suitable for echinacea production.

Some general guidelines for the chemical quality of water for growing echinacea:

- Water having a sodium absorption ratio (SAR) of 4 or less and an electrical conductivity (EC) of below $0.8 \mathrm{mS} / \mathrm{cm}$ is good for echinacea production.

- Water having an SAR of above 4 and EC above $0.8 \mathrm{mS} / \mathrm{cm}$ will result in growth problems. An alternate water source should be considered.

\section{Microbiological quality}

In echinacea production, producers need to be concerned with the presence of fungi, such as Pythium, which can cause such diseases as dampingoff and root rot. This fungus can be found in Alberta water supplies. Therefore, treat water with chlorine and use hydrogen peroxide in the nutrient solution. 
Water tests are available from a number of laboratories in Alberta (see the Resources chapter for details).

\section{Managing pests}

The following general practices will reduce pest problems in greenhouse production of echinacea. For information on managing specific diseases and insect pests, see the Pest Management section in the Field Production chapter.

\section{Disease management}

The warm, humid and wind-free greenhouse environment is excellent for plant growth, but it is also very good for disease development. Growing media containing field soil usually contain pathogens while soil-less media are less likely to contain pathogens.

Echinacea, like any other plant, is susceptible to damage by diseases at most stages of its growth and development. In early plant stages, seed decay and damping-off are common. Seedling blight and diseases caused by other root- or crown-infecting pathogens may occur periodically.

Key disease management practices in the greenhouse include the following:

- Avoid over-watering.

- Ensure good air movement (avoid overcrowding, etc.).

- Ensure the growing medium drains well and is well aerated.

- Establish good sanitation practices, removing all diseased material, disinfecting between crops and ensuring diseases are not introduced to the greenhouse.

Good sanitation practices are critical to the successful production of greenhouse echinacea, whether it be bare root seedlings, plugs or a root crop. To prevent the introduction and spread of pathogens, producers should use new containers or surface-sterilize used containers with 1 per cent bleach or 2 per cent hydrogen peroxide. Containers made of materials that cannot be sterilized, such as wood or other porous materials, should not be used.
Producers should follow a rigorous monitoring program and be firm in their removal of diseased plants. Do not sacrifice a whole crop for the sake of a few plants. If a disease appears, remove all diseased plants immediately. Place them in a plastic bag and take them from the greenhouse.

\section{Insect management}

Insect pests are not common on greenhouse echinacea plants. Thrips can cause some damage, although not at economic levels. Biological controls may be used to control any insect pests that are seen.

\section{Organic considerations}

Organic producers may have difficulty in growing transplants organically. Extra care is needed to ensure that adequate nutrients are supplied in alternative ways.

At the same time, all materials used in production would have to be evaluated for compliance with organic standards. Some commercial soil-less media mixes come with a "starter charge" of soluble fertilizer, which would not be organic. Organic soilless mixes may be available.

Organic producers must be aware of the requirements of the organic certifying body with regard to sources of plants, accepted inputs, etc. Organic management of diseases and pests is possible using cultural practices.

\section{Root production - experimental method}

Greenhouse production of echinacea from seed to harvested root may have the potential to reduce or avoid some of the risks associated with field operations, especially environmental risks. Some research studies suggest that roots grown in greenhouses may reach reasonable levels of bioactive compounds faster than field-grown roots. For example, a study by the University of Saskatchewan found that in terms of quality, roots of 10-month-old Echinacea angustifolia grown in greenhouses were comparable to field-grown material three to four years old, based on total alkamide levels. 
However, the economics of this type of operation have not been fully explored. The net returns from greenhouse root production may not be as high as field production simply because of the high capital costs associated with set-up.

If producers are interested in trying greenhouse production of roots, it would be best to start small with just a few plants. The production of other crops might be necessary to offset the cost of setting up for echinacea.

\section{Root culture systems}

Hydroponics can be defined as the science of growing plants without the use of soil. Since many hydroponic methods use some type of growing medium, they are often termed soil-less culture, while water culture alone would be true hydroponics. In soil-less culture, an inert medium such as gravel, sand, peat, vermiculite, pumice, rockwool or sawdust is used, and a nutrient solution containing all the essential elements needed by the plant for its normal growth and development is added.

Aeroponics is another type of hydroponic system. In aeroponics, roots are sprinkled with a nutrient solution. Roots grow in an enclosed space, and growth can be seen and monitored. One of the biggest advantages of such a system is that no washing is required after harvest.

\section{Root production in soil-less hydroponic system}

The production of harvested echinacea root in a greenhouse has been studied at CDCN. Transplants are started from seed and grown to a sufficient size for replanting into the growing medium (for details, see the section on Transplant Production). The $\mathrm{CDCN}$ technique for replanting these transplants and growing them for root harvest is as follows.

\section{Growing medium}

The ideal medium for root production is a good, medium-porosity growing medium that drains well.

\section{Growing containers}

For root production, plants should be grown in larger, bulk containers with sufficient depth to allow good root growth. Research at CDCN used containers $120 \mathrm{~cm}$ wide by $244 \mathrm{~cm}$ long by $15 \mathrm{~cm}$ deep (48 in. $x 96$ in. $x 6$ in.) (see Figure 33).

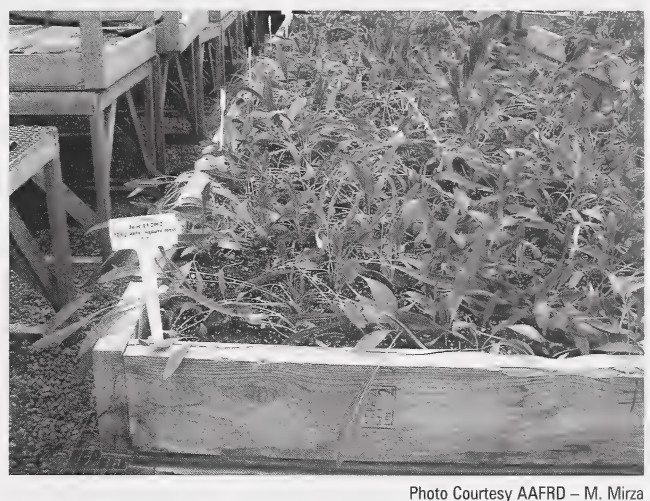

Figure 33. Root production of Echinacea angustifolia in a greenhouse hydroponic growing system at CDCN

\section{Plant spacing}

Based on research, the highest biomass yields and echinacoside levels were obtained when plants were spaced at approximately $5 \mathrm{~cm} \times 5 \mathrm{~cm}$ ( 2 in. $\times 2$ in.) or 320 plants $/ \mathrm{m}^{2}$ (about 36 plants $/ \mathrm{ft}^{2}$ ).

\section{Temperature}

Nighttime temperatures should be maintained between 16 and $18^{\circ} \mathrm{C}\left(61\right.$ and $\left.64^{\circ} \mathrm{F}\right)$. Daytime temperatures should be maintained between 18 and $22^{\circ} \mathrm{C}\left(64\right.$ and $\left.72^{\circ} \mathrm{F}\right)$ with the venting set point at $20^{\circ} \mathrm{C}\left(68^{\circ} \mathrm{F}\right)$, which allows for humidity and temperature control.

\section{Fertility management}

The nutrient demands of a developing echinacea plant vary throughout the growth cycle. Fertilizer applications should be adjusted depending on the stage of growth. 
Stage 1 - Immediately after transplanting, fertilize plants with $10-52-10$ or 9-45-15 (nitrogenphosphorus-potassium) once a week for three weeks at a rate of $1 \mathrm{~g} / \mathrm{L}$ or $100 \mathrm{~g} / 100 \mathrm{~L}$ (100 lb./100 gal.).

This rate may be adjusted to compensate for injector dilutions or other factors.

Stage 2 - After plants have grown for three weeks, adjust the fertilizer supply. The following fertilizer blend may be applied up to week 16:

- $20-10-20$ or $20-8-20: 50 \mathrm{~g} / 100 \mathrm{~L}$ (Stock $=50 \mathrm{~g} / \mathrm{L}$ at 1:100 dilution)

- magnesium sulphate: $50 \mathrm{~g} / 100 \mathrm{~L}$ (Stock $=50 \mathrm{~g} / \mathrm{L}$ at 1:100 dilution)

- iron chelate $(13 \%): 1 \mathrm{~g} / 100 \mathrm{~L}($ Stock $=1 \mathrm{~g} / \mathrm{L}$ at 1:100 dilution)

- 15.5-0-0 (calcium nitrate): $50 \mathrm{~g} / 100 \mathrm{~L}$ (Stock = $50 \mathrm{~g} / \mathrm{L}$ at $1: 100$ dilution)

All components can be mixed together if in $100 \mathrm{~L}$ of water. If using an injector, calcium nitrate must be kept separate to prevent precipitation.

Stage 3 - Starting at week 16 and going through to harvest, apply $50 \mathrm{~g} / 100 \mathrm{~L}$ of $15.5-0-0,13-0-46$ and magnesium sulphate. Keep calcium nitrate separate if using injectors.

The use of nitrate-nitrogen sources has been found to yield more high quality roots than when ammonium-nitrogen sources are used.

Carefully monitor the $\mathrm{pH}$ and $\mathrm{EC}$ of the growing medium. The $\mathrm{pH}$ should be maintained in the range between 5.8 and 6.2. Typically, $\mathrm{pH}$ will shift towards alkaline conditions, necessitating correction using phosphoric acid in the feed solution (see the section on Correcting $\mathrm{pH}$ for details). The EC should remain below $2.5 \mathrm{mS} / \mathrm{cm}$. To prevent the $\mathrm{EC}$ from building up, flush the root system periodically with pure water.

\section{Water management}

Plants should be watered thoroughly but less frequently than seedlings. Avoid waterlogging because echinacea does not like waterlogged conditions in the root zone. Avoid water with sodium levels over $100 \mathrm{ppm}$.

\section{Aeroponic root production}

Aeroponics is a type of hydroponic production where no growing medium is used. Plants are grown suspended over a growth space, and nutrient solution is sprayed onto the roots periodically. This type of system was used for greenhouse echinacea root production at CDCN (Figure 34 - color section). The following protocol was followed:

1. Two-month-old Echinacea angustifolia seedlings in rockwool cubes were planted into a covered polystyrene growth channel $(30 \mathrm{~cm} \times 30 \mathrm{~cm} \times$ $30 \mathrm{~cm} ; 12$ in. $x 12$ in. $x 12$ in.). Plants were inserted into the channel through a hole.

2. An irrigation pipe with mist nozzles at a flow rate of $0.87 \mathrm{lpm}$ at $2.53 \mathrm{~kg} / \mathrm{cm}^{2}(0.23 \mathrm{gpm}$ at $36 \mathrm{psi})$ at $40 \mathrm{~cm}$ (16 in.) intervals was placed inside the channel. The pipe was connected to a $1 / 4 \mathrm{hp}$ aquarium sump pump with a timer.

3. A complete solution of all the macronutrients and micronutrients with an electrical conductivity of $2.0 \mathrm{mS} / \mathrm{cm}$ was supplied to the roots through the sprinklers. The nutrient solution was applied for 5 minutes of each 10 minute block of time when the plant roots started to grow.

4. The nutrient solution was collected and recycled in a $300 \mathrm{~L}$ ( 66 gal.) plastic tank.

5. Thirty ppm of hydrogen peroxide was added on a daily basis to control algae and other microbial growth.

6. When the EC dropped to $0.8 \mathrm{mS} / \mathrm{cm}$, the nutrient solution was brought back to the original strength $(2.0 \mathrm{mS} / \mathrm{cm})$.

The plants were harvested 6 months after planting (4 months after transplanting). The average root dry weight was higher than what was obtained in plants grown in a soil-less mix. The root biomass was also higher than the shoot biomass, which is a desirable characteristic. 


\section{Organic considerations}

The production of echinacea in a hydroponic greenhouse system would be difficult to do organically, mostly due to the difficulty in supplying adequate nutrition. Disease and pest management can be done organically with little difficulty. Organic producers would likely have to consider the use of soil as a part of the growing medium mix and would have to compensate for this choice to ensure good drainage and aeration. 


\section{Good Agricultural Practices}

Canada's new Natural Health Products (NHP) Regulations came into effect January 1, 2004. A set of Good Agricultural Practices (GAPs) was developed for producers by industry along with the Natural Health Products Directorate of Health Canada to flow directly into the Good Manufacturing Practices (GMPs) that manufacturers are required to adhere to under Canada's NHP Act.

GAPs help preserve a strong value chain of traceability and safety, tightly linked with the existing processing GMPs in both the culinary and medicinal worlds. Developing GAPs that connect with GMPs boosts consumer confidence and builds strong business relationships.

Although producers are not included in the regulations and GAPs are voluntary, manufacturers and buyers are expecting producers of raw materials to follow GAPs. There are very specific GMP requirements for incoming raw materials, as the quality of raw materials is key to the safety, efficacy and quality of the finished product. Therefore, producers who provide raw materials for the manufacturing industry play a fundamental role in ensuring product safety and quality.

The majority of quality and safety issues that arise from raw materials are due to the failure to ensure correct identity and/or failure to ensure product purity. Botanical identity includes ensuring the correct species, variety or chemotype (chemical constituents), plant part and processing methods.

For echinacea producers, the primary concern is to ensure proper identity and species purity of the mincriak iliey provide to processors. They must also ensure product purity of their materials. Product purity can be at risk from contamination with microorganisms, heavy metals, pesticide residues, environmental toxins and adulterants.

\section{On-Farm Food Safety and HACCP-based GAPs}

To address issues on the production side and ensure market access, the Canadian Herb, Spice and Natural Health Products Coalition (CHSNC, formerly the National Herb and Spice Coalition) has been working with the American Herbal Products Association (AHPA), the American Spice Trade Association (ASTA) and Canada's Natural Health Products Directorate (NHPD) to develop comprehensive GAPs based on the Hazard Analysis and Critical Control Points (HACCP) principles under the Canadian On-Farm Food Safety (COFFS) program. These GAPs include a strong, internationally recognized plant identification practice.

The goal of the COFFS program is to use HACCP principles to enable a facility or operation to prevent contamination of the food supply from the farm through to the consumer. Natural health products, medicinal and culinary herbs (cultivated and wild harvested) and spice crops are covered under the herb and spice program. The CHSNC COFFS program and GAPs are expected to be available by the end of 2005 .

GAPs have three fundamental purposes:

- Ensure that producers clearly state all the activities that occur on their farms ("saying what you do on your farm"). 
- Ensure that producers do carry out the stated activities ("doing what you say you do on your farm").

- Verify that the stated activities have been carried out ("verifying that you did what you said you were going to do on your farm").

Although GAPs do require the development of consistent ways of doing things on a particular farm, as well as formal record keeping, the real benefits for producers are traceability and safety assurances. Should manufactured products be recalled, GAPs provide producers with a recognized method of verifying whether or not their raw materials were part of the problem.

For certified organic producers, many of the records required will already be in place. However, organic producers will still have to develop GAPs to ensure food safety on the farm as a certified organic system won't necessarily have all the GAP elements in place.

\section{HACCP basics}

The seven HACCP principles:

- Principle 1 - Conduct a hazard analysis.

- Principle 2 - Identify critical control points.

- Principle 3-Establish critical limits for each critical control point.

- Principle 4 -Establish critical control point monitoring requirements.

- Principle 5 - Establish corrective actions.

- Principle 6-Establish record keeping procedures.

- Principle 7 - Establish procedures for verifying the HACCP system is working as intended.

There are three types of hazards to be identified: biological (microorganisms or toxins), chemical (residues or contaminants) and physical (objects). Hazards may take many forms.

A critical control point (CCP) is defined as a point, step or procedure at which control can be applied and a food safety hazard can be prevented, eliminated or reduced to acceptable levels.
Examples include chemical residues as a result of pre- and post-harvest chemical applications and improper product identification, which may lead to contamination.

If a procedure on a farm operation exceeds critical limits, it is important to have a standardized, written procedure to correct the problem. Producers must also ensure there is enough monitoring in place to detect a practice that is outside of acceptable limits and to ensure the problem is corrected. Procedures may be ranked according to priority and the level of control that must or may be in place.

\section{One up, one down model}

Producers need to recognize that they are responsible for their product one level up from their operation and one level down, or one step before and one step after. For example, producers need to know what they are buying, what goes into the production of it and where it goes. Good records are critical. The market and consumers are demanding that these processes be verifiable and traceable to at least a one up, one down responsibility. The responsibility for the implementation of this record keeping process falls on the producer.

\section{Auditing/certification}

Auditing is a system where the producer or a third party asks a series of questions about the operation to validate that what was said would be done has actually happened. Asking the 4 W's (what, who, when and where) and an $\mathrm{H}$ (how) will usually make sure all the answers and documentation are in place. For example:

- What is being done at any specific time or step?

- Who is responsible for ensuring that the procedure is completed?

- How is the process controlled, and are there written instructions in place?

- When will the "what" be completed, and when will these procedures be monitored?

- Where is all of this recorded? 
The audit is in place to ensure traceability. It ensures that when looking backwards at any stage, all questions can be answered and supporting documentation is in place. For example, if there were a recall, could a product at one buyer's operation be separated from a product at another buyer's operation based on records? Are the products different, the same or does the producer know?

Auditing may also be a tool to ensure that producers are up to date and aware of regulations or changes to regulations that affect their operation. Being a part of an organization can or should support this aspect of an operation.

If the correct process is followed, a paper trail will be developed for an auditor, with farm maps, field history, input records, harvest and post-harvest records, storage data and sales information in place to confirm all processes and due diligence.

\section{Traceability}

Traceability in the food chain refers to the ability to follow a food, feed, food-producing animal, substance or identified product through all stages of production and distribution by means of recorded information.

Traceability is driven by many factors. Some of the key factors:

- consumer confidence in the product

- product credibility and market access

- brand and fraud protection

- supply chain management

- quality factors

- insurance requirements

There are many options for tracking a product, including a hard-copy paper trail, a computerized system or a system that can scan and computerize automatically.
Traceability is important, as it does the following:

- is synonymous with accountability

- is driven by market-based issues

- is a tool in food safety and quality systems

- is an identity and source certification

- will work well in a value chain system

- is a trace-back - trace-forward system

It quickly becomes apparent that all these systems are interconnected, and in many cases, the paperwork for one will work well for another, so there is not necessarily any duplication taking place. For example, if producers choose to implement the On-Farm Food Safety program and are organic producers, most or all of the steps will already be recorded in the organic certification process.

\section{GAPs for echinacea production}

Echinacea producers need to carefully assess their individual situation and develop GAPs for all aspects of their operation. They need to have written standard operating procedures (SOPs) for every step of the operation and to document all activities that are carried out, including receiving and storage of materials, production/harvesting processes, plant identification and the management of facilities.

The following represent some areas where GAPs should be developed.

\section{Plant and product identification}

Accurate plant and/or product identification is important at all stages of production including seed and transplant purchase, growing, harvesting, postharvest handling, storage and shipping. Producers should be able to prove the authenticity of their product, either through self-declaration (records demonstrating their sources and/or practices), certification by a recognized expert or an authentication process. Proper labelling, voucher specimen storage and record keeping are essential to this process. 
Botanical identity is a priority for the entire value chain, from producers and buyers to manufacturers and those conducting clinical trials. Plant identification is considered a 'must do' under the CHSNC GAP program. To assist in carrying out this process correctly, the CHSNC Plant Identification Practice is available on-line (http:// www.saskherbspice.org).

\section{Purchasing, storing, handling and application of pest control products}

Proper receiving, handling, storage, mixing and application of registered pest control products (which include biological controls and organic products) are important in an operation.

Standardized procedures and activities can prevent accidents and ensure safety. Proper documentation of any activity relating to pest control products will also ensure traceability if problems occur.

Documentation may include receiving procedures, inventory documentation and control as well as application schedule, harvest dates, worker training, problems and corrective actions, disease and insect assessments and reports. Producers should also remember that all pest control products used must be registered by the Pest Management Regulatory Agency (PMRA).

\section{Purchasing, handling and application of inputs and other materials}

Producers should also ensure that they have good documentation of the purchase and handling of all other materials relating to their operation. This record may include fertilizers, packaging materials, cleaning products, fuels, seed and vegetative material, soil amendments and water supplies. Keeping a sample or voucher specimen of incoming seeds or vegetative material is important. Maintaining a list of suppliers and documenting orders, delivery and receipt of each product again will support traceability and ensure and demonstrate that producers are exercising due diligence.

\section{Production: on farm and wild harvesting}

The general production practices should be outlined, in part to help producers recognize areas where refinement or improvement might be made, but also to provide a system to track the activities of the operation. Producers should have a series of written SOPs for each activity in their operation. This series may include field or site assessment and testing, field preparation (e.g. fertilizer, soil amendments, weed control), seeding/planting, chemical control (spray record sheets), biological pest control, wild animal control and harvesting.

For producers using raw manure or compost, guidelines for application timing and application methods should be strictly adhered to. Steps should be taken to minimize any risks of contamination by microorganisms.

With harvesting (both on-farm and wild harvesting), some consideration should be given to plant identification, toxic plants, equipment and labelling, as well as the potential for cross-contamination or pathogen contamination. Wild harvesters must also adhere to good collection practices.

Producers should document all on-farm or wild harvesting production activities.

\section{Post-harvest handling and processing}

Post-harvest activities should have a similar set of standard operating procedures, and producers should clearly document all activities. Post-harvest activities may include washing, drying, packaging and storage, milling/cutting/sifting and shipping of the product. Potable water must be used at all stages of post-harvest processing. Producers should consider integrated pest management and labelling (harvested lots, lot identification) as well as having records of storage conditions.

As with all GAPs, there should be written SOPs available for all processes.

\section{Personnel training}

Employee training is critical to the proper implementation and continued success of any operation. Clear roles and responsibilities must be established and communicated to ensure everyone involved understands who is responsible for what.

Employees should be trained in HACCP, GAP, including any SOPs, and personal hygiene to address the program requirements and prevent 
product contamination. Accurate records should be kept of all training activities provided as well as the training that each employee participated in.

Staff must be properly trained on any equipment and must be able to follow instructions very proficiently. They should also be trained in personal hygiene for all farm procedures, but especially where personal contact is made with the product.

Various kinds of employees (full-time, part-time, seasonal and casual) may be employed on a farm. These may be trained differently because of the tasks assigned. Any potential risk of crosscontamination between various farm operations should be considered, and employees should be trained to minimize the risk of occurrence. SOPs can be developed to ensure standardization for both the producer and the employees.

\section{Preventative maintenance}

Critical pieces of equipment and buildings in an operation should be identified, and a preventative maintenance schedule should be established. Preventative maintenance can help prevent breakdown or contamination due to faulty or inefficient equipment. Preventative maintenance inside and outside buildings reduces the risk of pest infestations or other problems. Detailed maintenance records should be kept.

\section{Record keeping}

Records must be kept on all aspects of an operation. A good record keeping system includes three phases: planning, implementation and control. Records can help a producer to know and manage what is happening in all areas of the farm and to quickly identify changes or problem areas. Records are also important for auditing, traceability and other processes.

Some of the records that should be kept include a filed copy of all SOPs and related documents. Backup copies of all important documents should be stored off the premises.

Records should provide traceability of inputs and product through a yearly cycle and should include field location, production practices, harvest date, harvester information, lot numbers, storage duration, transportation and buyer information.

Records are key to being able to prove due diligence in the case of a lawsuit or questions about processes by officials.

\section{CHSNC Growers' GAP Workbook}

The Canadian Herb, Spice and Natural Health Products Coalition has developed a Growers' Good Agricultural Practices Workbook to assist producers in assessing their operations, formalizing plans to ensure food safety and keeping records for verification. The workbook also helps producers understand the purpose of the On-Farm Food Safety program by involving them in the process of doing an intensive inventory of their production unit.

The workbook is not a 'How to Farm' document but rather an inside look at food safety on the farm. It includes detailed modules complete with sample forms for use by producers.

Producers who participate in this voluntary CHSNC COFFS GAP Program will benefit greatly by reducing risks on their farms, ensuring food safety and improving traceability throughout the entire value chain. Many buyers are already asking to purchase raw materials produced under a GAP system. Where problems arise, producers who have a GAP system in place will be in a better position to prove the safety and quality of their products. As raw material suppliers, producers play a key role and are the foundation of a safe, effective and strong natural health products industry.

Training and information workshops on these programs for producers across Canada will be available in future. The principles outlined above represent good, sensible practices that can improve the efficiency of any operation. Existing producers should consider their existing operation and the potential for implementing the outlined procedures and practices. New or potential producers are strongly recommended to include these practices in their plans and then implement them. 


\section{Natural Health Products Regulations and Echinacea}

NOTE: This chapter is based on information from the NHPD website at http://www.hc-sc.gc.ca/hpfb-dgpsa/nhpd-dpsn/ index_e.html and from Overview of Canadian NHP

Regulations, December 19, 2003, by Len Monheit and posted on the NPI Center website at http://www.npicenter.com/ Default.aspx.

Natural Health Products (NHP) Regulations came into effect on January 1, 2004. Anyone who produces a product that fits under the definition of an NHP (see below) must comply with the new regulations to get a Natural Product Number (NPN) and put the product on the market.

The Natural Health Products Directorate (NHPD) is the government body set up to review the NPN applications. It uses the evidence submitted by the applicant to critically assess the safety and efficacy of finished natural health products before approving the product for sale in Canada. The regulations and supporting guidance documents are posted on the NHPD website (http://www.hc-sc.gc.ca/hpfb-dgpsa/ nhpd-dpsn/index_e.html).

The aim is for the requirements to be rigorous enough to protect public health and increase consumer confidence in product safety and efficacy, and yet be flexible enough for industry to develop useful natural health products while accommodating changing scientific developments.

It is believed that a product with an NPN will hold an image of Canadian quality, and this image will likely assist in increasing long-term product sales both within Canada and globally.

\section{Definition of a natural health product}

A natural health product is defined as a substance set out in Schedule 1 of the NHP Regulations or a combination of substances in which all the medicinal ingredients are substances set out in Schedule 1, a homeopathic medicine or a traditional medicine that is manufactured, sold or represented for use in the following:

- the diagnosis, treatment, mitigation or prevention of a disease, disorder or abnormal physical state or its symptoms in humans

- restoring or correcting organic functions in humans

- modifying organic functions in humans, such as modifying those functions in a manner that maintains or promotes health

A natural health product does not include a substance set out in Schedule 2 of the Natural Health Products Regulations or any combination of substances that includes a substance set out in Schedule 2. Table 30 shows Schedule 1 and Table 31 shows Schedule 2.

Some examples of products covered by Schedule 1 include traditional Chinese medicines, native North American medicines, homeopathic medicines, and vitamin and mineral supplements. 
Table 30. Included substances - Schedule 1 of the Natural Health Products Regulations

\begin{tabular}{|c|l|}
\hline Ilom & \multicolumn{1}{|c|}{ Substances } \\
\hline 1 & A plant or a plant material, an alga, a bacterium, a fungus or a non-human animal material \\
\hline 2 & $\begin{array}{l}\text { An extract or isolate of a substance described in item 1, the primary molecular structure of } \\
\text { which is identical to that which it had prior to its extraction or isolation }\end{array}$ \\
\hline 3 & $\begin{array}{l}\text { Any of the following vitamins: biotin, folate, niacin, pantothenic acid, riboflavin, thiamine, } \\
\text { vitamin } \mathrm{A}, \text { vitamin } \mathrm{B}_{6}, \text { vitamin } \mathrm{B}_{12}, \text { vitamin } \mathrm{C}, \text { vitamin } \mathrm{D} \text {, vitamin } \mathrm{E}\end{array}$ \\
\hline 4 & An amino acid \\
\hline 5 & An essential fatty acid \\
\hline 6 & A synthetic duplicate of a substance described in any of items 2 to 5 \\
\hline 7 & A mineral \\
\hline 8 & A probiotic \\
\hline
\end{tabular}

\section{Table 31. Excluded substances - Schedule 2 of the Natural Health Products Regulations}

\begin{tabular}{|c|l|c|}
\hline Ifem & \multicolumn{1}{|c|}{ Substances } & References \\
\hline 1 & A substance set out in Schedule C of the Act & Appendix 3 of Schedule 2 \\
\hline 2 & $\begin{array}{l}\text { A substance set out in Schedule D of the Act, except for the } \\
\text { following: } \\
\text { a. drug that is prepared from any of the following microorganisms, } \\
\text { namely, an alga, a bacterium or a fungus; and } \\
\text { b. any substance set out in Schedule D when it is prepared in } \\
\text { accordance with the practices of homeopathic pharmacy } \\
\text { A substance regulated under the Tobacco Act } \\
\text { A substance set out in any of Schedules I to V of the Controlled } \\
\text { Drugs and Substances Act }\end{array}$ & Appendix 4 Appendix 5 of Schedule 2 \\
\hline 5 & $\begin{array}{l}\text { A substance that is administered by puncturing the dermis } \\
\text { An antibiotic prepared from an alga, bacterium or fungus or a } \\
\text { synthetic duplicate of that antibiotic }\end{array}$ & \\
\hline 6 &
\end{tabular}

\section{Applying for a Natural Product Number}

Echinacea is considered a Natural Health Product by the above definition, and therefore, anyone manufacturing products of echinacea for sale must apply to the NHPD for a Natural Product Number (NPN). (It is not necessary to apply for an NPN if the product is made for sale outside Canada only, for animal uses or for use in individual product(s) compounded specifically for a patient.)
There are two main components in the NPN application process:

1. completion of the site license (including compliance with Good Manufacturing Practices), and

2. completion of the product license (including the ongoing monitoring of adverse reaction reporting) 


\section{Site license application}

- All manufacturers, packagers, labellers and importers must have a site license.

'Manufacturer' does not include pharmacists or producers.

- A Quality Assurance (QA) Report must be provided by a QA person or third-party auditor with training and/or education to assess Good Manufacturing Practices (GMPs) compliance.

- Foreign sites must meet NHP GMPs or equivalent.

- GMPs apply to distributors, but a site license is not required.

- A Canadian parent company of direct sellers is considered primary importer and must also comply with the regulations.

- Even sub-contractors must comply.

- While producers, harvesters and cleaning, drying and freezing facilities are not required to have site licenses, once processing of ingredients begins, the NHP regulations apply, and a site license is required. Importation of some herbs as raw materials will require a site license.

- The Natural Health Products Directorate regulates NHP sites, and the Health Products and Food Branch Inspectorate manages compliance for site licensing. Inspectors will use the Compliance and Enforcement Policy for NHPs.

- As of January 1, 2006, all current manufacturers, packagers, labellers, importers and distributors must have site licenses, but they must apply for site licenses immediately for any new products.

- Site licenses must be renewed every year for the first three years, every two years from years four to nine, and every three years thereafter.

\section{Forms and other requirements for Site License} Application (all available from NHPD website):

- Site Application Form

- Contact information and addresses

- Activities: manufacturing, packaging, labelling or importing
- Quality assurance (QA) program (samples of standard operating procedures based on Good Manufacturing Practices)

- People: personnel and quality assurance

- Process: sanitation program and operations

- Products: specifications, stability, samples, records, etc.

- Places: premises and equipment

- A 67-page Guidance document, which covers the GMP regulations, is available as a resource.

- Quality Assurance Person Qualifications Form

- Quality Assurance Report Form including the following records:

- Master production document orders

- Manufacturing/batch, packaging, labelling

- Test results: raw material, packaging material, finished product

- Specifications: raw material, packaging material, finished product

- Lists: ingredients, products, distribution

- Sanitation program

\section{Product licensing application}

- Pre-market authorization in the form of a product license is required.

- A license holder can be in Canada or abroad but has legal responsibility (including adverse event record keeping and notification).

- Products that contain different ingredients or quantities of ingredients will require separate product licenses.

- The source (substance from which it has been derived) of the ingredient must be identified on the product license.

- Different claims for separate labels require separate product licenses.

- Approved ingredients can be combined so long as they are safe and there is a rationale.

- If a product monograph exists and is the basis for the product license, then a 60 -day performance standard for turnaround applies. 
- Prior to sale, the seller must provide all site license information including manufacturers, packagers and labellers and site license numbers for each as it becomes available.

- Any changes that may affect safety and efficacy require an amendment, which must be evaluated and authorized prior to implementation.

- Fundamental changes require a new product license.

- Standards of evidence will allow levels of claims to be made including treatment, risk reduction and structure-function claims. All licensed products must include a claim.

- If a claim is a 'traditional use' claim, two 50-year or older references supporting the use are to be provided in addition to information supporting the conditions of use and safety information.

- If a monograph (listed by NHPD) is not being used, then an evidence summary report and safety summary report must also be submitted.

- The totality of evidence, both favourable and unfavourable, and including literature search results, will be considered.

- Combination products are allowed provided they contain combinations allowed under Schedule 1 of the regulations and provided there are no safety concerns and there is a rationale for the combination.

- Non-medicinal ingredients have guidelines.

- Clear guidelines for inner and outer labelling and small package requirements exist. Some information must be in both French and English.

- Product license holders are required to provide Health Canada with information about serious adverse reactions and any serious unexpected adverse reactions to their products.

- Licensees must submit, fully and promptly, when required, adverse reaction case reports, annual summary reports and interim summary reports.

- Guidelines and templates exist for what types of adverse reactions need to be recorded in case reports and annual and interim summaries, as well as for these reports and summaries themselves.
Forms and other requirements for a Product Licensing Application (all available from NHPD website):

- Product Licensing Form

- Sample of label containing the following:

- Natural Product Number (assigned by the NHPD)

- Brand name and contact information

- Source, dosage form, quantity

- Potency of the medicinal ingredients

- Recommended dose and route of administration

- Non-medicinal ingredients

- Lot number and expiry date

- Tamperproof container

- Health claim(s) and risks

- Evidence and safety summary reports

- 85-page Guidance document available as a resource

- Quality analysis

- Finished product standards and specifications such as identity, purity, quantity and potency tests, test methods and tolerances

- Adverse reaction reporting (standard form found on NHPD website) 


\section{Sample monograph}

The following monograph for echinacea is available from the NHPD, and can be used in completing the NPN application process. The monograph is based on scientific studies supporting the efficacy and safety of echinacea. Applicants must comply with the minimum specifications outlined.

ECHINACEA - DRAFT January 19, 2004

Class:

Proper Name:

Common Names:

Sources:

Route of Administration:

Dosage Form:

Use or Purpose:

Oral:

Dose:

Oral:

Duration of Use:
Plant

Echinacea angustifolia DC. (Asteraceae) (USDA 2003)

Narrow-leaf echinacea, Kansas snakeroot, Narrow leaf-purple coneflower (McGuffin et al., 2000)

Roots, rhizomes (Bisset and Wichtl, 2001)

Oral

Those suited to the allowable routes(s) of administration.

Statement to the effect of:

- Traditionally used to fight off colds, flus and infections (Barnes et al., 2002; Bradley, 1992).

- Acts as supportive therapy in the treatment of colds, flus, upper respiratory infections and urinary infections (Blumenthal et al., 2000; Bruneton, 1995; Melchart et al., 1994; Bisset and Wichtl, 2001; Iwu, 1993; Bauer, 1991; Bradley, 1992; Schöneberger, 1992; Awang, 1991).

- Traditionally used for the relief of sore throat due to colds (TPD Labelling Standard; Blumenthal et al., 2000).

- Powdered: 1g, 3x/day (Bradley, 1992)

- Fluid extract: $0.5-1 \mathrm{~g}$ dried equivalent, $3 \mathrm{x} /$ day. (1:1, 45\% ethanol) Take with water (Bradley, 1992).

- Tincture: $0.4-1 \mathrm{~g}$ dried equivalent, $3 \mathrm{x} /$ day. (1:5, 50\% ethanol by volume) (Bradley, 1992).

May be used up to 10-21 days (Brinker, 2001; DeSmet et al., 1993; Blumenthal et al., 1998; McGuffin, 1997). 


\section{Risk Information:}

Cautions/Warnings:

Contraindications:

Non-medicinal Ingredients: Must be chosen from the List of Acceptable Non-medicinal Ingredients and must meet the limitations outlined in the list.

Specifications:
Must comply with the minimum specifications outlined in the Compendium.

\section{References:}

Awang DVC, Kindack DG. Herbal medicine, Echinacea. Canadian Pharmaceutical Journal 1991; 124:512-6.

Barnes J, Anderson LA, Phillipson JD. Herbal Medicines: A guide for healthcare professionals. $2^{\text {nd }}$ ed. London (UK): Pharmaceutical Press; 2002.

Bauer R, Wagner H. Echinacea species as potential immunostimulatory drugs; 1991. In: Wagner H, Farnsworth NR, editors. Economic and medicinal plants research. Vol. 5. London (UK) Academic Press; 1991.p.253-321.

Bisset NG, Wichtl M. Herbal Drugs and Phytopharmaceuticals. $2^{\text {nd }}$ Ed. Stuttgart (Germany): medpharm GmbH Scientific Publishers; 2001.

Blumenthal M, Goldberg A, Brinkmann J, editors. Herbal Medicine: Expanded Commission E Monographs. Boston (MA): Integrative Medicine Communications; 2000.

Blumenthal M, Busse WR, Goldberg A, Gruenwald J, Hall T, Klein S, et al., editors. The Complete German Commission E Monographs: Therapeutic Guide to Herbal Medicines. Austin (TX): American Botanical Council; 1998. 


\section{References (continued):}

Boon H, Smith M. The Botanical Pharmacy: The Pharmacology of 47 Common Herbs. Kingston (Ontario): Quarry Press Inc; 1999.

Bradley PR, editor. (1992). British Herbal Compendium Vol. 1. Bournemouth (UK): British Herbal Medicine Association; 1992.

Brinker F. Herb Contraindications \& Drug Interactions. $3^{\text {rd }}$ ed. Sandy (OR): Eclectic Medical Publications; 2001.

Bruneton J. Pharmacognosy, Phytochemistry, Medicinal Plants. Paris (France): Lavoisier; 1995.

DeSmet PAGM, Keller K, Hansel R, Chandler RF, editors. Adverse Effects of Herb Drugs 2. Berlin (Germany): Springer-Verlag; 1993.

Iwu MM. Handbook of African Medicinal Plants. Boca Raton (FL): CRC Press; 1993.

Jellin JM, Batz F, Hitchens K. Pharmacist's Letter / Prescriber's Letter Natural Medicines

Comprehensive Database. Stockton (CA): Therapeutic Research Faculty; 2003.

McGuffin M, Hobbs C, Upton R, Goldberg A, editors. Botanical Safety Handbook. Boca Raton (FL): CRC Press; 1997.

McGuffin M, Kartesz JT, Leung AY, Tucker AO. Herbs of Commerce. $2^{\text {nd }}$ ed. USA: The American Herbal Products Association; 2000.

Melchart D, Linde K, Worku F, Bauer R, Wagner H. Immunomodulation with Echinacea: a systematic review of controlled clinical trials. Phytomedicine 1994;1:245-254.

Mills S, Bone K. Principles and Practice of Phytotherapy. Edinburgh (UK): Churchill Livingstone; 2000.

Schöneberger D. The influence of immune-stimulating effects of pressed juice from Echinacea purpurea on the course and severity of colds. Forum immunologie 1992;8:2-12.

Schulz V, Hansel R, Tyler VE. Rational Phytotherapy. Berlin (Germany): Springer-Verlag Berlin Heidelberg; 1998.

TPD-Web Labelling Standard. Echinaceae [internet] [cited Dec 5 2003]. Available from: http://www.hc-sc.gc.ca/hpfb-dgpsa/tpd-dpt/echinace_e.html

USDA, ARS, National Genetic Resources Program. Germplasm Resources Information Network (GRIN). Echinacea angustifolia [Internet] - [cited 2003 Dec 1]. Available from:

http://www.ars-grin.gov/cgi-bin/npgs/html/tax_search.pl 


\section{Resources}

\section{Equipment and material suppliers}

\section{Equipment}

Northern Horticulture Equipment

Box 752

Calmar, AB T0C 0V0

Tel: (780) 987-3217 Fax: (780) 987-4364

E-mail: raincare@telusplanet.net

Gallant Sales (potato equipment)

280 Southglen Blvd.

Winnipeg, MB R2N 3L5

Tel: (204) 254-8126 Fax: (204) 254-8124

E-mail: gallantsales@shaw.ca

Website: www.gallantsales.com

\section{Materials}

WestGro Horticulture Supplies Inc. (chemicals, fertilizers, hydrogen peroxide, Ethrel)

1557b Hastings Crescent S.E.

Calgary, AB T2G 4C8

Toll-free: 1-800-661-2991

Tel: (403) 387-3988 Fax: (403) 243-7470

Website: www.growercentral.com

The Professional Gardener Co. Ltd. (mulch, fertilizers, chemicals, hydrogen peroxide)

915 - 23 Ave S.E.

Calgary, AB T2G 1P1

Toll-free/Fax: 1-866-783-4038

\section{Governments - information and contacts}

\section{Alberta Agriculture, Food and Rural Development (AAFRD)}

\author{
Alberta Ag-Info Centre \\ Postal Bag 600, 4705 - 49 Ave. \\ Stettler, AB T0C 2L0 \\ Toll-free: 1-866-882-7677 \\ Tel: (403) 742-7901 Fax: (403) 742-7527 \\ E-mail inquiries \\ duke@gov.ab.ca \\ Ropin' the Web \\ www.agric.gov.ab.ca
}

\section{Health Canada/NHP Regulation information}

Natural Health Products: Natural Health Products

Directorate (general inquiries)

Tel: 1-888-774-5555 Fax: (613) 948-6810

E-mail: NHPD_DPSN@hc-sc.gc.ca

Website: http://www.hc-sc.gc.ca/hpfb-dgpsa/nhpd-

dpsn/index_e.html

Drugs and Medical Devices: Therapeutic Products Directorate (general inquiries)

Tel: (613) 957-0368 or (613) 957-0369

Fax: (613) 946-3916

E-mail: sipdmail@hc-sc.gc.ca

Website: http://www.hc-sc.gc.ca/hpfb-dgpsa/tpd-dpt/

Food: Food Directorate (general inquiries)

Tel: (613) 957-1821 Fax: (613) 957-1784

E-mail: food-aliment@hc-sc.gc.ca

Website: http://www.hc-sc.gc.ca/food-aliment/ 
Cosmetics: Cosmetics Programme, National Consumer Product Safety Office

Tel: (613) 957-4467 Fax: (613) 952-3039

E-mail: CPS-SPC@hc-sc.gc.ca

Website: http://www.hc-sc.gc.ca/hecs-sesc/cosmetics/ index.htm

\section{Pest Management Regulatory Agency (PMRA)}

2720 Riverside Drive

Ottawa, Ontario

A.L. $6606 \mathrm{D} 2$ K1A 0K9

Tel: 1-800-267-6315 (within Canada)

Fax (613) 736-3798

E-mail: pmra_infoserv@hc-sc.gc.ca

PMRA website: http://www.pmra-arla.gc.ca/english/ index-e.html

ELSE Label search website: http://

www.eddenet.pmra-arla.gc.ca/4.0/4.0.asp

\section{Research centres conducting echinacea research}

Canada-Saskatchewan Irrigation Diversification Centre (CSIDC)

Agriculture and Agri-Food Canada/PFRA

901 McKenzie St., South

P. O. Box 700

Outlook, SK SOL 2N0

Tel: (306) 867-5400 Fax: (306) 867-9656

E-mail: csidc@agr.gc.ca

Website: http://www.agr.gc.ca/pfra/csidc/csidc.htm

Crop Diversification Centre North (CDCN)

Alberta Agriculture, Food and Rural Development 17507 Fort Road

Edmonton, $\mathrm{AB}$ T5Y $6 \mathrm{H} 3$

Tel: (780) 422-1789 Fax: (780) 422-6096

Website: www.agric.gov.ab.ca

Crop Diversification Centre South (CDCS)

Alberta Agriculture, Food and Rural Development

SS\#4

Brooks, AB T1R 1E6

Tel: (403) 362-1300 Fax: (403) 362-1306

Website: www.agric.gov.ab.ca

\section{Laboratory services}

\section{Plant health diagnostics}

20/20 Seed Labs

\# 201, 509 - 11 Avenue

Nisku, AB T9E 7N5

Toll-free: 1-877-420-2099

Tel: (780) 955-3435 Fax: (780) 955-3428

Website: www.2020seedlabs.ca

BioVision Seed Labs

7225 B Roper Road

Edmonton, $\mathrm{AB}$ T6B 3J4

Toll-Free: 1-800-952-5407

Tel: (780) 436-8822 Fax: (780) 437-6875

E-mail: biovision@biovision.ca

Website: www.biovision.ca

\section{Bioactive compound analysis}

EnviroTest Laboratories

9936 - 67 Ave

Edmonton, AB T6E 0P5

Tel: (780) 413-5227

\section{Soil and water testing laboratories}

EnviroTest Laboratories

9936 - 67 Avenue

Edmonton, $\mathrm{AB}$ T6E 0P5

Toll-free: 1-800-668-9878

Tel: (780) 413-5227

Bay 2, 1313 - 44 Avenue NE

Calgary, AB T2E 6L5

Toll-free: 1-800-668-9878

Tel: (403) 291-9897

103, 10919 - 96 Avenue

Grande Prairie, AB T8V 3J4

Toll-free: $1-800-668-9878$

Tel: (780) 539-5196

Bay 1, 235 MacDonald Crescent

Fort McMurray, AB T9H 4B5

Toll-free: 1-800-668-9878

Tel: (780) 791-1524 
Norwest Labs

7217 Roper Road

Edmonton, $\mathrm{AB}$ T6B 3J4

Toll-free: 1-800-661-7645

Tel: (780) 438-5522

\#9, 2712 - 37 Avenue NE

Calgary, AB T1Y 5L3

Toll-free: 1-800-661-1645

Tel: (403) 291-2022

4605 - 12 Street NE

Calgary, AB T2E 4R3

Toll-free: 1-800-331-8266

Tel: (403) 291-3024

3131 - 1 Avenue South

Lethbridge, AB T1J 4H1

Toll-Free: 1-800-773-3962

Tel: (403) 329-9266

11301 - 96 Avenue

Grande Prairie, AB T8V 5M3

Tel: (780) 532-8709

\section{Producer associations}

Alberta Natural Health Agricultural Network

(ANHAN)

4301 - 50 Street

Leduc, AB T9E 7H3

Tel: (780) 986-0262 Fax: (780) 986-0862

Website: www.anhan.org

Canadian Herb, Spice and Natural Health Products

Coalition (CHSNC)

c/o Saskatchewan Herb and Spice Association

Box 18

Phippen, SK S0K 3E0

Tel: (306) 694-4622 Fax: (306) 694-2182

E-mail:shsa@imagewireless.ca

Website: www.nationalherbspice.com

\section{Seed cleaning services}

Centre for Agri-Industrial Technology (CAIT)

Alberta Agriculture, Food and Rural Development 6312 - 50 Street

Edmonton, $\mathrm{AB}$ T6B $2 \mathrm{~N} 7$

Tel: (780) 427-8764 Fax: (780) 427-4852

E-mail: cait@gov.ab.ca

Website: www.agric.gov.ab.ca

\section{Other resources (literature, websites)}

- AgVentures: Commercial echinacea, Agdex 188/830-3, AAFRD

- AgStrategies: Market research, Agdex 848-6, AAFRD

- Diseases of echinacea on the Canadian Prairies, Agdex 630-2, AAFRD

- Land classification for irrigation in Alberta, Agdex 560-3, AAFRD

- Land classification for irrigation: Consulting agrologists, AAFRD (go to www.agric.gov.ab.ca and Search for "consulting agrologists")

- Production practices for Echinacea angustifolia, CSIDC

- ATTRA - National Sustainable Agriculture Information Service website (http://attra.ncat.org/ and http://attra.ncat.org/ attra-pub/echinacea.html)

- Natural Health Products Industry Canada: Industry \& Suppliers Guide (an annual directory available from www.contactcanada.com) 


\section{Appendix A}

Sample soil test report

Interpreting soil test results

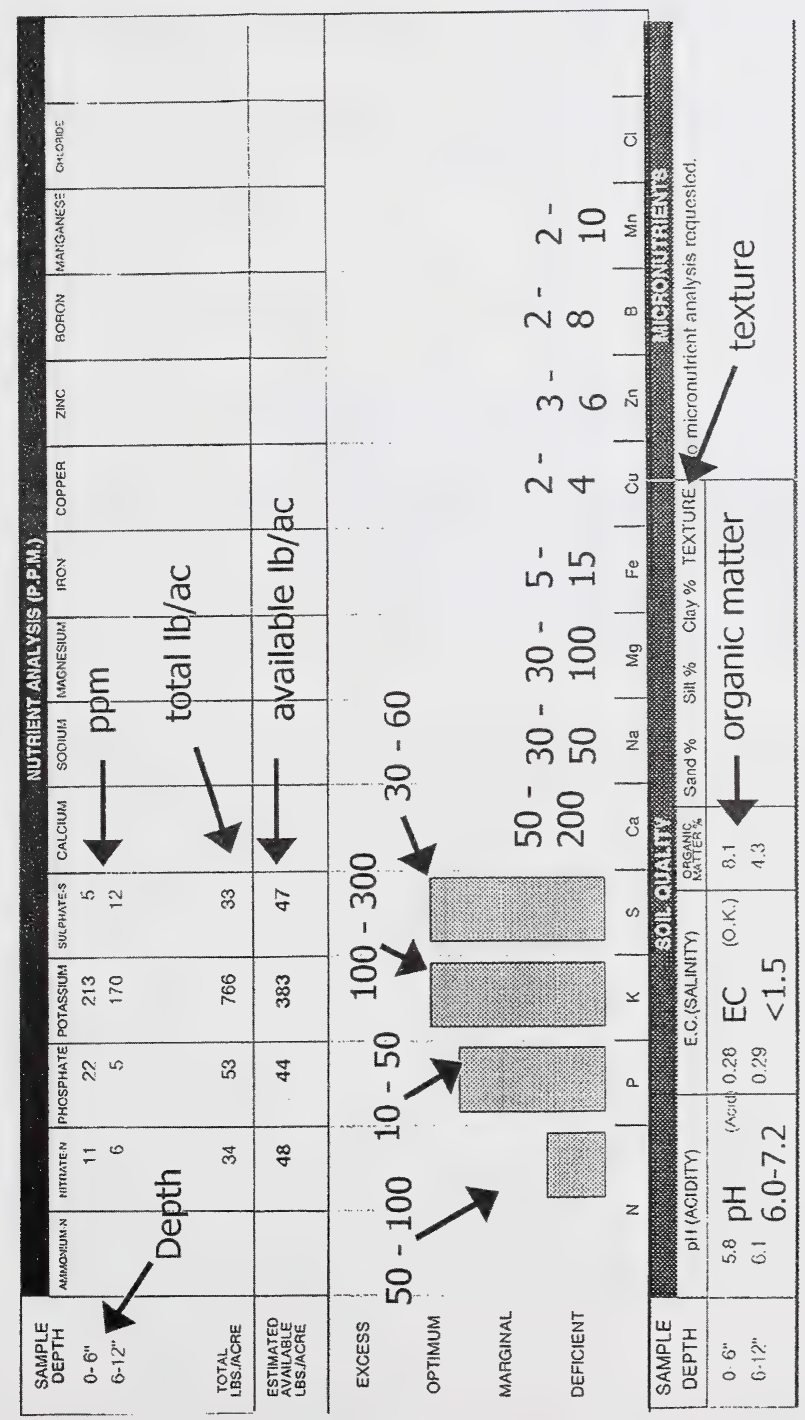




\section{Appendix B}

Plant populations and dry root yields - trial data

Seeding rate and row spacing effects on dry root yield for direct seeded Echinacea angustifolia grown under dyyland or irrigated conditions (Adapted from CSIDC 1999 annual report)

\begin{tabular}{|c|c|c|c|c|c|}
\hline & & \multicolumn{4}{|c|}{ Dry root yield } \\
\hline \multicolumn{2}{|c|}{ Seeding rate } & \multicolumn{2}{|c|}{ Dryland } & \multicolumn{2}{|c|}{ Irrigated } \\
\hline Seeds $/ \mathrm{m}^{2}$ & Seeds/ft ${ }^{2}$ & kg/ha & lb./acre & $\mathrm{kg} / \mathrm{ha}$ & lb./acre \\
\hline 60 & 6 & 876 & 788 & 1147 & 1032 \\
\hline 90 & 8 & 1090 & 981 & 1013 & 912 \\
\hline 120 & 11 & 1448 & 1303 & 1459 & 1313 \\
\hline 150 & 14 & 1352 & 1217 & 1103 & 993 \\
\hline 180 & 17 & 2089 & 1880 & 1263 & 1137 \\
\hline \multicolumn{2}{|c|}{ Row spacing } & \multicolumn{2}{|c|}{ Dryland } & \multicolumn{2}{|c|}{ Irrigated } \\
\hline $\mathrm{cm}$ & in. & $\mathrm{kg} / \mathrm{ha}$ & lb./acre & $\mathrm{kg} / \mathrm{ha}$ & lb./acre \\
\hline 40 & 16 & 1272 & 1145 & 1218 & 1096 \\
\hline 60 & 24 & 1457 & 1311 & 1177 & 1059 \\
\hline
\end{tabular}

Seeding rate and row spacing effects on $3^{\text {rd }}$ year dry root yield for direct seeded Echinacea angustifolia grown under dryland or irrigated conditions (Adapted from CSIDC 2000 annual report)

\begin{tabular}{|c|c|c|c|c|c|}
\hline & & \multicolumn{4}{|c|}{ Dry root yield } \\
\hline \multicolumn{2}{|c|}{ Seeding rate } & \multicolumn{2}{|c|}{ Dryland } & \multicolumn{2}{|c|}{ Irrigated } \\
\hline Seeds $/ \mathrm{m}^{2}$ & Seeds/ft ${ }^{2}$ & kg/ha & lb./acre & kg/ha & lb./acre \\
\hline 60 & 6 & 750 & 668 & 1157 & 1030 \\
\hline 90 & 8 & 1237 & 1101 & 1158 & 1030 \\
\hline 120 & 11 & 1313 & 1173 & 994 & 885 \\
\hline 150 & 14 & 1119 & 996 & 1801 & 1603 \\
\hline 180 & 17 & 1480 & 1317 & 1343 & 1195 \\
\hline \multicolumn{2}{|c|}{ Row spacing } & \multicolumn{2}{|c|}{ Dryland } & \multicolumn{2}{|c|}{ Irrigated } \\
\hline ETII & in. & kg/ha & lb./acre & kg/ha & lb./acre \\
\hline 40 & 16 & 1007 & 896 & 1507 & 1341 \\
\hline 60 & 24 & 1354 & 1205 & 1074 & 996 \\
\hline
\end{tabular}


Seeding rate and row spacing effects on $4^{\text {th }}$ year dry root yield for direct seeded Echinacea angustifolia grown under dryland or irrigated conditions (Adapted from CSIDC 2001/2002 annual report)

\begin{tabular}{|c|c|c|c|c|c|}
\hline & & \multicolumn{4}{|c|}{ Dry root yiald } \\
\hline \multicolumn{2}{|c|}{ Seeding rate } & \multicolumn{2}{|c|}{ Dryland } & \multicolumn{2}{|c|}{ Irrigated } \\
\hline Seeds $/ \mathrm{m}^{2}$ & Seeds/ft ${ }^{2}$ & $\mathrm{~kg} / \mathrm{ha}$ & lb./acre & $\mathrm{kg} / \mathrm{ha}$ & lb./acre \\
\hline 60 & 6 & 327 & 292 & 940 & 839 \\
\hline 90 & 8 & 326 & 291 & 814 & 727 \\
\hline 120 & 11 & 624 & 557 & 1010 & 902 \\
\hline 150 & 14 & 401 & 358 & 966 & 863 \\
\hline 180 & 17 & 511 & 456 & 1024 & 915 \\
\hline \multicolumn{2}{|c|}{ Row spacing } & \multicolumn{2}{|c|}{ Dryland } & \multicolumn{2}{|c|}{ Irrigated } \\
\hline $\mathrm{cm}$ & in. & $\mathrm{kg} / \mathrm{ha}$ & lb./acre & $\mathrm{kg} / \mathrm{ha}$ & Ib./acre \\
\hline 40 & 16 & 396 & 354 & 939 & 839 \\
\hline 60 & 24 & 426 & 380 & 963 & 860 \\
\hline
\end{tabular}

Planting density effects on yields of transplanted Echinacea angustifolia at CDCS

\begin{tabular}{|c|c|c|c|c|c|c|}
\hline & \multicolumn{6}{|c|}{2 -year old plants } \\
\hline Treatment & $\begin{array}{l}\text { Foliage dry } \\
\text { wt (kg/ha) }\end{array}$ & $\begin{array}{l}\text { Rootlet } \\
\text { \#/crown }\end{array}$ & $\begin{array}{l}\text { Root yield } \\
(\mathrm{kg} / \mathrm{ha})\end{array}$ & $\begin{array}{c}\text { Echinacoside } \\
\text { content }(\%)\end{array}$ & $\begin{array}{l}\text { 1000-Seed } \\
\text { weight (g) }\end{array}$ & $\begin{array}{c}\text { Seed yield } \\
\text { (kg/ha) }\end{array}$ \\
\hline $30 \mathrm{~cm} \times 15 \mathrm{~cm}$ & 4558 & - & 3681 & 0.97 & 4.8 & 1214 \\
\hline $30 \mathrm{~cm} \times 30 \mathrm{~cm}$ & 4211 & - & 2963 & 1.01 & 4.8 & 671 \\
\hline Average & 4384 & - & 3322 & 0.99 & 4.8 & 943 \\
\hline $60 \mathrm{~cm} \times 15 \mathrm{~cm}$ & 2323 & - & 2037 & 0.77 & 4.9 & 532 \\
\hline $60 \mathrm{~cm} \times 30 \mathrm{~cm}$ & 2514 & - & 2013 & 0.67 & 5.0 & 499 \\
\hline \multirow[t]{2}{*}{ Average } & 2419 & - & 2025 & 0.72 & 5.0 & 516 \\
\hline & \multicolumn{6}{|c|}{3 -year old plants } \\
\hline $30 \mathrm{~cm} \times 15 \mathrm{~cm}$ & - & 13 & 5500 & 0.73 & - & 365 \\
\hline $30 \mathrm{~cm} \times 30 \mathrm{~cm}$ & - & 8 & 4097 & 0.54 & - & 170 \\
\hline Average & - & 10 & 4799 & 0.64 & - & 268 \\
\hline $60 \mathrm{~cm} \times 15 \mathrm{~cm}$ & - & 10 & 5359 & 0.69 & - & 375 \\
\hline $60 \mathrm{~cm} \times 30 \mathrm{~cm}$ & - & 13 & 3571 & 0.40 & - & 311 \\
\hline Average & - & 12 & 4465 & 0.55 & - & 343 \\
\hline
\end{tabular}




\section{Appendix C}

\section{Hydrogen peroxide}

Hydrogen peroxide is an unstable, colourless, heavy

liquid that is a powerful oxidizing agent. It is commonly used as a disinfectant (like bleach) in pools or spas and as an antiseptic in households. It can be used to control algae and has been found to reduce the growth of other microorganisms, such as fungal pathogens.

Hydrogen peroxide is available as Food Grade (35 per cent) or Technical Grade (50 per cent). It can be purchased in $202 \mathrm{~L}$ ( 50 US gallons) drums or in smaller quantities (see the Resources chapter for suppliers). A 3 per cent solution is available from drug stores. Hydrogen peroxide is generally considered compatible with organic practices; however, producers should consult with their particular certifying body regarding specific uses.

For greenhouse use, it is recommended that hydrogen peroxide be applied regularly at 100 ppm or a constant feed of 30 to $50 \mathrm{ppm}$ can be used. The 100 -ppm rate is also useful for treating water in storage tanks.

Hydrogen peroxide is affected by the organic load of the water source. Water that is dirty will require a higher rate of hydrogen peroxide as the concentration will be reduced more quickly than in distilled water. A water test is recommended.

Hydrogen peroxide can be used to disinfect harvested roots after washing and before drying. Cleaned roots should be soaked for 5 to 10 minutes in a 1 to 2 per cent solution. This procedure will reduce the level of decay that may occur during storage and will improve the quality of the harvested, dried root.

\section{Calculating ppm}

Begin with the following equation:

ppm of hydrogen peroxide required $x$ total amount of water in litres grade of hydrogen peroxide $\times 10$

This formula determines the amount of hydrogen peroxide required in grams. One millilitre of hydrogen peroxide weighs approximately 1 gram (for practical purposes), so simply substitute the millilitres for the grams.

It is also important to remember to include the dilution factor if an injection system is being used. Take stock tank volumes and multiply this figure by the dilution factor to determine the total water volume.

Caution: Hydrogen peroxide is corrosive and should be handled with care. Use rubber gloves and eye protection when handling it. Rinse materials or skin that contacts hydrogen peroxide thoroughly. Plastic materials will not be affected as much as metal parts. Inspect metal parts periodically for corrosion and replace when required. 


\section{Appendix D}

\section{Bioactive compounds in echinacea species}

\section{Compounds with immunostimulatory activities}

\section{Alkamides}

Alkamides are fatty acid amides with one or more double bonds. Amides $\left(\mathrm{RCONR}_{2}\right.$ ) are functional chemical groups in which a carbon-oxygen double bond is connected with an amino group (a nitrogencontaining compound, N) and an alkyl group (saturated hydrocarbon chain, $\mathrm{R}$ ) or aryl group (aromatic hydrocarbon fragment, R). Fatty acids are long, straight-chain carboxylic acids that contain an even number of carbon atoms.

Alkamides are found in the rhizomes (or roots) of E. angustifolia and the rhizomes and aerial parts of E. purpurea in relative abundance. Small amounts of alkamides can be detected in the rhizomes of E. pallida (Sloley et al., 2001), but at nowhere near the amounts found in the root systems of the other two species. The types of alkamides found in these species are mainly acetylenic (H-C:::C-R). Fifteen alkamides have been identified in the roots of E. angustifolia and are mainly derived from undecanoic and dodecanoic acids, as well as isobutylamide (Bauer et al., 1989). Ten alkamides have been identified in the roots of $E$. purpurea, and they are almost all 2,4-diene types (a diene is a compound that contains two double bonds) (Bauer et al., 1988a). The aerial parts of E. purpurea contain the same diene type of alkamides as the roots (Bauer et al., 1988b).

\section{Glycoproteins}

Glycoproteins are organic compounds composed of both a protein and a carbohydrate joined together in a covalent chemical link. The attached carbohydrates have several functions:

- help the protein to fold into its proper geometry

- stabilize the protein

- affect physical properties such as solubility or viscosity

- help the molecule orient correctly in a membrane

- make the molecule recognizable to other biochemicals or cells

Echinacea glycoproteins may induce cytokine production (cytokines are small protein molecules that provide communication between immune system cells as well as between immune system cells and cells belonging to other tissue types) and stimulate mitogenic activity (the beginning of cell division) (Bauer et al., 1993; 1994). The protein moiety of the echinacea glycoproteins are mainly aspartate, glycine, glutamate and alanine (Beuscher et al., 1987), while the carbohydrate portions are arabinose (64 to 84 per cent), galactose (1.9 to 5.3 per cent) and glucosamines (6 per cent). E. anfustifolia and E. purpurea roots contain similar amounts of glycoproteins, but E. pallida contains fewer glycoproteins (Beuscher et al., 1987; 1995).

\section{Polysaccharides}

Polysaccharides are complex carbohydrates. They are polymers made up of many monosaccharides joined together by glycosidic linkages. A glycoside is a molecule where a sugar group is bonded through a carbon to a non-sugar group by either an oxygen or a nitrogen atom, called a glycosidic bond.

Polysaccharides are very large and usually branched molecules. They tend to be amorphous, insoluble in water and have no sweet taste. 
Two polysaccharides with immunostimulatory properties have been isolated from the aerial parts of E. purpurea (Wagner and Proksch, 1981; Stimpel et al, 1984). One of the polysaccharides from E. purpurea tissue culture was found to stimulate phagocytosis (activity conducted by specialized phagocytotic cells or phagocytes, which remove bacteria, dead cells, small mineral particles, etc. and fight infection, the cells include large macrophages and smaller granulocyte blood cells) both in vitro and in vivo (Wagner et al., 1988). A different polysaccharide from tissue culture stimulated macrophages (large cells that are a part of the innate immune system) to release tumour necrosis factor. It should be noted that polysaccharides derived from tissue culture are very distinct from those derived from field-grown plant material and relatively little characterization of those polysaccharides has been conducted. Consequently, little is known about the possible immunostimulatory activity of polysaccharides derived from field-grown plants.

\section{Cinnamic acids}

Standard cinnamic acid $\left(\mathrm{C}_{6} \mathrm{H}_{5} \mathrm{CHCHCOOH}\right)$ is an odorless, white, crystalline acid, that is slightly soluble in water. There are various types of cinnamic acid that differ in their attached esters. From plant sources, phenolic esters are fragrant and can be extracted from aromatic resins. Cinnamic acid and its derivatives are used as important components in flavours, perfumes, synthetic indigo and pharmaceuticals.

In echinacea, caffeoyl quinic and caffeoyl tartaric esters are the characteristic phenolics. The particular structures present can be used to distinguish between the three echinacea species. The roots of E. angustifolia have cynarin and lack chicoric acid (which the other two species have), whereas the roots of $E$. purpurea lack echinacoside which E. pallida and E. angustifolia have (Stoll et al., 1950). E. pallida is particularly rich in caffeoyl conjugates and its plant parts differ in their caffeoyl chemical profiles. Chicoric acid is the major component in all plant parts, whereas echinacoside is a major caffeoyl contituent of the roots, but present in moderate amounts in the flowers and only in trace amounts in the leaves. The flowers of
E. pallida have substantial amounts of 3,5-0dicaffeoyl quinic acid, 4,5-0-dicaffeoyl quinic acid, verbascoside, and desrhamnosylverbascoside (Cheminat et al., 1988). In contrast, all the plant parts of $E$. purpurea had similar profiles of chicoric acid, caftaric acid and chlorogenic acid (Cleminat et al., 1988).

Chicoric acid from echinacea has been shown to have phagostimulatory effects in vitro (Bauer et al., 1989) and to inhibit hyaluronidase activity.

Hyaluronic acid is a glycosaminoglycan distributed widely throughout connective, epithelial and neural tissues. It is one of the chief components of the extracellular matrix, contributes significantly to cell proliferation and migration, and may be involved in the progression of some malignant tumours (Facino et al., 1993).

\section{Other compounds}

\section{Alkaloids}

Alkaloids are a structurally diverse set of compounds isolated from plants that contain an $s p^{3}$-hybridized nitrogen atom. Two pyrrolizidine alkaloids (which are five-membered-ring, nitrogencontaining, heteroaromatic molecules), tussilagine and isotussilagine, were isolated from $E$. angustifolia and E. purpurea extracts (Roder et al., 1984). The two chemicals comprise about 15 per cent of the crude extract and 0.006 per cent of $E$. purpurea dried root (Britz-Kirstgen, 1985). Some "pyrrolic" derivatives can have toxic effects on the liver, but because tussilagine and isotussilagine lack a 1,2unsaturated necine ring, it is believed that they should not cause liver damage (Mattocks, 1986).

\section{Hydrocarbons}

Hydrocarbons consist of a carbon backbone and atoms of hydrogen attached to that backbone. Eleven hydrocarbons have been identified in E. pallida roots, serving to identify E. pallida. These hydrocarbons are mainly polyacetylenes (Heinzer $e t$ al., 1988; Schulte et al., 1967). Two simple alkenes, pentadec-1-ene and (Z)-pentadec-1,8-diene, have been detected as major root constituents of both E. pallida and E. angustifolia (Voaden et al., 1972; Schulte et al., 1967). Only one hydrocarbon has been detected in E. purpurea, but it is also found in roots 
of $E$. angustifolia (Heinzer et al., 1988). The profile of polyacetylene hydrocarbons is a useful way to distinguish species, especially among the various root preparations sold commercially (Bauer et al., 1988).

\section{Essential oils}

An essential oil is a water-immiscible (cannot undergo blending or mixing) material produced by distillation from some plant material. The material (flowers, leaves, stems or roots) is put in a distillation apparatus over water, and the volatile compounds distill into a receiving vessel in two parts (as these compounds require less vapour pressure to evaporate with the presence of steam). The upper portion is the oil and the lower is the hydrosol (plant water). They are drained with two spigots. Most oils are distilled in a single process, but some have to be fractionated.

The roots of $E$. purpurea have been found to have up to 0.2 per cent essential oil (Bauer, 1999), of which caryophyllene makes up 2.1 per cent, caryophyllene epoxide 1.3 per cent and humulene 0.6 per cent (Becker, 1982; Martin, 1985).

The flowering aerial parts of all three species were found to have less than 0.1 per cent essential oil. The aerial essential oils were borneol, bornyl acetate, germacrene D, caryophyllene and caryophyllene epoxide (Bauer, 1999).

Over 70 compounds were identified in the headspace from all plant parts from the three species (Mazza and Cottrel, 1999). The headspace is the gas space in a chromatography vial above the essential oil sample. Headspace analysis is therefore the analysis of the components present in that plant volatile gas.

The main essential oils found for all plant parts in all species are camphene, $\alpha$-pinene, limonene, acetaldehyde, dimethyl sulphide and hexanal. Aerial parts also contain myrcene, $\alpha$-pinene, transocimene, 3-hexen-1-ol and 2-methyl-4-pentenal. The roots of $E$. angustifolia and E. purpurea have $\alpha$-phellandrene as a major essential oil component, whereas this chemical is not present in E. pallida.
Aldehydes make up 41 to 57 per cent of the headspace from roots, 19 to 29 per cent of leaf headspace and 6 to 14 per cent of flower and stem headspace. On the other hand, terpenoids account for 81 to 91 per cent of the flower and stem headspace, 46 to 58 per cent of leaf tissue headspace and 6 to 21 per cent of the root headspace (Mazza and Cottrell, 1999).

\section{Flavonoids}

Flavonoids are chemicals that have a characteristic 15-carbon backbone ring structure (C6-C3-C6) consisting of two aromatic rings, generally each containing a number of phenolic hydroxyl groups. They are divided into different subclasses that are categorized by the structure of the $\mathrm{C}$ ring. The most common subclasses are the anthocyanins, flavonols, flavones, flavanones and flavanols.

There are many individual compounds within each of these subclasses. The compounds differ in the number and arrangement of the -OH (hydroxyl) groups, the extent that they are substituted (e.g. with sugar, gallic acid, etc.) and their threedimensional arrangement. They make up the largest group of plant polyphenols and are usually bound to sugar molecules. They are not considered to be essential nutrients, but some flavonoids support health by strengthening capillaries and connective tissue, function as an anti-inflammatory agents, antihistaminics and antiviral agents. The major anthocyanins found in the flowers of E. purpurea and E. pallida are reported to be cyanidin 3-glucoside and cyanidin 3-(6"-malonylglucoside) (Cheminat et al., 1989). Three anthocyanins have also been isolated from suspension cultures. These are cyanidin 3-glucoside and two other acylated cyanidin glycosides that have not been characterized. 


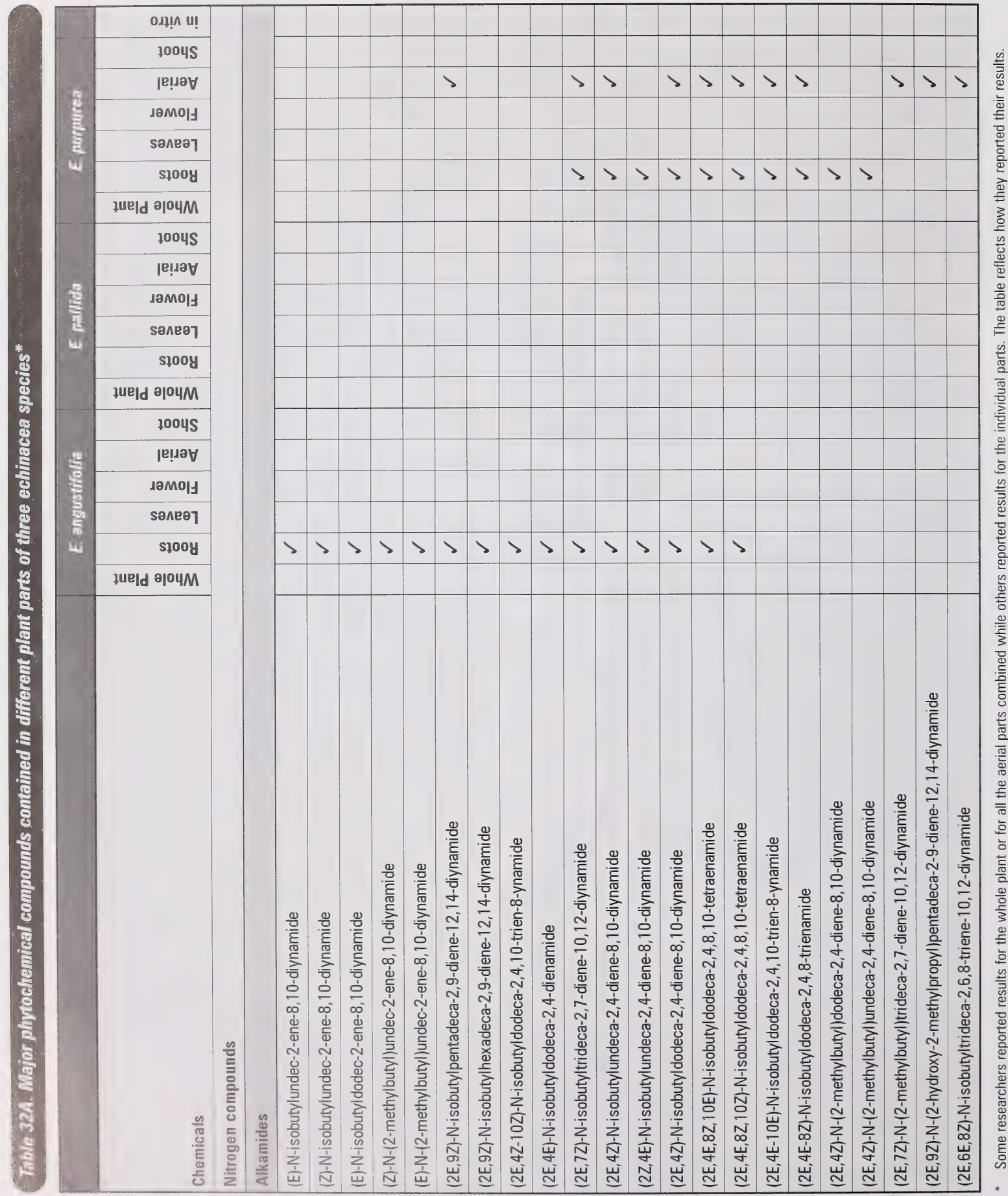




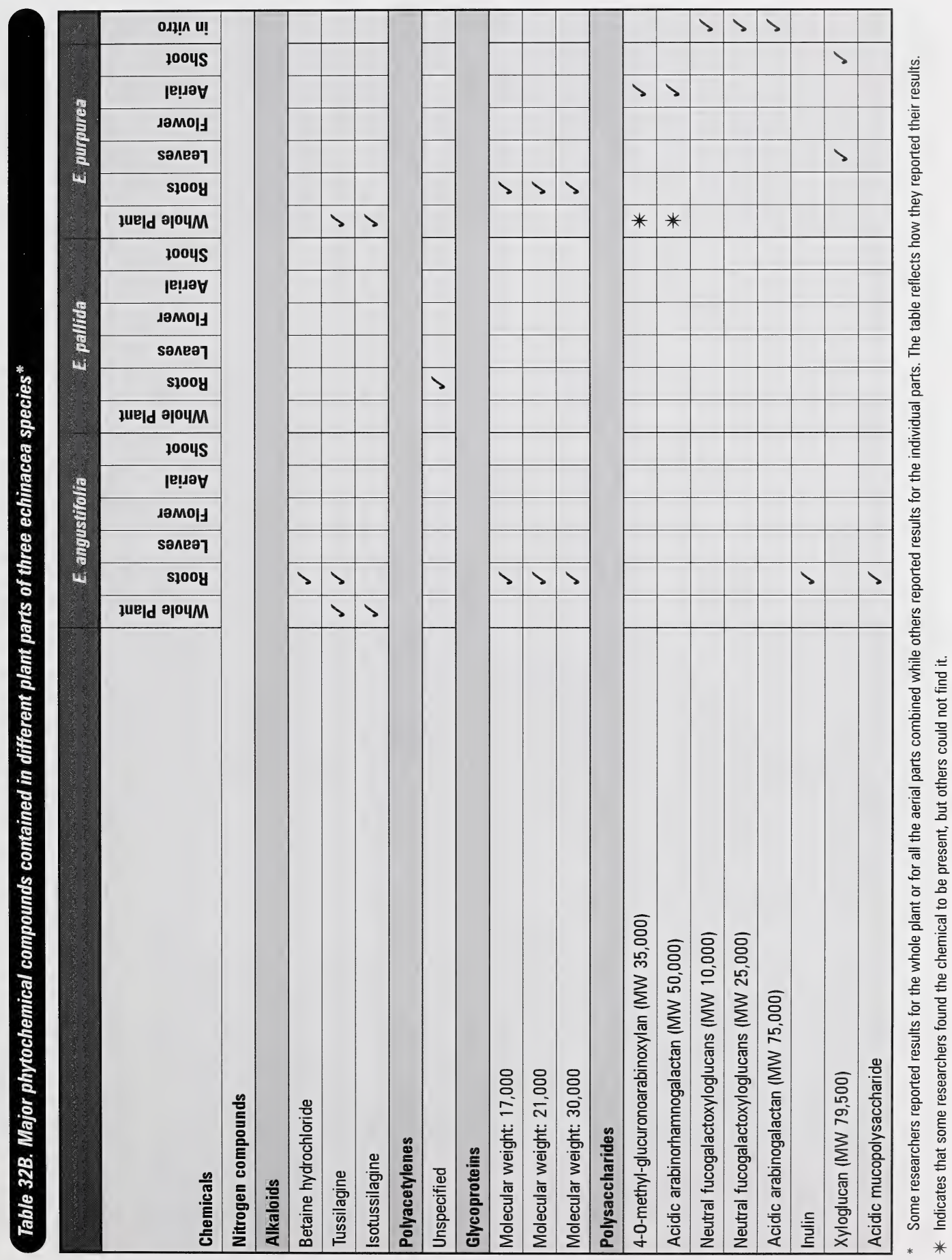




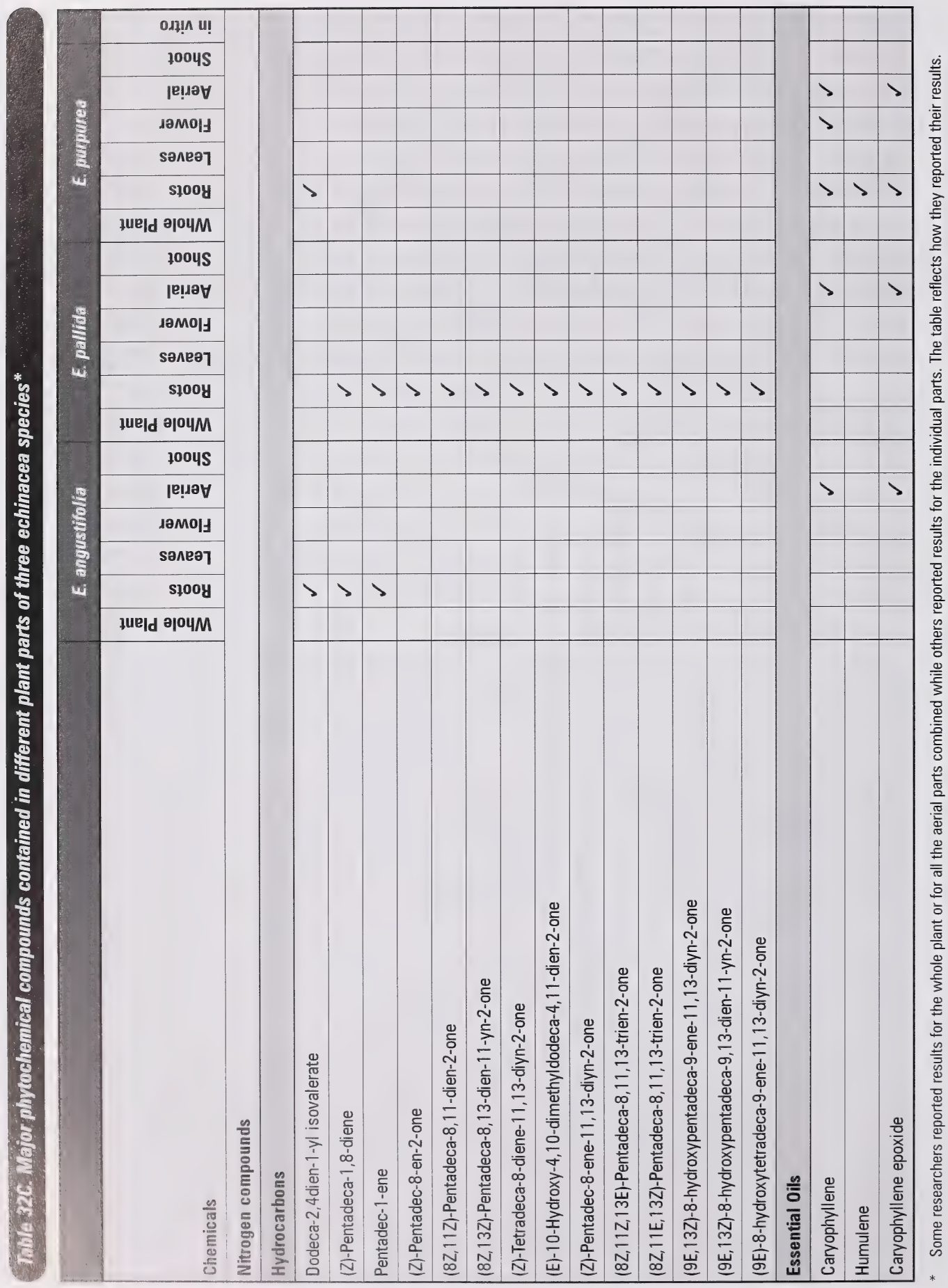




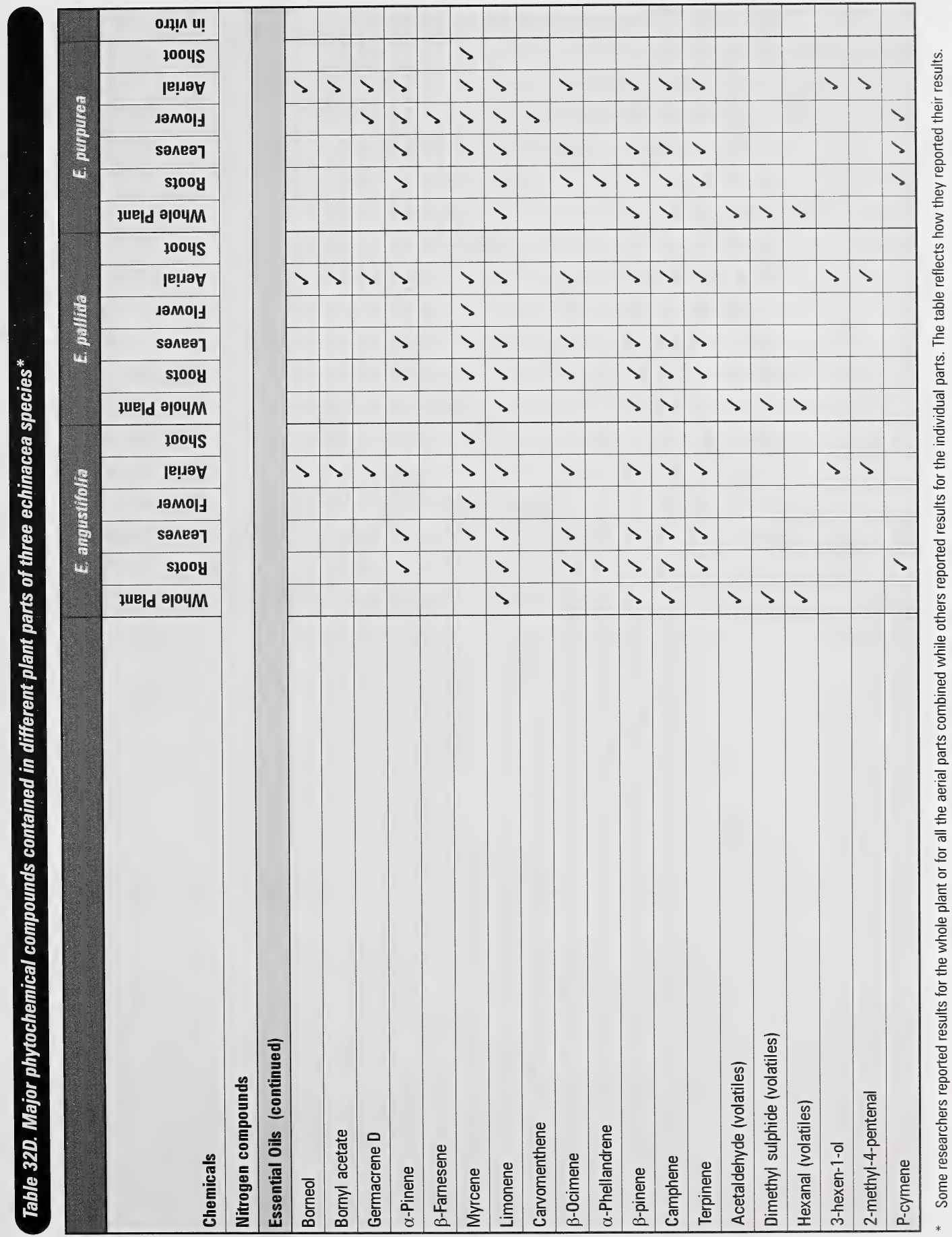




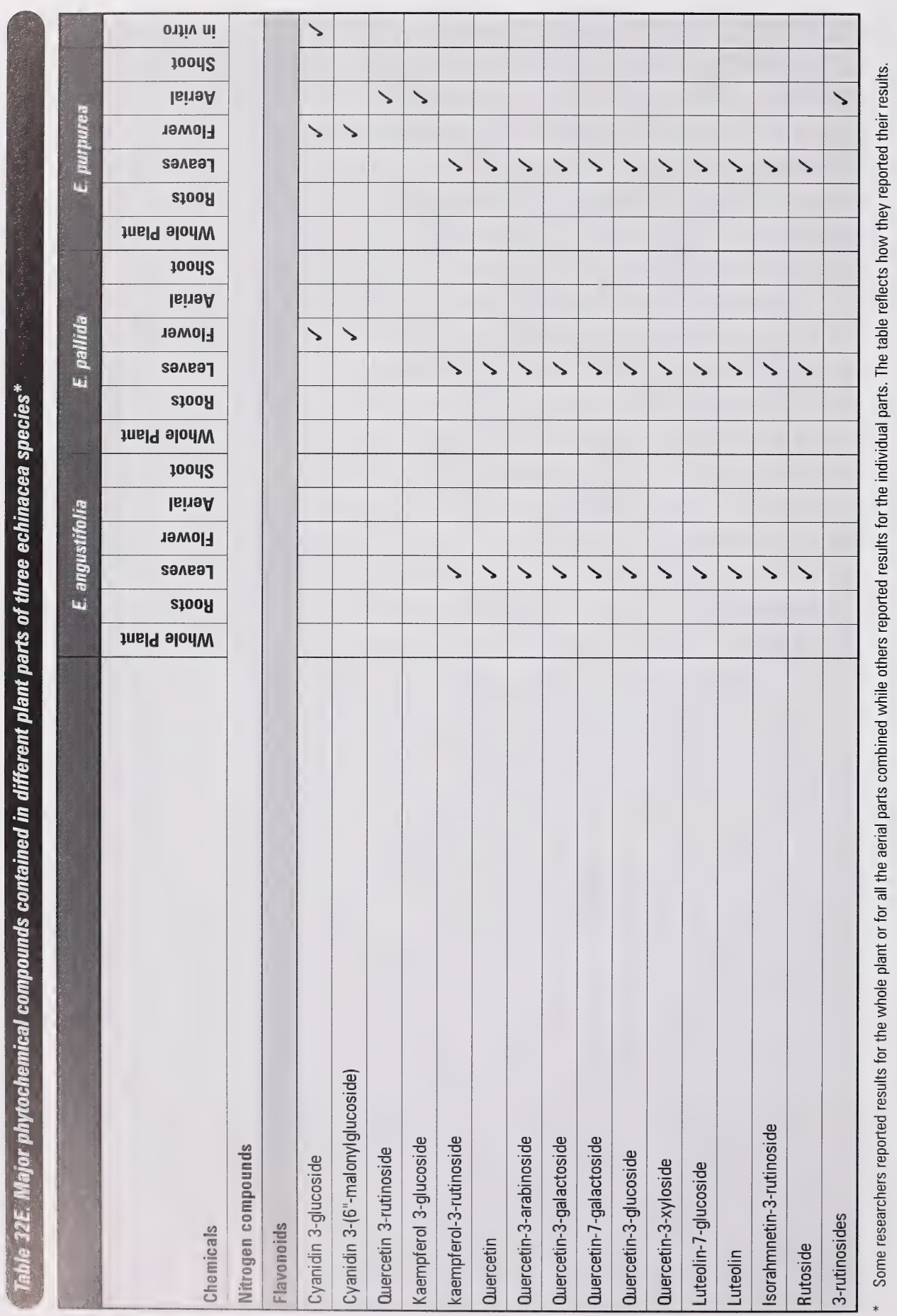




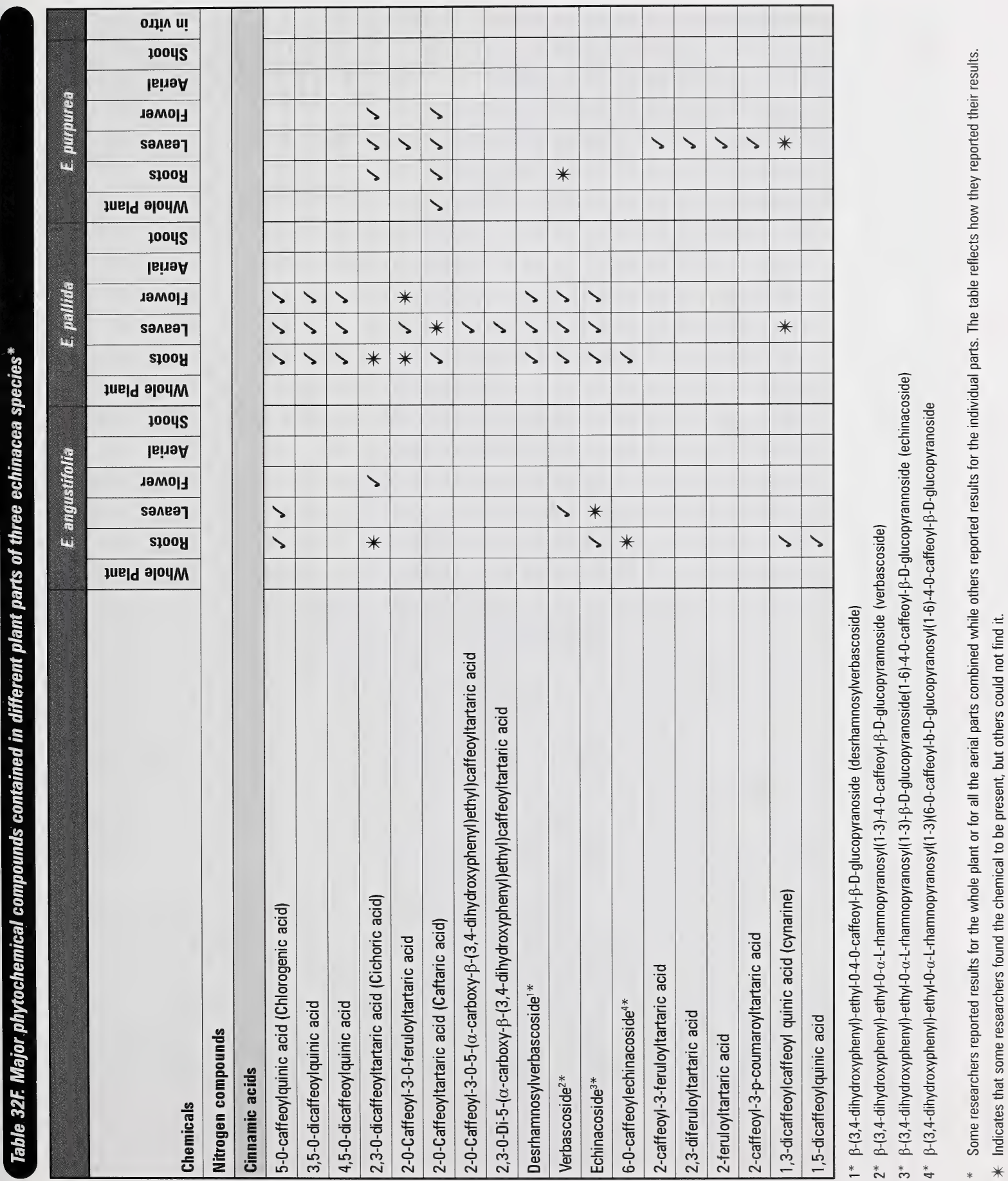




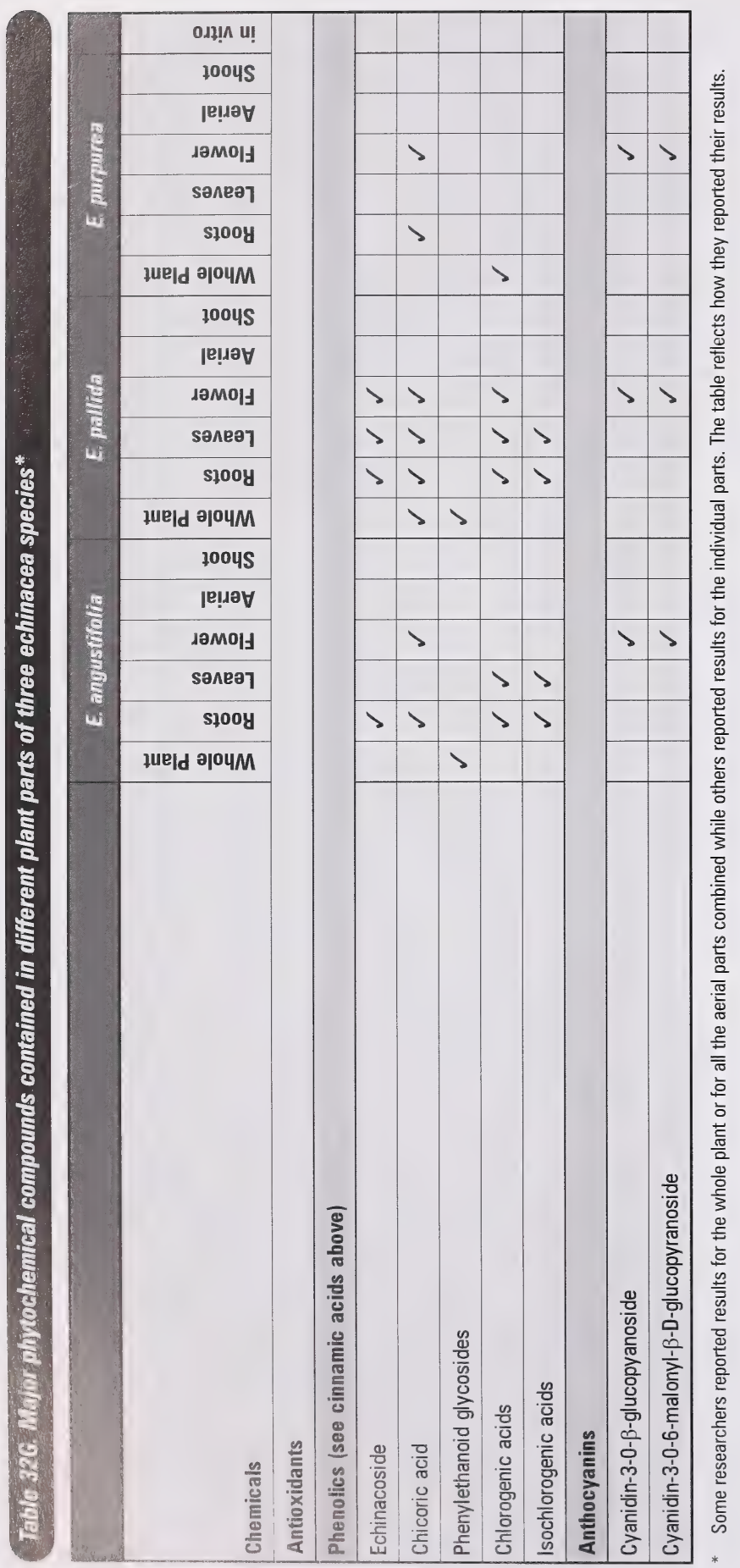




\section{Glossary}

Acclimation: A reversible change in the form or physiology of an organism in response to an environmental change.

Aerial: The parts of plants growing above ground; of or pertaining to the air, atmosphere.

Aeroponic: A technique for growing plants without soil or hydroponic media. The plants are held above a system that constantly mists the roots with nutrient-laden water.

Air porosity: Proportion of volume of soil that is filled with air at any given time or under particular given conditions, such as at a specified moisture level.

Alkamides: Certain types of fatty acid amides that are found in Echinacea angustifolia and that are thought to be biologically active.

Anaerobic: Living, active or occurring in the absence of oxygen; without oxygen.

Annual (plant): A plant that grows and completes its life cycle in a single year. Annual plants are typically focused on seed production.

Axillary: In the axil or in the angle between petiole and stem.

Bacteriostatic: Slowing or stopping the proliferation of bacteria. This term refers to a substance that inhibits the growth of bacteria, but does not destroy bacteria.

Bioactive: Chemical compounds that have proven or suspected biologically active properties or marker compounds associated with biological activity.
Biological pest control: Pest control using natural predatory or parasitic organisms (e.g. predatory wasps). Control is accomplished by release or introduction of a population of the biological organism.

Biologically active: Having some influence on biological systems, either enhancing or altering response or activity.

Biomass: All the living material in a given area; often refers to vegetation.

Biomass (root or shoot): The total living material or vegetation, either above ground (shoot) or below ground (root).

Breathable (material): A fabric that allows the movement of air and prevents the accumulation of moisture next to the product.

Broker: Person who acts as an intermediary between a buyer and a seller, usually charging a commission.

Certified: Endorsed authoritatively or holding appropriate documentation demonstrating having met certain requirements.

Certified organic: Denotes products that have met strict accreditation guidelines, set up by government-approved certifying associations, when grown and/or processed and/or handled; generally refers to production that is free from synthetic chemical inputs (e.g. pesticides, fertilizers).

Chemotype: Plants of the same genus that appear externally identical, but have a variation in their chemical constituents, often due to climatic, altitude or soil conditions. 
Competition (plant): One of the biological interactions that can limit population growth; occurs when two organisms with similar requirements contend for resources (e.g. light, water, nutrients and space) that are in limited supply.

Compost, composting: Organic material (e.g. manure or biodegradable trash or plant material) that has been decomposed by bacteria to create a soil amendment. Making compost requires turning, mixing and exposing the materials to air. The process of composting involves allowing the material to reach a critical temperature, resulting in death of harmful microbes.

Contaminant: An undesirable substance not normally present, or an unusually high concentration of a naturally occurring substance, in water, soil or other environmental medium.

Contingency: A possible but uncertain outcome of an existing situation. It may be positive or negative.

Conventional (agricultural production): No special ecological growing practices, allowing for the possibility of agri-chemicals to be used.

Conventional (medical use): Focused on man-made or conforming with accepted standards.

Cotyledon: A leaf-like structure that is present in the seeds of flowering plants. It appears during seed germination and sometimes is referred to as a seed leaf.

Critical control point: Step or phase in which a hazard is noticed and can be removed through specific and controlled measures or reduced to an acceptable level with the target to control risks; a point, step or procedure at which control can be applied and a food safety hazard can be prevented, eliminated or reduced to acceptable levels.

Decomposition: The breakdown of a chemical or substance into different parts or simpler compounds due to heat, chemical reaction, decay, etc.; the breakdown or decay of organic materials.
Direct seeding: The process of starting an echinacea crop by placing the seeds directly in the field, as opposed to germinating and growing the seedlings in a greenhouse and then transplanting the young plants in the field.

Documentation: The act or process of substantiating by recording actions and/or decisions.

Due diligence: The task of carefully confirming all critical assumptions and facts presented.

Echinacoside: A cinnamic acid compound, found in Echinacea angustifolia, that has been suggested to have biological activity.

Eclectic or Traditional (medical use): Focused on native tribe-derived medicines or remedies; uses that stem from natural sources.

Electrical conductivity: The measure of a solution's ability to conduct electricity. EC units are used to express salinity levels in soil and water. When salt is dissolved in water, the conductivity increases, so the more salt, the higher the EC value.

Floret: A small flower that is part of a much larger compound flower head. The ray and disc florets make up the compound flower in the Sunflower Family (Asteraceae).

Foliar: Pertaining to the leaves (foliage) of a plant. Foliar fertilizers and pesticides are applied directly to the leaves.

Fumigation: Application of vapour or gas, especially for the purpose of disinfecting or destroying pests.

Fungicidal, fungicide: Prevents and combats fungal infection.

Genotype: The specific genetic makeup or "blueprint" of an organism.

Grade (fertilizer): Analysis or per cent amount of a specific nutrient in fertilizer (e.g. 10-52-10 equals $10 \%$ N, $52 \%$ P, $10 \%$ K). 
Green manure, green manuring: A crop grown specifically to be ploughed or incorporated back into the soil. The crop may be grown to prevent soil erosion between crops, to stop nutrients leaking away or to provide organic matter and nitrogen ready for the next crops. Examples of common green manure crops include rye, mustard, nitrogenfixing legumes and buckwheat.

Herbarium: A collection of well documented, preserved (usually dry) plant samples labelled with the name (if available), geographical, chronological and collector data, and typically archived in a natural history collection. Dry plant samples provide data for systematic and area-geographical studies, also document "type specimens."

Homeopathic: Pertaining to homeopathy (also spelled homœeopathy or homoeopathy), from the Greek words homoios (similar) and pathos (suffering); a controversial system of alternative medicine involving the use of remedies without chemically active ingredients. The theory of homeopathy was developed by the Saxon physician Samuel Hahnemann (1755-1843) and first published in 1796.

Host: Body of an organism that harbours another organism. The host provides a microenvironment that supports the growth and reproduction of the other organism.

Hyaluronic acid: A compound that is widely distributed throughout connective, epithelial and neural tissues. It contributes significantly to cell proliferation and migration, and may be involved in the progression of some malignant tumours.

Hyaluronidase: An enzyme that splits hyaluronic acid and so lowers its viscosity and increases the permeability of connective tissue and the absorption of fluids.

Hydroponic: Growing of plants without soil, using other types of growing media (e.g. peat moss, sawdust, rockwool, water or air).
Immunostimulatory: Strengthening or enhancement of the activity or capability of the immune system, rendering something more able to resist disease, infection or illness.

Impermeable: Not easily penetrated; the property of a material or soil that does not allow, or allows only with great difficulty, the movement or passage of something, such as water or roots.

Infusion: The process of extracting certain active properties (as a drug from a plant) by steeping or soaking (usually in water).

Integrated pest management (IPM): A systematic approach that uses a variety of techniques to reduce pest damage or unwanted vegetation to tolerable levels. IPM techniques may include natural predators and parasites, genetically resistant hosts, environmental modifications, and when necessary and appropriate, chemical pesticides or herbicides. Pesticides are used only after monitoring indicates they are needed according to established guidelines, and treatments are made with the goal of removing only the target organism.

Intercropping: When two crops are planted together in the same field for special purposes. This is often done to inhibit weed growth, minimize soil erosion, attract beneficial insects or deter non-beneficial insects.

Interferon: A protein produced by cells. Interferon helps regulate the body's immune system, boosting activity when a threat, such as a virus, is found.

Isolate: A substance that has been separated from a combined mixture; pure microbial culture, separated from its natural origin.

Lesion: A change in tissue structure due to injury or disease, usually manifesting itself as tissue discolouration or death, with the potential for spread. Appearance will vary with the pathogen and the species. 
Macronutrient: A nutrient that is used by the plant in large amounts, often more than 0.1 per cent of the plant's dry weight, and that may be applied as a fertilizer. The term usually refers to nitrogen $(\mathrm{N})$, phosphorus ( $\mathrm{P}$ ) and potassium (K), but may include calcium $(\mathrm{Ca})$, magnesium $(\mathrm{Mg})$ and sulphur $(\mathrm{S})$.

Marker compound: A compound that occurs naturally in botanical material and aids in the identification and/or monitoring of the quality or stability of the botanical.

Medium (growing): A substance or material that supports the plant and absorbs and releases nutrients. It may include mineral soils, peat moss or other organic materials, water, air or some other material.

Microclimate: The local climate near the ground that is peculiar to a small area (usually, the radius is less than a kilometre and can be as small as a centimetre). A microclimate may be influenced by such factors as hills, hollows, structures or proximity to bodies of water.

Micronutrient: A nutrient required by plants in very small quantities, but toxic in large quantities. They are iron $(\mathrm{Fe})$, manganese $(\mathrm{Mn})$, molybdenum $(\mathrm{Mb})$, copper $(\mathrm{Cu})$, boron $(\mathrm{B})$, zinc $(\mathrm{Zn})$ and chloride $(\mathrm{Cl})$.

Microsclerotium (pl. microsclerotia): A small clump of dark-coloured, more or less thick-walled cells of the fine threads that make up the vegetative portion of a fungus. Microsclerotia serve as resting structures for the fungus.

Moiety: A portion of a molecular structure having some property of interest.

Mycelium: The filamentous vegetative portion of a fungus, specifically excluding the fruiting structure or reproductive phase of the life cycle. The mycelium may be invisible or conspicuous.

Mycotoxin: A toxic substance produced by a fungus.

Necrotic: Relating to the death of a portion of tissue; having symptoms characterized by the death or disintegration of cells or tissues, usually accompanied by darkening or discolouration.
Organic matter: Substances of or derived from plant or animal matter. Organic matter is characterized by its carbon-hydrogen structure. Soil organic matter is that fraction of the soil that includes plant and animal residues at various stages of decomposition and substances synthesized by various soil organisms.

Oxidation, oxidized: The addition of oxygen, removal of hydrogen, or the removal of electrons from an element or compound. For example, in the environment, organic matter is oxidized to form more stable substances.

Particulates: Very small solids suspended in water. They can vary in size, shape, density and electrical charge and can gather together to form clumps under some conditions.

Pathogen: Any disease-producing microorganism or material.

Perennial (plant): A plant that produces flowers and seeds more than one time in its lifespan and therefore lives for more than one year; a plant persisting for several years, usually dying back to a perennial crown during the winter and initiating new growth each spring.

Petiole: The stalk by which a leaf is attached to the stem; leaf stalk.

pH: A measurement of a nutrient solution's relative concentration of positive hydrogen ions. $\mathrm{A} \mathrm{pH}$ of 7 is considered neutral; below 7 is called acidic; above 7 is called alkaline.

Phagocytosis: The consumption of invading organisms by white blood cells and lymphocytes; activity conducted by specialized phagocytotic cells or phagocytes, which remove bacteria, dead cells, small mineral particles, etc. and fight infection.

Phagostimulatory: Enhancement of immune activity; stimulation of phagocytosis.

Phyllody: Abnormal formation of leaves from floral parts. 
Physiology: The activities and processes of living organisms (e.g. water movement, nutrient transport, respiration); the study of these activities and processes.

Phytochemical: Chemical compounds or chemical constituents formed in the plant's metabolic processes. The chemicals are often referred to as "secondary metabolites." Secondary metabolites are typically formed by the plant as a part of a defensive mechanism, in many cases in response to environmental cues. There are several classes of secondary metabolites, including alkaloids, anthraquinones, coumarins, flavonoids, glycosides, gums, iridoids, mucilages, phenols, phytoestrogens, tannins, terpenes and terpenoids. Extracts contain many chemical constituents while chemicals that have been isolated from the plant are considered pharmaceutical drugs.

Plant-available (fertilizers, nutrients): In a chemical form that can be readily taken up or used by plants (e.g. nitrate-nitrogen).

Plant extract: A concentrate made by steeping raw plant material(s) in a solvent (alcohol and/or water), after which the solvent is allowed to evaporate.

Plug: A type of seedling for transplanting, grown in its own separate cell in a greenhouse tray with the roots surrounded by a growing medium.

Post-harvest: Any activity taking place or affecting a product after harvest (e.g. washing, drying, storage, handling).

Poultice: A thick mixture of herbs applied externally for an extended period. It is usually made with just enough boiling water to cover or dampen the herbs, then applied between two thin layers of material to hold the herbs in place and keep the heat in.

Precipitation (fertilizer related): The condensation of a solid from a solution during a chemical reaction; the combination of various compounds (e.g. fertilizer components) that results in the formation of a solid, which then falls out of solution.
Preventative maintenance: The activities, including adjustments, replacements and cleaning, that forestall machine breakdowns. A machine that is well cared for will last longer and cause fewer problems.

Raw materials: Resources in their naturally occurring unrefined or unprocessed state.

Rhizomes: Horizontal underground stems distinguished from a root by the presence of nodes and buds.

Roguing: Removing and destroying undesired individual plants from a planting due to disease infection, not being true-to-type, insect infestation or other reason.

Saline: Pertaining to the level of salt in soil or in water. The salinity levels in water or soil affect its usefulness for a range of purposes.

Sclerotium (pl. sclerotia): A compact mass of hardened mycelium that serves as a dormant stage in some fungi; a vegetative resting body of a fungus.

Seed dormancy: A physical or physiological condition of a viable seed that suspends or prevents germination even in the presence of otherwise favourable germination conditions. The breaking of seed dormancy may require moisture, cold temperatures and/or abrasion of the seed coat.

Soil amendment: A material that is added to the soil for the purpose of improving the physical and biological characteristics of the soil including improving the tilth, porosity, aeration, aggregation, water-holding potential, or to increase the organic content, ion exchange capacity and microbial viability. Soil amendments might include liming agents or composted materials.

Soil-less culture: Growing in a medium composed of substances other than soil.

Solonetzic soils: Soils with a very thin, crumbly surface soil underlain by a dark, hard columnar layer, usually highly alkaline. 
Standard operating procedure (SOP): Established procedure to be followed in carrying out a given operation or in a given situation.

Stratification: The process of removing dormancy in seeds by exposing seeds to low temperatures and moisture for a time.

Sublimation: The transition of a substance from the solid phase directly to the vapour phase, or vice versa, without passing through an intermediate liquid phase.

Taxon (pl. taxa): A taxonomic category or group, such as a phylum, order, family, genus or species.

Tillage: The operation of implements through the soil to prepare seedbeds and rootbeds, control weeds and brush, aerate the soil and cause faster breakdown of organic matter and minerals to release plant foods.

Tilth: The physical condition of soil as related to its ease of tillage, fitness as a seedbed and ease of seedling emergence and root penetration.

Tincture: A liquid usually made by soaking a whole herb or its parts in a mixture of water and ethyl alcohol. The alcohol helps extract the herb's active components, concentrating and preserving them.

Topography: The shape of the physical features of a landscape, described by such characteristics as elevation, slope and orientation.

Traceability: A process that will trace the history, application or location of an identified product by means of recorded information; in the food chain, the ability to trace and follow a food, feed, foodproducing animal or substance through all stages of production and distribution.

Transplant: A plant that has been seeded, germinated and developed in a seedbed or a greenhouse and is replanted into a field by hand or machine.
Trap strip: A crop or portion of a crop that is planted with the purpose of attracting a pest, in the interest of reducing an area where chemical controls are applied. Trap strips are usually around the periphery of a crop.

Truncated: Abruptly or sharply marked, having a square or broad end; sometimes appearing as cut off.

Tumour necrosis factor: A type of biological response modifier (a substance that can improve the body's natural response to disease). Three types of tumour necrosis factor have been identified: alpha, beta and gamma. Tumour necrosis factor seems to play a role in the breakdown of cancer cells.

Value chain: The network of firms that bring products to market, from companies that produce raw materials to retailers and others that deliver finished products to consumers. Economic value is added through the coordinated management of the flow of physical goods and associated information at each stage of the chain.

Vector: An organism, such as an insect, that transmits a pathogen from one host to another

Vegetative propagation: Producing new plants from parts of a parent. The resulting plants are genetically identical to the parent plant.

Vertebrate: An animal with a backbone. Vertebrates include mammals, birds, reptiles, amphibians and fishes.

Virescence: The abnormal development of green colouration in plant parts normally not green.

Voucher specimen: A representative specimen preserved to permit independent verification of identity and to allow further examination (e.g. pressed plants, non-human animal material in preserving fluids).

Water-holding capacity: The amount of water a soil can hold, influenced by the size and mix of mineral particles and the amount of organic matter present. 
Waterlogged (soil): Soil that is saturated as a result of excessive rainfall, over-watering or proximity to a water source and that often drains very slowly.

Wetting agent: Substance that reduces the surface tension of a liquid, thereby causing the liquid to spread more readily on a solid surface.

Wild crafting, wild harvesting: The practice of collecting plant materials in their natural habitat for food, medicine and craft.

Winterkill: A condition that happens when plants have not hardened enough to withstand severe winter conditions. 


\section{References}

American Botanical Council. Terminology. http:// www.herbalgram.org/default.asp?c=ed_terminology

Andersen, A. (2000). 1999 Tonnage Survey Results. Prepared for American Herbal Products Association. Silver Spring, MD.

Barl, B., Tanino, K. and Krieger, K. (2002). Northern Vigour ${ }^{\circledast}$ Potential in Medicinal and Aromatic Plants, ADF \# 98000073

Bauer, R., Remiger, P. and Wagner, H. (1988a). Alkamides from the roots of Echinacea purpurea, Phytochemistry. 27:2339-2342.

Bauer, R., Remiger, P. and Wagner, H. (1988b). Echinacea Vergleichende DC und HPLC: Analyze der Herba-Drogen von Echinacea purpurea, E. pallida und E. angustifolia, Dtsch. Apoth. Ztg. 128: $174-180$.

Bauer, R., Remiger, P. and Wagner, H. (1989). Alkamides from the roots of Echinacea angustifolia, Phytochemisrty. 28: 505-508.

Bauer, R. (1993). Echinacea-Drogen-Neue Ergebnisse zur Frage der Wirksubstanzen, Natur und Ganzheits-medizin. 6: 13-22.

Bauer, R. (1994). Echinacea-Eine Arzneidroge auf dem Weg zum rationalen Phytotherapeutikon, Dtsch. Apoth. Ztg. 134: 94-103.

Bauer, R. (1998). Pflanzliche Immunstilanzien in der Selbstmedikation, Pharmazie unserer $Z$. 27: $144-157$.

Bauer, R. (1999). Chemistry, analysis and immunological investigations of Echinacea phypharmaceuticals. In Wagner, $\mathrm{H}$. ed. Immunomodulatory Agents from Plants. Birkhauser Verlag, Basel. pp. 41-88.
Beuscher, N., Kopanski, L. and Ernwein, C. (1987). Modulation der Immunantwort durch polymere substanzen aus Baptisia tinctoria and Echinacea angustifolia, Adv. Biosic. 68: 329-336.

Beuscher, N., Bodinet, C., Willigmann, I. and Egert, D. (1995). Immunodulierende Eigenschaften von Wurzelextrakten verschiedener Echinacea-Arten, Z. Phytother. 16: 157-336.

Binns, S.E., Baum, B.R. and Arnason, J.T. (2002). A taxonomic revision of the genus Echinacea (Heliantheae; Asteracea), Syst. Bot. 27: 610-632.

Blumenthal, M., Goldberg, A. and Brinckmann, J. (2000). Herbal Medicine Expanded Commission E Monographs. Integrative Medicine Communications.

Blumenthal, M., Busse, W.R., Goldberg, A., Gruenwald, J., Hall, T., Riggins, C.W. and Rister, R.S. (1998). The Complete German Commission E Monographs Therapeutic Guide to Herbal Medicines. Integrative Medicine Communications.

Blumenthal, M., Hall, T., Goldberg, A., Kunz, T., Dinda, K., Brinckmann, J. and Wollschlaeger, B. (2003). The ABC Clinical Guide to Herbs. American Botanical Council.

Brevoort, P. (1996). The US botanical market: an overview, Herbalgram. 36: 49-57.

Britz-Kirstgen, R. (1985). Phytochemische Untersuchungen an Senecio cacallaster L. Echinacea angustifolia DC und Pulmenaria officinalis. Ph. D. Thesis, University of Bonn.

Cheminat, A., Zawatzky, R., Becker, H. and Brouillard R. (1988). Caffeoyl conjugates from Echinacea species: structures and biological activity, Phytochemistry. 27: 2787-2794. 
Cheminat, A., Brouillard, R., Guerne, P., Bergmann, P. and Rether, B. (1989). Cyanidin 3malonylglucoside in two Echinacea species, Phytochemistry. 28: 3246-3247.

Ficino, R.M., Carini, M., Aldini, C., Marinello, C., Arlandini, E., Franzoi, L., Colombo, M., Pietta, P. and Mauri, P. (1993). Direct characterization of caffeoyl esters with antihyaluronidase activity in crude extracts from Echinacea angustifolia roots by fast atom bombardment tandem mass spectrometry, Farmaco: 48: 1447-1461.

Foster, S. (1991). Echinacea: Nature's Immune Enhancer. Published by Healing Arts Press, Rochester, NY. 150pp.

Global Industry Analysts, Inc. (January 2004). Herbal supplements/remedies. A Global Strategic Business Report. 5645 Silver Creek Valley Road, Suite 200, San Jose, CA 95138.

Gunner, A. (March 2000). Botanical Extracts and Essential Oils: Industry Study and Development Recommendations. British Columbia Ministry of Agriculture Food and Fisheries. Government Publication Services. www.publications.gov.bc.ca.

Heinzer, F., Chavanne, M., Meusy, J.-P., Maitre, H.P., Giger, E. and Baumann, T.W. (1988). Ein Beitrag zur Klassifizierung der therapeutisch verwendeten Arten der Gattung Echinacea, Pharm. Acta. Helv. 63: 132-136.

Hobbs, C. (1990). Echinacea the Immune Herb. Published by Interweave Press, Inc.

Jategaonkar, L. (2003). Editor's Notes - PBI Bulletin. NRC-CNRC. Issue 1: 2-3.

Kabganian, R., Carrier, D.J. and Sokansanj, S. (2002). Drying of Echinacea angustifolia roots, Journal of Herbs, Spices \& Medicinal Plants. 10(1): 11-18.

Kabganian, R., Carrier, D.J., Rose, P.A., Abrams, S.R. and Sokhansanj, S. (2002). Localization of alkamides, echinacoside and cynarin with Echinacea angustifolia, Journal of Herbs, Spices \& Medicinal Plants. 10(2): 73-81.
Kapteyn, J., Goldsbrough, P.B. and Simon, J.E. (2002). Genetic relationships and diversity of commercially relevant Echinacea species, Theor. Appl. Genet. 105: 369-376.

Little, R. (1999). Taming Echinacea angustifolia: Research at SDSU and Insights from a Grower. www.abs.sdstate.edu/bui/reesen/Echinaca/ newsletter.htm.

Mattocks, A.R. (1986). Chemistry and Toxicology of Pyrrozidine Alkamides. Academic Press. London.

Mazza, G. and Cottrell, T. (1999). Volatile components of roots, stems, leaves and flowers of Echinacea species, J. Agric. Food Chem. 47:3081-3085.

McBeath, J.H. (2002). Snow mold-plant antagonist interactions: Survival of the fittest under the snow, The Plant Health Instructor.

Miller, S.C. and Yu, H. ed. (2004). Echinacea: the Genus Echinacea. CRC Press. New York. 296pp.

Nutrition Business Journal. (January 2004). Raw Material and Supply Markets VI. Volume IX No.1.

Peng, T.S. (1997). Echinacea: botany and chemistry identification, Whole Foods. Feb 97: 62-65.

Roder, E., Wiedenfeld, H., Hille, T. and BritzKirsgen, R. (1984). Pyrrolizidine in Echinacea angustifolia DC. and Echinacea purpurea MoenchIsolerung und Analytik, Dtsch. Apoth. Ztg. 124: 2316-2318.

Small, E. and Catling, P.M. (1999). Canadian Medicinal Crops. NRC Research Press. Ottawa. pp. 47-52.

Schulte, K.E., Rucker, G. and Perlick, J. (1967). Das Vorkommen von Polyacetylen-Verbindungen in Echinacea purpurea Moench und Echinacea angustifolia DC, Arzneim-Forsch. 17: 825-829.

Sloley, B.D., Urichuk, L.J., Tywin, C., Coutts, R.T., Pang, P.K. and Shan, J.J. (2001). Comparison of chemical components and antioxidant capacity of different Echinacea species, J. Pharm. Pharmacol. 53: 849-857. 
Stimple, M., Proksch, A., Wagner, H. and LohmannMatthes, M.L. (1984). Macrophage activation and induction of macrophage cytotoxicity by purified polysaccharide fraction from the plant Echinacea purpurea, Infect. Immun. 46: 846-849.

Stoll, A., Renz, J. and Brack, A. (1950). Isolierung und constitution des Echinacosides, eines Glykosids aus den Wurzeln von Echinacea angustifolia DC, Helv. Chim. Acta. 33: 1877-1893.

Voaden, D.J. and Jacobson, M. (1972). Tumor inhibition 3: Identification and synthesis of an oncolytic hydrocarbon from American coneflower roots, J. Med. Chem. 15: 619-623.

Wagner, H. and Proksch, A. (1981). Uber ein immustimulerendes workprinzip aus Echinacea purpurea Moench. Z. Angew, Phytother. 2: 166-171.

Wagner, H., Stuppner, H., Schafer, W. and Zenk, M. (1988). Immunologically active polysaccharides of Echinacea purpurea cell cultures, Phytochemistry. 27: 119-126. 

